UNIVERSIDADE DE SÃO PAULO

ESCOLA DE ENFERMAGEM

SONIA MARIA JUNQUEIRA VASCONCELLOS DE OLIVEIRA

COMPARAÇÃO DO TEMPO DE APLICAÇÃO DA BOLSA DE GELO PARA O ALÍVIO DA DOR PERINEAL APÓS O PARTO NORMAL:

ENSAIO CLÍNICO RANDOMIZADO

SÃO PAULO 


\title{
COMPARAÇÃO DO TEMPO DE APLICAÇÃO DA BOLSA DE GELO PARA O ALÍVIO DA DOR PERINEAL APÓS O PARTO NORMAL: ENSAIO CLÍNICO RANDOMIZADO
}

\begin{abstract}
Tese apresentada à Escola de Enfermagem da Universidade de São Paulo, como parte dos requisitos para o Concurso de Livre-Docência junto ao Departamento de Enfermagem Materno-Infantil e Psiquiátrica, na área de conhecimento Enfermagem e Assistência ao Parto: Modelos e Práticas
\end{abstract}

\section{SÃO PAULO}




\section{Catalogação na Publicação (CIP) \\ Biblioteca "Wanda de Aguiar Horta" \\ Escola de Enfermagem da Universidade de São Paulo}

Oliveira, Sonia Maria Junqueira Vasconcellos de.

Comparação do tempo de aplicação da bolsa de gelo para o alívio da dor perineal após o parto normal: ensaio clínico randomizado. / Sonia Maria Junqueira Vasconcellos de Oliveira. São Paulo, 2009.

$88 \mathrm{p}$.

Tese (Livre-docência) - Escola de Enfermagem da Universidade de São Paulo.

1. Enfermagem obstétrica 2. Períneo 3. Parto normal 4. Dor

5. Crioterapia 6. Analgesia. I. Título. 


\begin{abstract}
À RAFAELA, para você que tem sido minha companheira, desejo que continue sendo como é hoje: estudiosa, honesta, exemplo de perseverança e motivo de imenso orgulho, dedico todas as coisas boas que consegui realizar até hoje...
\end{abstract}

Ao inesquecível CELSO que, apesar do tempo, continua vivo em minha memória, me guiando e dando forças nessa trajetória de busca Saudades... 


\section{Agradecimento Especial}

À colega, companheira e querida amiga Maria Luiza Gonzalez Riesco, por todos esses anos de convivência, com quem tenho compartilhado momentos difíceis, mas também de muitas alegrias, dizer apenas muito obrigada é pouco... Não tenho palavras para expressar toda minha gratidão, pois sua contribuição tem sido valiosa no aprimoramento deste e de outros trabalhos.

Ao Dr Moacyr Roberto Cuce Nobre, muitíssimo obrigada pela dedicação, parceria e amizade, que tem permitido momentos de reflexão e aperfeiçoamento dos projetos.

As todas as puérperas que se dispuseram a participar e sem as quais seria impossível a concretização deste trabalho. 
Agradecer parece uma tarefa fácil, mas não é quando você não quer cometer injustiça esquecendo de pessoas ou simplesmente estabelecendo a ordem de importância. Assim, independente da seqüência aqui apresentada, as pessoas mencionadas tiveram uma participação valiosa nesta fase da minha vida acadêmica e pessoal.

Às colegas da área Enfermagem Obstétrica que acreditaram e depositaram confiança no meu trabalho o meu profundo agradecimento.

À amiga Maria do Rosário Dias de Oliveira Latorre pela assessoria estatística.

À colega Ruth Hitomi Osava pelo acolhimento e parceria que tem apoiado a utilização do Amparo Maternal como campo de pesquisa.

Às enfermeiras Daniela Biguetti Martins Lopes, Jaqueline Sousa Leite e Priscila Molina pelo auxílio na coleta dos dados.

Aos funcionários da Biblioteca da EEUSP, aqui representados por Nadir Aparecida Lopes.

À secretaria do Departamento ENP, em especial, ao Marcello Batista Pimentel.

Ao estatístico Ricardo Luis Barbosa pela oportunidade de discussão dos dados.

À Fundação de Amparo à Pesquisa do Estado de São Paulo meus agradecimentos pelo auxílio financeiro. 
Oliveira SMJV. Comparação do tempo de aplicação da bolsa de gelo para o alívio da dor perineal após o parto normal: ensaio clínico randomizado [tese livre-docência]. São Paulo: Escola de Enfermagem, Universidade de São Paulo; 2009.

Introdução: A dor perineal no pós-parto vaginal, com ou sem trauma local, é uma das principais morbidades observadas entre as puérperas. A crioterapia tem sido utilizada no pós-parto para o alívio da dor perineal. Objetivo: Comparar a eficácia da bolsa de gelo para o alívio da dor perineal no pós-parto em sessões de 10, 15 e 20 minutos de duração. Método: Trata-se de ensaio clínico de fase II, controlado, aleatorizado, com cegamento da participante em relação à duração da intervenção. Consiste na segunda etapa de um projeto realizado em duas etapas. Na primeira, concluiu-se que a crioterapia com bolsa de gelo durante 20 minutos é eficaz para o alívio da dor perineal. A amostra das duas etapas constituiu-se de 114 puérperas com parto normal internadas no Alojamento Conjunto do Amparo Maternal, que referiram dor perineal $\geq 3$, pela escala numérica de 0 a 10 . Foram divididas em três grupos de 38 mulheres que usaram a bolsa de gelo no períneo: Grupo A - durante 10 minutos; Grupo B - durante 15 minutos; Grupo $C$-, durante 20 minutos. As 76 puérperas dos Grupos A e B foram tratadas na segunda etapa do estudo e as 38 do Grupo C, que integram a primeira etapa, foram incluídas na análise para comparação. A coleta de dados foi realizada entre julho e setembro de 2008, após a aprovação do Comitê de Ética em Pesquisa. As participantes foram avaliadas em quatro momentos: 1. antes da crioterapia; 2. imediatamente após a crioterapia; 3. 20 minutos após a crioterapia; 4. 40 minutos após a crioterapia. Resultados: A idade média foi $22,6 \pm 4,6$ anos. A temperatura do períneo antes da crioterapia variou de $31,1^{\circ} \mathrm{C} \pm 2,1$ a $32,7^{\circ} \mathrm{C} \pm 1,3$; após a crioterapia, a temperatura perineal foi de $13,3^{\circ} \mathrm{C} \pm 4,9$ (Grupo $\left.\mathrm{A}\right), 11,3^{\circ} \mathrm{C} \pm$ 4,5 (Grupo B) e $12,6^{\circ} \mathrm{C} \pm 4,8$ (Grupo C). As médias de dor perineal intra-grupo na primeira e na segunda avaliação apresentaram diferença estatisticamente significativa nos três grupos (teste de Tukey $\mathrm{p}<0,001$ ). Após a aplicação da bolsa de gelo, não houve diferença estatística na comparação da dor perineal entre os grupos na segunda, terceira e quarta avaliações. Também não houve diferença significativa intragrupo entre a segunda e terceira e entre a terceira e quarta avaliações, demonstrando que o efeito da analgesia permaneceu durante 40 minutos. A maioria das puérperas referiu alívio da dor, sendo que $72,8 \%$ delas indicaram redução da dor perineal acima de $50 \%$ e $21,9 \%$, entre $30 \%$ e $50 \%$. Todas as puérperas submetidas a crioterapia foram favoráveis ao procedimento realizado. Conclusão: $O$ tratamento com gelo é seguro e o tempo de 10 ou 15 minutos é tão eficaz quanto o de 20 minutos para o alívio da dor perineal, devendo ser consideradas as variações individuais de cada mulher. São necessários mais estudos para avaliar a duração do efeito analgésico para determinar a periodicidade das aplicações de crioterapia.

Palavras-chave: Crioterapia. Períneo. Dor. Período pós-parto. Enfermagem Obstétrica. 
Oliveira SMJV. Comparison of application time of an icepack for relief of perineal pain after normal birth: randomized clinical trial [thesis]. São Paulo: School of Nursing, University of Sao Paulo; 2009.

Introduction: Postpartum perineal pain after vaginal birth, with or without local trauma, is one of the primary morbidities observed among women during the puerperium. Cryotherapy has been used postpartum to relieve perineal pain. Objective: To compare the efficacy of using an icepack to relieve postpartum perineal pain for 10-, 15- and 20-minute sessions. Method: A phase-II randomized, single-blind, controlled clinical trial with participants blinded as to the duration of the intervention. This trial comprises the second stage of a twostage project. The first stage concluded that application of an icepack for 20 minutes is efficacious to relieve perineal pain. The subject during both stages consisted in 114 women during puerperium after a normal birth staying in the Communal Recovery Area of the Amparo Maternal, who rated their perineal pain $\geq 3$ on a scale of 0 to 10 . The women were divided into three groups of 38 women each who used an icepack on the perineum: Group $A$ - for 10 minutes; Group B - for 15 minutes; Group $C$ - for 20 minutes. The 76 women from Groups A and B were treated in the second stage of the study, and the 38 women from Group $\mathrm{C}$, who comprise the first stage, were included in the analysis for comparison. The data were collected between July and September 2008 after approval by the Research Ethics Committee. The participants were evaluated at four different moments: 1. before cryotherapy; 2. immediately after cryotherapy; 3. 20 minutes after cryotherapy; 4. 40 minutes after cryotherapy. Results: The average age of the subjects was $22.6 \pm 4.6$ years. The perineal temperature before cryotherapy varied between $31.1^{\circ} \mathrm{C} \pm 2.1$ to $32.7^{\circ} \mathrm{C} \pm 1.3$; after cryotherapy, the perineal temperature varied between $13.3^{\circ} \mathrm{C} \pm 4.9$ (Group $\mathrm{A}$ ), $11,3^{\circ} \mathrm{C} \pm 4,5$ (Group B) and $12.6^{\circ} \mathrm{C} \pm 4,8$ (Group C). The average intra-group perineal pain in the first and second evaluation showed a statistically significant difference in the three groups (Tukey test $\mathrm{p}<0.001)$. After application of the icepack, there was no statistical difference in the comparison of perineal pain among the groups in the second, third and fourth evaluations. Also, there was no significant intra-group difference between the second and third evaluations and between the third and fourth evaluations, which showed that the analgesic effect remained throughout the 40 minutes. The majority of the women reported pain relief, with $72.8 \%$ of the women reporting a decrease in perineal pain greater than $50 \%$, and $21.9 \%$ of women reporting a $30 \%$ to $50 \%$ decrease. All the postpartum women subject to cryotherapy were in favor of the procedure conducted. Conclusion: Ice treatment is safe, and 10- or 15-minute durations are as efficacious as 20-minute durations for the relief of perineal pain, it being important to take the individual needs of each woman into consideration when applying the pack. More studies are necessary to evaluate the duration of the analgesic effect to determine the periodicity of applying cryotherapy.

Keywords: cryotherapy; perineal, pain, postpartum period; obstetric nursing. 
Oliveira SMJV. Comparación del tiempo de aplicación de la bolsa de hielo para el alivio del dolor perineal después del parto normal: ensayo clínico randomizado [tesis]. São Paulo: Escuela de Enfermería, Universidade de São Paulo; 2009.

Introducción: El dolor perineal en el post-parto vaginal, con o sin trauma local, es una de las principales morbilidades observadas entre las puérperas. La crioterapia viene siendo utilizada el la atención post-parto para o alivio del dolor perineal. Objetivo: Comparar la eficacia de la bolsa de hielo para el alivio del dolor perineal en el post-parto en sesiones de 10, 15 y 20 minutos de duración. Método: Se trata de ensayo clínico de fase II, controlado, aleatorizado, con cegamiento de la participante con relación a la duración de la intervención. Consiste en la segunda etapa de un proyecto realizado en dos etapas. En la primera, se concluyó que la crioterapia con bolsa de hielo durante 20 minutos es eficaz para el alivio del dolor perineal. La muestra de las dos etapas se constituyó de 114 puérperas con parto normal ingresadas en el Alojamiento Conjunto del Amparo Maternal, que refirieron dolor perineal $\geq 3$, por la escala numérica de 0 a 10 . Fueron divididas en tres grupos de 38 mujeres que usaron la bolsa de hielo en el perineo: Grupo A - durante 10 minutos; Grupo B durante 15 minutos; Grupo $C$-, durante 20 minutos. Las 76 puérperas de los Grupos A y B fueron tratadas en la segunda etapa del estudio y las 38 del Grupo C, que integran la primera etapa, fueron incluidas en el análisis para la comparación. La recolección de los datos se realizó entre Julio y Septiembre de 2008, después de la aprobación del Comité de Ética en Investigación. Las participantes fueron evaluadas en cuatro momentos: 1. antes de la crioterapia; 2. inmediatamente después de la crioterapia; 3. 20 minutos después de la crioterapia; 4. 40 minutos después de la crioterapia. Resultados: La edad media fue 22,6 $\pm 4,6$ años. La temperatura del perineo antes de la crioterapia varió de $31,1^{\circ} \mathrm{C} \pm 2,1$ a $32,7^{\circ} \mathrm{C} \pm 1,3$; después de la crioterapia, la temperatura perineal fue de $13,3^{\circ} \mathrm{C} \pm 4,9$ (Grupo A), $11,3^{\circ} \mathrm{C} \pm 4,5$ (Grupo B) e $12,6^{\circ} \mathrm{C} \pm 4,8$ (Grupo C). Las medias de dolor perineal intra-grupo en la primera $\mathrm{y}$ en la segunda evaluación presentaron diferencia estadísticamente significativa en los tres grupos (prueba de Tukey $p<0,001$ ). Después de la aplicación de la bolsa de hielo, no hubo diferencia estadística en la comparación del dolor perineal entre los grupos en la segunda, tercera y cuarta evaluaciones. Tampoco hubo diferencia significativa intra-grupo entre la segunda y tercera y entre la tercera $y$ cuarta evaluaciones, demostrando que el efecto de la analgesia permaneció durante 40 minutos. La mayoría de las puérperas refirió alivio del dolor, siendo que 72,8\% de ellas indicaron reducción del dolor perineal sobre el $50 \%$ y $21,9 \%$, entre $30 \%$ y $50 \%$. Todas las puérperas sometidas a la crioterapia fueron favorables al procedimiento realizado. Conclusión: El tratamiento con hielo es seguro y el tiempo de 10 o 15 minutos es tan eficaz cuanto el de 20 minutos para el alivio del dolor perineal, debiéndose considerar las variaciones individuales de cada mujer. Son necesarios más estudios para evaluar la duración del efecto analgésico para determinar la periodicidad de las aplicaciones de crioterapia.

Palabras-clave: Crioterapia. Perineo. Dolor. Período post-parto. Enfermería Obstétrica. 


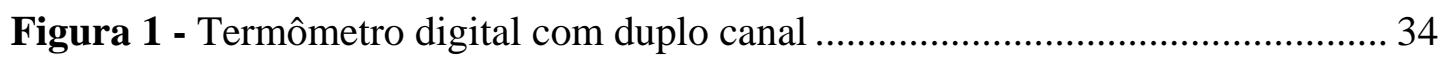

Figura 2 - Peri-rule®, régua empregada na avaliação da extensão

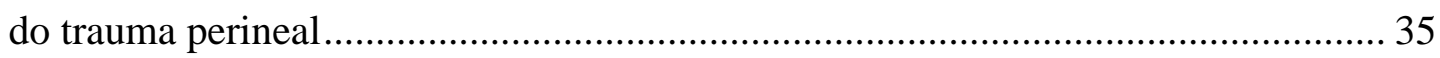

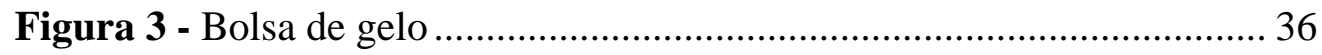

Figura 4 - Diagrama de recrutamento e seguimento das puérperas

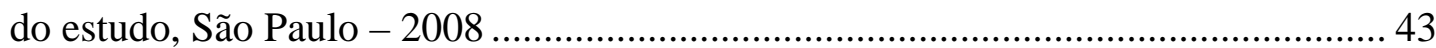


Tabela 1 - Distribuição das puérperas dos Grupos A, B e C segundo as características sociodemográficas, São Paulo - 2008.

Tabela 2 - Distribuição das puérperas Grupos A, B e C segundo a presença de acompanhante no parto, ocorrência e tipo de trauma perineal, São Paulo - 2008..... 45

Tabela 3 - Indicação da episiotomia médio-lateral direita e mediana nos Grupos A, B e C, São Paulo - 2008 46

Tabela 4 - Comparação das médias e desvio-padrão (dp) das variáveis quantitativas dos Grupos A, B e C, antes da intervenção, São Paulo - 2008.

Tabela 5 - Médias da temperatura $\left({ }^{\circ} \mathrm{C}\right)$ do períneo e da bolsa de gelo antes (T0) e no intervalo de 5, 10, 15 e 20 minutos após o início da crioterapia (T5, T10, T15 e T20), nos Grupos A, B e C, São Paulo - 2008.

Tabela 6 - Comparação das médias de dor antes e imediatamente após a aplicação da bolsa de gelo segundo nos Grupos A, B e C, São Paulo - 2008. 50

Tabela 7 - Comparação das médias da dor perineal imediatamente após e 20 minutos depois da aplicação da bolsa de gelo nos Grupos A,B e C, São Paulo - 2008 51

Tabela 8 - Comparação das médias de dor 20 e 40 minutos após o término da aplicação da bolsa de gelo nos Grupos A, B e C, São Paulo - 2008

Tabela 9 - Opinião das puérperas dos Grupos A, B e C sobre a intervenção, São Paulo - 2008. 53

Tabela 10 - Porcentual de redução da dor perineal imediatamente após a intervenção nos Grupos A, B e C, São Paulo - 2008 53

Tabela 11 - Sensações referidas pelas puérperas durante a intervenção, segundo os grupos, São Paulo - 2008 55

Tabela 12 - Posições assumidas pelas puérperas dos Grupos A, B e C durante os primeiros 20 minutos após o término da crioterapia, São Paulo - 2008.

Tabela 13 - Posições assumidas pelas puérperas dos Grupos A, B e C no período entre 20 e 40 minutos após o término da crioterapia, São Paulo - 2008 
Gráfico 1 - Comparação da dor em quatro tempos (antes da aplicação da bolsa, imediatamente após, 20 e 40 minutos depois) nos Grupos A, B e C,

São Paulo - 2008 52

Gráfico 2 - Porcentagem de redução da dor perineal nos Grupos A, B e C, São Paulo - 2008 
Resumo

Abstract

Resumen

Lista de Figuras

Lista de Tabelas

Lista de Gráficos

1. INTRODUÇÃO

2. HIPÓTESE

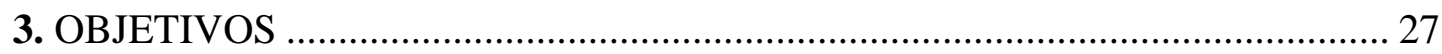

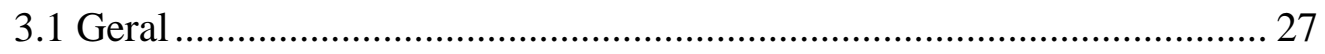

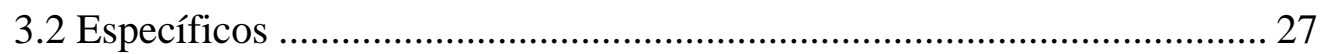

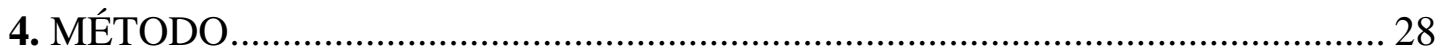

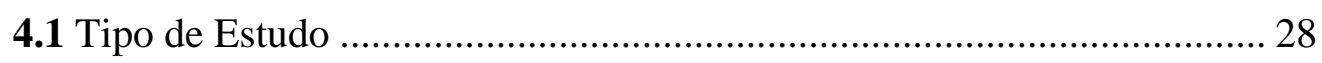

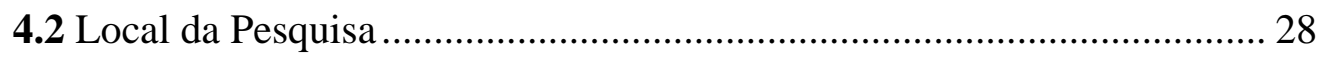

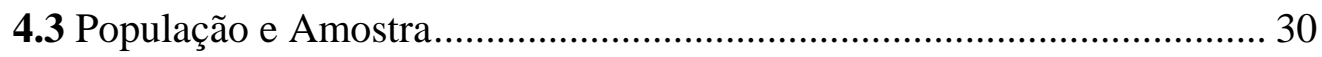

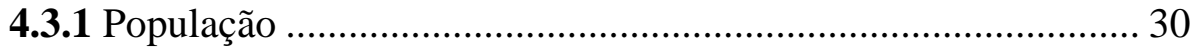

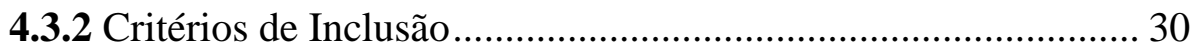

4.3.3 Critérios de Exclusão................................................................. 30

4.3.4 Amostra e Randomização....................................................... 31

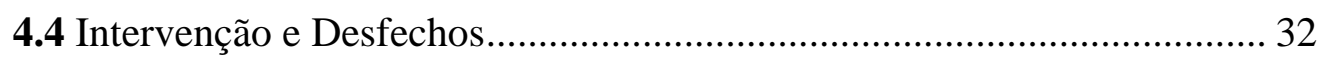

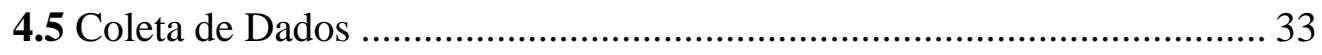

4.5.1 Equipamentos e Instrumentos................................................... 33

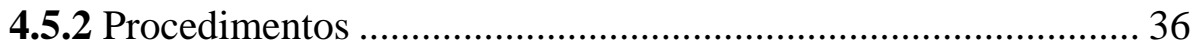

4.6 Variáveis do Estudo ................................................................................. 38

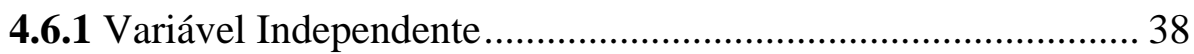

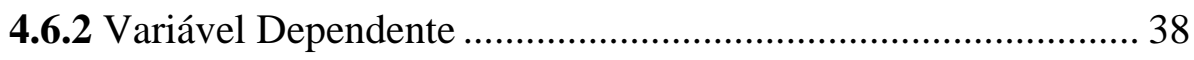

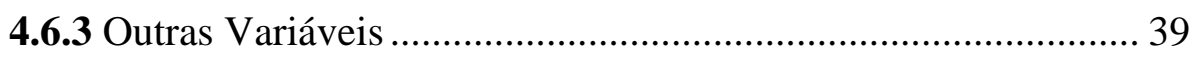

4.7 Tratamento e Análise dos Dados......................................................... 40

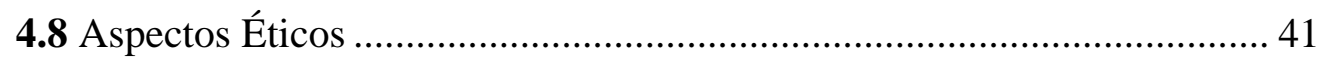


5. RESULTADOS 42

6. DISCUSSÃO 57

7. CONCLUSÃO 72

8. REFERÊNCIAS. 73

\section{APÊNDICES}

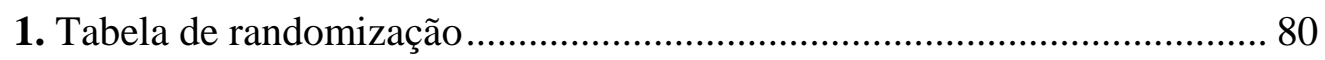

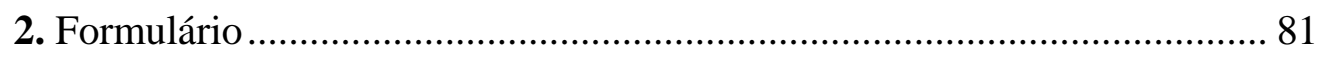

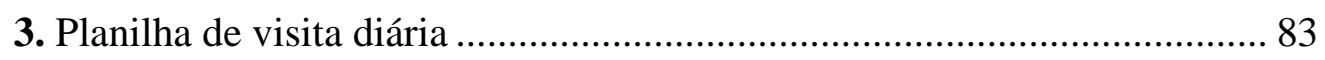

4. Termo de Consentimento Livre e Esclarecido ......................................... 86

\section{ANEXOS}

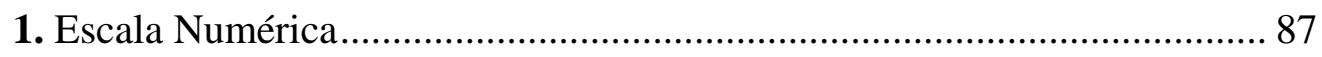

2. Parecer do Comitê de Ética em Pesquisa .................................................. 88 
1. INTRODUÇÃO 
A Pesquisa Nacional de Demografia e Saúde da Criança e da Mulher (PNDS2006) aponta que 98\% dos partos com recém-nascidos (RN) vivos nos cinco anos anteriores à entrevista aconteceram em ambiente hospitalar (Berquó, Garcia, Lago, 2009).

Dados do Sistema de Informações sobre Nascidos Vivos (SINASC) indicam que no ano de 2006 ocorreram aproximadamente 1,5 milhão de partos via vaginal nos hospitais brasileiros (Brasil, 2009). Após o parto vaginal, é extremamente frequente a ocorrência de traumatismo perineal, como conseqüência de episiotomia e lacerações espontâneas do trato genital.

Estudos realizados nos Estados Unidos (EEUU) e na Suécia apontam taxas de lesões perineais que variam entre 85\% a 93,4\% (Albers et al., 1999; Samuelsson et al., 2002). Em nosso país, Silva et al. (2000) constataram que, entre 3.064 partos normais ocorridos no Centro de Parto Normal do Hospital Geral de Itapecerica da Serra, 73,1\% das mulheres tiveram algum grau de traumatismo. Outro estudo brasileiro realizado em um hospital universitário aponta que praticamente a totalidade das mulheres (94\%) submetidas ao parto vaginal apresentou necessidade de sutura perineal (Alexandre et al., 2006).

Nas ultimas décadas, um elo de causalidade entre trauma pós-parto e a disfunção do soalho pélvico tem sido estabelecido (Kearney et al., 2006). O grau de morbidade puerperal está diretamente associado com a extensão e complexidade da lesão ocorrida na região genital (Albers et al., 1999; Macarthur, Macarthur, 2004).

O trauma na região perineal acarreta problemas de curto e longo prazo para as puérperas. Entre as intercorrências de curto prazo, identificadas imediatamente após o parto, estão incluídas a perda sanguínea, a necessidade de sutura e a dor perineal (Albers et al., 2005). Além dessas, outras morbidades podem estar presentes como edema, equimose, hematoma e infecção (Riesco, Oliveira, 2007).

Nas complicações de longo prazo, são citados persistência da dor perineal, problemas sexuais e dispareunia, incontinência urinária, problemas intestinais e hemorróidas, que estão bem documentados nos estudos de Klein et al. (1994), Glazener (1997), Brown, Lumley (1998), Signorello et al. (2001), Thompson et al. (2002) e Andrews et al. (2008).

Enkin et al. (2005) afirmam que o traumatismo causado pelo parto vaginal pode não estar visível, contudo, a mulher pode referir desconforto perineal. Nesse 
sentido, Williams, Herron-Marx, Hicks (2007) constataram que puérperas com períneo íntegro também relataram alto índice $(34,8 \%)$ de incontinência urinária de stress e dispareunia $(25,3 \%)$.

Essas intercorrências, em geral, são angustiantes para as mulheres e podem afetar sua relação com o parceiro e o vínculo com o RN. As conseqüências dessas complicações interferem na movimentação e nas atividades das puérperas, prejudicando o autocuidado e a interação mãe-filho, e estão citadas nos trabalhos de Lydon-Rochelle, Holt, Martin (2001), Steen (2005), Alexandre et al. (2006), Andrews et al. (2008) e Beleza (2008).

Foram encontradas interferências da dor perineal limitando as atividades funcionais das puérperas como: sentar, deitar, deambular, eliminações (micção e evacuação), alimentação, sono, higiene intima, além de amamentação e dos cuidados com o RN (Alexandre, 2002; Macarthur, Macarthur, 2004; Steen, Marchant, 2007; Andrews et al., 2008; Beleza, 2008).

Declercq et al. (2008) constataram, em uma ampla pesquisa do tipo survey realizada nos EEUU, que 10,6\% e 15,3\% das primíparas com partos vaginais, sem e com episiotomia, respectivamente, responderam que a dor interferia muito em suas atividades rotineiras nos primeiros dois meses depois do parto.

É bem documentado que as puérperas frequentemente têm problemas imediatamente após o parto, mas é pouco reconhecido que estes possam persistir por muito tempo depois que os cuidados pós-natais convencionalmente terminam (Glazener, 1997).

A dor perineal no pós-parto vaginal, independente da condição perineal, é uma das principais morbidades observadas entre as mulheres, que diminui com o passar do tempo. Cavalcante (2005) classifica clinicamente a dor em crônica e aguda, sendo que esta decorre primariamente de uma lesão ou dano.

A freqüência e a duração da dor aguda perineal varia segundo os trabalhos que estão citados a seguir.

Estudo realizado com 697 puérperas (356 primíparas e 341 multíparas) constatou que entre o primeiro e o décimo dia após o parto, de 50\% a 90,9\% das mulheres receberam medicação para dor perineal, dependendo do tipo e gravidade do trauma na região. Três meses após o parto, a dor ainda estava presente em 42\% das mulheres com períneo íntegro, 53\% daquelas com laceração de primeiro e segundo 
graus, 54\% com episiotomia e 79\% com laceração de terceiro e quarto graus (Klein et al., 1994).

Albers et al. (1999) observaram maior prevalência de dor perineal no segundo dia de pós-parto espontâneo comparado com o terceiro mês, (41\% versus 3\%) nas mulheres com períneo íntegro, (65\% versus 5\%) naquelas com lacerações espontâneas de primeiro e segundo graus e (95\% versus 14\%) de terceiro e quarto graus, respectivamente.

Estudo de coorte australiano conduzido com puérperas que tiveram partos espontâneos e assistidos encontrou 22\% de dor perineal na oitava semana, 6\% na décima sexta e 3\% na vigésima quarta (Thompson et al., 2002).

Pesquisa descritiva, realizada em nosso meio, com 100 puérperas de partos espontâneo e fórcipe, constatou que a dor perineal foi referida por 73 mulheres nas primeiras 24 horas. Mesmo decorridos dez dias do parto, a segunda causa de dor continuou sendo o períneo, com 49 casos (Alexandre, 2002).

Estudo de coorte prospectivo foi conduzido para avaliar a relação entre o trauma e a dor perineal após o parto vaginal. Verificou-se que a incidência de dor variou de acordo com o grau da lesão perineal. No primeiro e no sétimo dia depois do parto, sentiam dor, respectivamente, $75 \%$ e 38\% das mulheres com períneo intacto, $95 \%$ e $60 \%$ das com lacerações de primeiro e segundo graus, $97 \%$ e $71 \%$ daquelas com episiotomia e $100 \%$ e $91 \%$ das com lacerações de terceiro e quarto graus. Com seis semanas de pós-parto não foi encontrada diferença estatística na dor entre os grupos (Macathur, Macathur, 2004).

Glazener (2005) observou que, durante o período de internação hospitalar, $42 \%$ das puérperas referiram dor perineal, dessas, $79 \%$ foram tratadas. A proporção de dor reduziu-se para aproximadamente metade quando se considerou o tempo de até dois meses (22\%) e para $10 \%$ entre dois e 18 meses. A dor persistente foi estatisticamente associada com os partos vaginais assistidos, em razão da alta prevalência de episiotomia (88\%).

Trabalho realizado com 1.573 mulheres com dois meses após o parto revelou que a dor perineal foi citada por $77 \%$ das primíparas e $52 \%$ das multíparas submetidas ao parto instrumental, por 73\% das primíparas com parto espontâneo, das quais 31\% tiveram episiotomia (Declerq et al., 2008).

Estudo australiano com 1.336 puérperas com seis a sete meses de pós-parto 
vaginal verificou que $31,1 \%$ das primíparas, contra $14,8 \%$ das multíparas, informaram ter dor perineal $(\mathrm{p}<0,0001)$ e as mulheres com parto vaginal assistido tiveram cinco vezes mais chance de relato de dor perineal em comparação com aquelas de parto vaginal espontâneo [odds ratio $(\mathrm{OR})=4,69$; intervalo de confiança (IC) $95 \%=3,2-6,8]$ (Brown, Lumley, 1998).

O estudo sobre a morbidade pós-natal prolongada e a relação com o traumatismo perineal apontou que 32,6\% das mulheres com episiotomia e laceração espontânea indicaram algum grau de dor perineal mesmo um ano após o parto (Williams, Herron-Marx, Hicks, 2007).

Por outro lado, estudo prospectivo citado anteriormente constatou que, entre 241 primíparas de parto vaginal, 92\% referiram dor perineal nas primeiras 24 horas, com completa resolução em 88\% dos casos em sete semanas (Andrews et al., 2008).

Em relação aos problemas sexuais, Glazener (1997) afirma que os profissionais de saúde deveriam estar cientes da alta frequência dessas complicações, e preparar as mulheres durante o pré-natal, considerando a elevada probabilidade de ocorrência de tais problemas no período puerperal, com a finalidade de reduzir a carga de morbidade materna.

Glazener (1997) identificou que a mediana de tempo para o retorno à atividade sexual depois do parto foram seis semanas e que 28,1\% das puérperas com menos de oito semanas informaram dor ou dificuldade para o ato sexual.

Aos três meses após o parto, a dispareunia ainda foi relatada por 32,8\% das mulheres com períneo íntegro, 48,2\% daquelas com laceração de segundo grau e $61,4 \%$ com laceração de terceiro e quarto graus. O retorno da atividade sexual ocorreu com seis semanas em 54\% do grupo com períneo íntegro, em 38,9\% daquele com laceração de segundo grau e em 25\% com terceiro e quarto graus. Considerando o total da população, foi encontrada dispareunia em $41 \%$ das mulheres no terceiro mês pós-parto e 22\% no sexto mês (Signorello et al., 2001).

Outro estudo citado anteriormente também constatou melhor função sexual das mulheres com períneo intacto e roturas de primeiro ou segundo graus, comparadas a episiotomia ou roturas de terceiro e quarto graus (Klein et al., 1994).

Assim, evitar ou minimizar as lesões perineais e reparar adequadamente em casos de traumatismo são condutas primárias para reduzir esses problemas, resultando em benefícios e melhor qualidade de vida para muitas mulheres e seus 
familiares (Enkin et al., 2005).

Como referido anteriormente, a episiotomia é uma variável determinante para o trauma perineal. São indicações para realizar episiotomia: sofrimento fetal, progressão insuficiente do parto e ameaça de laceração perineal de terceiro grau (OMS, 1996).

Pela primeira vez dados da PNDS-2006 demonstraram que a episiotomia foi realizada em $70 \%$ dos partos normais ocorridos no Brasil na última década, e assumiu proporções mais baixas apenas em partos de mulheres com mais de três filhos (Berquó, Garcia, Lago, 2009). O Guia Prático para Assistência ao Parto Normal, da Organização Mundial da Saúde, recomenda que a proporção de episiotomia de 10\% alcançada em um estudo inglês, sem conseqüências para mãe e neonato, seria uma boa referência para ser adotada (OMS, 1996).

A revisão sistemática que comparou o uso restrito com o rotineiro da episiotomia no parto vaginal observou maior benefício no uso restrito, com menos trauma perineal na região posterior [risco relativo $(R R)=0,67$; IC 95\%=0,49-0,91], menor necessidade de sutura $(\mathrm{RR}=0,71$; IC 95\%=0,61-0,81) e, também, quantidade inferior de complicações, contudo com maior risco de laceração na região anterior (RR=1,84; IC 95\%=1,61-2,10) (Carroli, Mignini, 2009).

Além do tipo e da extensão do trauma, a técnica e o material de sutura podem estar associados à morbidade perineal.

Ensaio clínico conduzido em 61 mulheres com episiotomia ou rotura de segundo grau, comparando a técnica convencional (sutura contínua da mucosa, pontos separados no músculo e na pele) com a técnica de sutura contínua da mucosa, do músculo e da intraderme, verificou que houve diferença estatística na freqüência de dor perineal à palpação com quatro dias de pós-parto, sendo mais freqüente entre as puérperas com sutura convencional (Almeida, Riesco, 2008).

A revisão sistemática da Biblioteca Cochrane que analisou dados de 3.822 mulheres apontou menor risco de dor perineal por até 10 dias com a técnica de sutura contínua, comparada com a técnica interrompida. Em relação à necessidade de resutura e à dor em longo prazo, não foram encontradas diferenças significativas (Kettle, Hills, Ismail, 2007).

Em outra revisão sistemática que avaliou o material de sutura de origem sintética e absorvível (ácido poliglicólico e poliglactina), versus categute, constatou 
que o fio sintético está associado a menos dor perineal nos três primeiros dias de pósnatal, menor necessidade de analgesia $(\mathrm{OR}=0,63$; IC $95 \%=0,52-0,77)$ e menos deiscência de sutura. Não houve diferença estatística na dor em longo prazo e na magnitude da dispareunia (Kettle, Johanson, 2007).

Estas evidências científicas indicam que o fio sintético absorvível e a técnica de reparo contínuo ocasionam menos dor aguda no períneo e, portanto, deveriam ser adotados na prática obstétrica.

Convencionalmente, para o controle da dor perineal no período pós-natal, têm sido empregados analgésicos orais e anestésicos locais. Para o tratamento por via oral, existe uma vasta opção farmacológica ativa. No entanto, apesar do expressivo número de estudos aleatorizados que avaliaram os analgésicos orais, as evidências não são úteis. A justificativa é que a maioria dos trabalhos demonstrou que as preparações ativas foram superiores aos placebos, mas não apontou diferenças clinicamente importantes entre as opções de analgésicos. Além disso, muitos medicamentos avaliados nesses estudos já foram retirados do mercado (Enkin et al., 2005).

Para o controle da dor aguda são empregados anti-inflamatórios não esteróides (AINEs), opióides e ansiolíticos. Os ansiolíticos (benzodiazepínicos), embora formulados com outras finalidades terapêuticas, apresentam ação analgésica, mas são pouco utilizados na prática clínica para o alívio da dor aguda. Os AINEs são o maior grupo de analgésicos, possuem ação analgésica moderada e são largamente utilizados na prevenção e tratamento da dor no pós-operatório (Corrêa, Pimenta, 2005).

Para a escolha do medicamento, deve-se levar em consideração a intensidade da dor, a possibilidade de a droga causar constipação materna, a irritação gástrica, a passagem para o leite materno com possível risco para o RN e também o custo. Segundo esses critérios, o paracetamol (acetaminofeno) é o analgésico oral que se utiliza para a dor perineal leve (Enkin et al., 2005).

A recente revisão sistemática que avaliou o emprego de dose única de acetaminofeno para dor aguda no pós-operatório concluiu que esse analgésico é efetivo e praticamente não tem efeitos colaterais (Barden et al., 2008a).

Entre os outros anti-inflamatórios, o ibuprofeno poderia ser a segunda alternativa, no caso de outra opção ao paracetamol. Caso o efeito analgésico não seja 
satisfatório, parece prudente associar com o tratamento local (Enkin et al., 2005).

A revisão sistemática que avaliou a dipirona oral, utilizada em dose única para dor moderada ou intensa no pós-operatório, demonstrou eficácia similar daquela em relação ao ibuprofeno 400 mg e outros analgésicos utilizados com freqüência. Os efeitos colaterais mais observados foram: sonolência, desconforto gástrico e náusea (Edwards et al., 2008).

Outra revisão sistemática atual sobre o uso de dose única de diclofenaco oral verificou que essa droga é efetiva no controle da dor moderada e severa, no pósoperatório. Não foi encontrada diferença significativa entre o diclofenaco e o placebo quanto aos efeitos indesejáveis, ou entre diclofenaco de sódio e de potássio (Barden et al., 2008b).

A revisão sistemática que analisou a eficácia dos anestésicos tópicos no alívio da dor perineal no pós-parto indicou que os benefícios não são convincentes. Os revisores sugerem que mais estudos sejam conduzidos para avaliar a qualidade de vida das puérperas, a efetividade de diferentes anestésicos e os resultados em longo prazo (Hedayati, Parsons, Crowther, 2008).

O controle da dor é mais eficaz se engloba intervenções múltiplas farmacológicas e não farmacológicas - que possam agir sobre os diversos componentes da dor. Os métodos não farmacológicos físicos abrangem aplicação de calor e frio superficial, técnica de estimulação elétrica transcutânea, massagens, técnicas de acupressão (“do-in”), exercício físico, entre outros (Corrêa, Pimenta, 2005).

Entre os métodos não farmacológicos, tradicionalmente, na obstetrícia são utilizadas compressas de gelo ou calor, banhos de assento e duchas para o alívio do desconforto perineal. O resfriamento por meio de gelo e aerossóis é freqüentemente empregado no período puerperal com a suposição de diminuir o edema e a dor (Enkin et al., 2005).

As aplicações de frio datam de antes de Cristo com os gregos e romanos utilizando neve e gelo natural para tratar vários problemas médicos (Knight, 2000).

Na área obstétrica, as primeiras referências do emprego do frio são de 1930, sendo originalmente aplicado na região retal para alívio da dor hemorroidal. A utilização da bolsa de gelo aumentou gradualmente a partir de 1960, principalmente após as décadas de 1970 e 1980 devido à rápida expansão do conhecimento 
produzido para o tratamento dos danos causados no soalho pélvico (Rhode, Barger, 1990) e ao aumento das taxas de episiotomia (Steen, Briggs, King, 2006).

A crioterapia é usada freqüentemente no período inicial do pós-parto e raramente continua depois das primeiras horas (Lafoy, Geden, 1989).

O conceito de crioterapia é qualquer emprego de gelo ou aplicação de frio, resultando em remoção do calor corporal e redução da temperatura dos tecidos, com finalidade terapêutica (Palastanga, 1994).

Em resposta à injúria tecidual, as terminações nervosas especializadas chamadas nociceptores são ativadas. Os nervos nociceptores transmitem sinais que são enviados ao cérebro pela medula espinal, onde a sensação de dor é reconhecida. Ao mesmo tempo, neurotransmissores iniciam um reflexo espinal que aumenta a atividade motora e tonicidade muscular no local da lesão, levando a uma contração muscular reflexa. Se persistente, o aumento do tônus muscular pode causar espasmos musculares dolorosos, que pode levar a maior dano tecidual, devido à diminuição do fluxo sanguíneo e de oxigênio aos tecidos circundantes. A dor, por sua vez, aumenta. Este processo de lesão é chamado de ciclo dor-espasmo-dor (Nadler, Weingand, Kruse, 2004).

Os efeitos fisiológicos da aplicação do frio, como diminuição de dor, do espasmo muscular, do metabolismo e da inflação, parecem ser universalmente aceitos, apesar dos mecanismos de ação não estarem completamente esclarecidos. O efeito de aplicações com frio por 20 a 40 minutos durante o processo de cicatrização de lesões é desconhecido. Entre as técnicas de crioterapia são citadas: aplicação de gelo ou compressa gelada, massagem com gelo, banho com água fria, compressas de gel frio, imersão em gelo; entre outras (Knight, 2000).

A ação analgésica do frio está relacionada com o espasmo vascular, redução do fluxo sanguíneo local e, portanto, do edema. São citados, ainda, diminuição na velocidade de condução nervosa, redução da chegada de estímulos nociceptivos à medula espinal e aumento do limiar de dor (Corrêa, Pimenta, 2005).

O tratamento tópico com o frio diminui a temperatura da pele e dos tecidos subjacentes a uma profundidade de dois a quatro centímetros $(\mathrm{cm})$, reduzindo o limiar de ativação dos nociceptores e a velocidade de condução da dor. Isto resulta em um efeito anestésico local chamado neuropraxia induzida pelo frio (Nadler et al., 2001 apud Nadler, Weingand, Kruse, 2004). 
A seguir, estão descritos alguns estudos que aplicaram ou avaliaram o emprego da crioterapia para o alívio da dor durante o parto e o puerpério.

Pesquisa conduzida com 50 maternidades na Inglaterra, para verificar quais práticas de obstetrícia são utilizadas para o alívio da dor perineal nos primeiros dias do puerpério, constatou que a bolsa de gelo foi o tratamento localizado mais citado pelas obstetrizes (84\%) (Sleep, Grant, 1988).

Um estudo mais recente no Reino Unido observou que as obstetrizes de 210 maternidades utilizam práticas não farmacológicas no final do expulsivo, para controlar a dor no períneo causada pelo avanço da cabeça fetal e estiramento do tecido perineal antes do parto espontâneo, como bolsas aquecidas (33\%), bolsa fria (21\%) e massagem perineal (52\%) (Sanders, Peters, Campbell, 2005).

Também no trabalho de parto, um estudo investigou a técnica acupressure usando massagem com gelo no ponto meridiano quatro do intestino grosso (IG4) para reduzir a dor durante as contrações uterinas. Os resultados sugerem que massagem com gelo reduziu a dor, foi seguro e pode ser considerado como um método de tratamento não invasivo no parto (Waters, Raisler, 2003).

Em nosso país, Nunes, Vargens (2007) realizaram uma investigação exploratória com 21 parturientes submetidas a crioterapia, independente da idade e do número de partos. Foram efetuadas até duas aplicações, utilizando compressa de gelo por 20 minutos na região lombar, com sete a nove $\mathrm{cm}$ de dilatação cervical. Verificaram que esse cuidado proporcionou alivio da dor e relaxamento das mulheres, sem nenhuma intercorrência para mãe e filho. Os autores não informaram o intervalo entre as aplicações e a aceitação do gelo pelas mulheres.

Um dos primeiros trabalhos encontrados na literatura empregando a bolsa de gelo para o controle da dor perineal foi o estudo de Pinkerton, Beard (1961) com 100 puérperas com laceração severa. A aplicação do gelo foi repetida se houvesse necessidade. O tempo de início, o intervalo e a duração das aplicações não foram informados e os desfechos avaliados foram o edema e a dor perineal, mediante uso de escala (sem desconforto, desconfortável, doloroso e muito doloroso). Os autores observaram que clinicamente as pacientes submetidas ao tratamento com gelo apresentaram menos ocorrência de edema 24 horas depois do parto. No segundo dia 86\% das mulheres relataram menos desconforto (sem desconforto e desconfortável) contra $60 \%$ do grupo sem tratamento. 
Outro autor recomenda o banho de assento alternado quente e frio, por 20 a 30 minutos a cada seis horas durante as primeiras 24 horas após o parto. Refere que grande parte das puérperas prefere o banho frio e relata alívio da dor por 4 a 6 horas depois do tratamento (Droegemueller, 1980).

Pesquisa conduzida em 40 puérperas com episiotomia e diferentes paridades avaliou a eficácia dos banhos de assento frio e quente por 20 minutos de duração, no alívio da dor perineal depois das primeiras 24 horas do parto. Nesse protocolo as autoras dividiram aleatoriamente as pacientes em dois grupos que serviram como seus próprios controles. Vinte mulheres iniciaram o tratamento com banho frio $\left(15,6^{\circ} \mathrm{C}\right.$ a $\left.18,3^{\circ} \mathrm{C}\right)$ e após seis horas receberam banho de assento quente $\left(36,7^{\circ} \mathrm{C}\right.$ a $44,4^{\circ} \mathrm{C}$ ) e o segundo grupo começou pelo banho quente e terminou com o frio. A dor foi mensurada em quatro momentos (antes e imediatamente depois da intervenção, com 30 minutos e uma hora após), pela escala numérica de 0 a 5 . Os resultados apontaram que o banho frio foi significativamente mais eficaz que o quente na primeira avaliação do tratamento (Ramler, Roberts, 1986).

O estudo exploratório de Lafoy, Geden (1989) também analisou a efetividade dos banhos frio $\left(0^{\circ} \mathrm{C}\right)$ e quente $\left(43^{\circ} \mathrm{C}\right)$, para o controle da dor perineal, em 20 puérperas submetidas a episiotomia. As mulheres foram divididas em dois grupos, com dez em cada um e, todas utilizaram os dois banhos de assento por 15 minutos entre 6 e 24h após o parto. Apenas a seqüência dos banhos foi randomizada e o intervalo entre os banhos foi de seis horas. Não houve diferença estatística nos efeitos associados com a ordem dos banhos. No entanto, começando pelo tratamento frio o resultado foi significativamente mais eficiente na diminuição do edema perineal.

Hill (1989) comparou os efeitos da bolsa gelada $\left(0^{\circ} \mathrm{C}\right)$, bolsa quente $\left(43^{\circ} \mathrm{C}\right)$ e banho de assento morno $\left(36,5^{\circ} \mathrm{C}\right.$ a $\left.39^{\circ} \mathrm{C}\right)$ utilizados nas primeiras 24 horas após o parto, por 20 minutos, em mulheres com episiotomia ou lacerações. Não observou diferença significativa no alívio da dor perineal entre os três grupos. A justificativa da autora é que em razão do material extra-absorvente que cobria a bolsa de gelo, a região pode não ter atingido a temperatura adequada.

Ensaio clínico controlado e randomizado foi conduzido por Steen et al. (2000) em 120 mulheres, submetidas ao parto instrumental, para avaliar a efetividade da bolsa de gelo, com anti-inflamatório local (Epifoam) e com uma bolsa de gel, 
utilizados por no máximo 30 minutos. A bolsa de gel usada no estudo foi desenvolvida por Steen, Cooper (1999) e consiste em uma almofada no formato de absorvente, especialmente desenhada para a região do períneo, contendo gel em seu interior que possui capacidade térmica de resfriamento. As puérperas tinham liberdade para escolher o momento de iniciar o tratamento, desde que fosse até quatro horas depois do parto, e também, para repetir os procedimentos até 48 horas. Os autores concluem que houve uma redução significativa, na avaliação de 48 horas, apenas da dor inicialmente classificada como severa e moderada.

Steen, Marchant (2007), dando continuidade ao trabalho citado anteriormente (Steen et al., 2000), ampliaram o ensaio clínico incluindo avaliação de dor perineal durante e após o período de internação hospitalar. O número de questionários respondidos foi 316 (71\%) dentre 450 mulheres submetidas ao parto espontâneo e instrumental com episiotomia ou rotura de segundo grau, sendo 101 no grupo sem tratamento, 107 no grupo da bolsa de gelo e 108 no grupo de bolsa com gel resfriada. A estimativa total de dor foi menor no grupo do gel, com diferença significativa no quinto e no décimo dia pós-parto.

Ensaio clínico foi realizado em uma maternidade localizada no interior do Estado de São Paulo, em 50 primíparas submetidas ao parto vaginal e com episiotomia, para avaliar o efeito da crioterapia no alívio da dor. A técnica de resfriamento consistiu em uma bolsa plástica na forma de absorvente, contendo gelo triturado que foi aplicada por 20 minutos em 24 mulheres do grupo experimental entre seis e 24 horas após o parto. Para a mensuração da dor foi utilizada a escala numérica de 0 a 10. A autora constatou redução significativa da dor perineal logo após a intervenção e uma hora depois da aplicação de crioterapia (Beleza, 2008).

Embora o resfriamento com gelo seja usado frequentemente na assistência pós-parto, não existem evidências científicas dos benefícios em longo prazo (Enkin et al., 2005). Também a última revisão sistemática da Biblioteca Cochrane, que analisou sete ensaios clínicos com 859 puérperas sobre a aplicação de frio para alívio da dor perineal em decorrência do trauma ocorrido após o parto, concluiu que havia pouca evidência para apoiar a eficácia dos tratamentos com a crioterapia. As revisoras referem que nenhum dos trabalhos avaliou a temperatura do local, indicando se houve redução da temperatura do períneo para $10^{\circ} \mathrm{C}$ a $15^{\circ} \mathrm{C}$, valor recomendado para o efeito analgésico. Sugerem incluir nos estudos variáveis como: 
paridade, tipo de parto, grau de traumatismo perineal, a facilidade de utilização e um grupo sem tratamento local para a comparação (East et al., 2008).

A revisão sistemática que avaliou apenas literatura original sobre tratamento com frio em lesões agudas dos tecidos moles identificou que, nos anos de 1940, era recomendado apenas nos primeiros 30 a 60 minutos, enquanto na década seguinte, foi usado por até 24 a 72 horas após a lesão. Os estudos analisados usaram a crioterapia por períodos que variaram de cinco a 85 minutos. Atualmente, a terapêutica com gelo está estabelecida como um componente essencial do tratamento da lesão de tecidos moles, mas, ainda, existe pouca consistência nas recomendações sobre a adequada duração de cada sessão, a freqüência de aplicação ou a duração da terapia (MacAuley, 2001).

A revisão conduzida por Steen, Briggs, King (2006), com o objetivo de identificar tipos de métodos de resfriamento utilizados nas pesquisas, eficácia do tratamento em relação à redução dos níveis de dor, redução da resposta inflamatória, efeitos adversos e a satisfação materna. Encontraram 12 estudos, dos quais excluíram quatro por não serem ensaios controlados randomizados ou por não estarem escritos em língua inglesa. Os revisores referem que a qualidade metodológica foi muito variada, apenas dois estudos citavam cálculo de amostra e análise com número necessário para tratar. Encontraram entre os tipos de tratamentos o banho de assento frio e alguns dispositivos de resfriamento, porém não fazem referência quanto à duração das aplicações. Constataram que houve redução da dor e da resposta inflamatória, contudo, referiram que mais pesquisas são necessárias para avaliar o impacto sobre a cicatrização e qual o método de resfriamento mais eficaz.

Conforme os estudos citados anteriormente, os protocolos de tratamento da crioterapia nos cuidados perineais foram muito variados quanto à temperatura utilizada, a freqüência e a duração da aplicação. Foram encontrados trabalhos empregando desde 15 até 30 minutos. Por outro lado, a análise feita por Rhode, Barger (1990) também indica variabilidade ainda maior na duração da terapia, entre 10 minutos e uma hora. Na revisão sistemática conduzida por East et al. (2008), os estudos incluídos utilizaram de 10 a 20 minutos de aplicação de tratamento frio.

Na prática clínica, isso reflete o tempo necessário para que ocorra diminuição da temperatura corporal (East et al., 2008).

No atendimento imediato das lesões agudas esportivas os estudos 
recomendam desde seis minutos até 24 a 48 horas continuamente, entretanto, a maioria dos médicos clínicos utiliza a aplicação intermitente, porque acredita que ocorra uma vasodilatação induzida pelo frio como pós-efeito ao tratamento (Knight, 2000).

A revisão sistemática indica evidência de redução da temperatura nos primeiros 10 minutos, seguida de pouca modificação entre 10 e 20 minutos. Conclui que o gelo é eficaz, mas deve ser aplicado por 10 minutos de modo intermitente para evitar os efeitos secundários, e ainda evitar possíveis lesões, tendo como meta a redução da temperatura entre $10^{\circ} \mathrm{C}$ e $15^{\circ} \mathrm{C}$ (MacAuley, 2001).

De acordo com Palastanga (1994), quando o gelo é aplicado sobre a pele ocorre um resfriamento imediato, com redução de $15^{\circ} \mathrm{C}$ dentro de dois a cinco minutos. Entretanto, os tecidos musculares mais espessos, como a coxa, exigem mais tempo para resfriar do que as regiões ósseas (Knight, 2000).

O resfriamento dos tecidos abaixo de $20^{\circ} \mathrm{C}$ é letal para as células, e grande parte das técnicas atuais de crioterapia provavelmente não é suficientemente fria para causar dano tecidual, exceto se empregada continuamente por uma hora ou mais ou estiver associada com pressão. Nas aplicações utilizadas na medicina esportiva, em geral, o resfriamento da pele é superficial, atingindo entre $1^{\circ} \mathrm{C}$ e $10^{\circ} \mathrm{C}$ (Knight, 2000).

As contra-indicações absolutas dos banhos de assento com gelo são raras, porém, não deve ser usada temperatura inferior a $0^{\circ} \mathrm{C}$ (Droegemueller, 1980). As contra-indicações da crioterapia são para indivíduos com doenças de Raynaud ou outro distúrbio vasoespástico, hipersensibilidade ao frio e distúrbios cardíacos com comprometimento da circulação local (Knight, 2000).

São poucos os livros textos de obstetrícia que recomendam o emprego de gelo profilático imediatamente após o parto para reduzir edema e desconforto, e aqueles que o fazem não especificam a frequência e a duração da aplicação (Olds, London, Ladewig, 1984; Ziegel, Cranley, 1985; Ellis, 1986; Neeson, May, 1986; Cunningham et al., 2000, Melson et al., 2002).

Nas orientações da Área Técnica de Saúde da Mulher do Ministério da Saúde, está indicado o uso de gelo no períneo na ocorrência de edema, equimose e hematoma e desconforto por dor na episiorrafia, nas primeiras 24 horas após o parto (Brasil, 2001). A crioterapia deve ser aplicada preventivamente no períneo nas duas horas seguintes ao parto, para reduzir a formação de edema e, como efeito 
anestésico, depois desse período (Stetson, 2002).

Segundo Ramler, Roberts (1986), a grande variedade de tratamentos usados no alívio da dor perineal reflete a incapacidade de um único método ter completa eficácia na resolução do problema. Beleza (2008) aponta como lacunas das pesquisas com aplicação de frio, a falta de grupo controle, os grupos de tratamentos não homogêneos e a falta de rigor na descrição do método.

Na última revisão sistemática da Biblioteca Cochrane, os revisores concluem que o número relativamente pequeno de mulheres proporcionou limitada evidência para apoiar a efetividade dos tratamentos com frio. Futuros estudos poderão considerar a duração das sessões de crioterapia, além de analisar os potenciais efeitos negativos da terapia prolongada (East et al., 2008).

Assim, justifica-se a necessidade de ensaios clínicos controlados e aleatorizados para avaliar a eficácia da aplicação da bolsa de gelo para alívio da dor perineal no pós-parto durante 10, 15 e 20 minutos, que corresponde à menor duração das sessões de crioterapia recomendada pela maioria dos estudos. 
2. HIPÓTESE 
- A duração da sessão de crioterapia inferior a 20 minutos é eficaz para o alívio da dor perineal moderada ou intensa, após o parto normal. 
3. OBJETIVOS

\section{(1)}




\subsection{Geral}

- Comparar a eficácia da bolsa de gelo para o alívio da dor perineal no pósparto em sessões de 10, 15 e 20 minutos de duração.

\subsection{Específicos}

- Mensurar a dor perineal antes e após a aplicação da bolsa de gelo.

- Verificar a proporção de redução da dor perineal após o emprego da bolsa de gelo.

- Identificar a temperatura da região perineal antes, durante e após a aplicação da bolsa de gelo.

- Identificar possíveis efeitos adversos causados pela aplicação da bolsa de gelo.

- Verificar a opinião das mulheres a respeito da bolsa de gelo. 
4. MÉTODO 
Este estudo é parte de um projeto realizado em duas etapas.

\section{- Primeira Etapa}

A primeira etapa foi concluída em 2008 e consistiu de um ensaio clínico controlado, paralelo, randomizado, com cegamento do avaliador do desfecho, sobre o uso da bolsa de gelo para alívio da dor perineal após o parto normal. Nessa etapa, a população foi dividida em três grupos: experimental, constituído de puérperas que usaram bolsa de gelo no períneo por 20 minutos; placebo, no qual foi utilizada bolsa de água na temperatura ambiente e controle, que não fez uso da bolsa. Concluiu-se que o uso da bolsa de gelo por vinte minutos foi eficaz para o alívio da dor perineal após o parto normal (Leventhal, 2008).

\section{- Segunda Etapa}

Consiste no presente estudo, descrito a seguir.

\subsection{Tipo de Estudo}

Trata-se de ensaio clínico de fase II, controlado, aleatorizado, com cegamento da participante em relação à duração da intervenção.

\subsection{Local da Pesquisa}

O estudo foi realizado no Alojamento Conjunto (AC) do Amparo Maternal, instituição localizada na zona sul da cidade de São Paulo. Essa maternidade é referência para gestações de baixo risco e presta assistência obstétrica e neonatal exclusivamente pelo Sistema Único de Saúde (SUS). O Amparo Maternal é uma entidade filantrópica, vinculada à Cúria Metropolitana da cidade de São Paulo.

O hospital possui um Centro de Parto Normal (CPN) com 16 leitos de préparto e seis de pós-parto imediato, além de oito de terapia intensiva neonatal e 84 de pós-parto. A assistência à mulher durante todo o parto é realizada por enfermeiras obstétricas e obstetrizes, que totalizam 17 , sendo três por plantão. A internação e a 
assistência das parturientes patológicas ou com distocias é da competência do médico obstetra.

Segundo dados estatísticos da maternidade, no mês de agosto de 2008, foram realizados 762 partos, dos quais 80,2\% foram espontâneos, 19,4\% cesarianas e 0,4\% fórcipes. Com relação à condição perineal, 42,9\% das mulheres tiveram períneo íntegro, 3,3\% episiotomia, 34,9\% laceração de primeiro grau, 8,6\% de segundo grau e $10,3 \%$ de terceiro grau.

Depois de admitida, a parturiente é encaminhada ao pré-parto, sendo estimulada a deambular, tomar banho de chuveiro ou de banheira. As práticas de uso rotineiro como tricotomia perineal, jejum, enema, infusão de ocitocina foram abandonadas após a reestruturação do CPN, ocorrida em 1998. No final do primeiro período do parto, a mulher é transferida para a sala de parto onde ocorre a expulsão fetal. O parto normal é realizado pela enfermeira obstétrica ou obstetriz. Um acompanhante de escolha da mulher ou doula pode permanecer durante o trabalho de parto e parto com a parturiente. A indicação da episiotomia é seletiva e o fio empregado na sutura é o categute zero simples.

A amamentação é estimulada, em geral, imediatamente após o parto e, em seguida, a mulher é encaminhada ao AC, enquanto o neonato continua no $\mathrm{CPN}$, em observação. Depois de avaliado pelo neonatologista, o RN também é encaminhado para o $\mathrm{AC}$, onde permanece com a mãe. No período de internação hospitalar, as puérperas são incentivadas a amamentar, exceto nos casos de hepatite C, AIDS ou patologia materna em que a droga administrada passa para o leite, quando é introduzido o leite artificial.

Durante o período de internação no AC, a prescrição médica de rotina no pósparto normal inclui um analgésico via oral (dipirona sódica 500 miligramas, a cada oito horas) e um anti-inflamatório via oral (diclofenaco de sódio 50 miligramas, a cada oito horas), administrado quando a queixa dolorosa persiste. No serviço, não é habitual o emprego de tratamento não farmacológico para aliviar a dor na região do períneo. 


\subsection{População e Amostra}

\subsubsection{População}

A população constituiu-se de puérperas com parto normal internadas no $\mathrm{AC} \mathrm{e}$ que atenderam aos critérios de inclusão. A população foi dividida em três grupos Grupo A, composto de mulheres que usaram a bolsa de gelo no períneo durante 10 minutos, Grupo B, composto de puérperas que usaram bolsa de gelo no períneo durante 15 minutos e Grupo C, composto pelas puérperas da primeira etapa do estudo, que usaram bolsa de gelo no períneo durante 20 minutos.

\subsubsection{Critérios de Inclusão}

Foram incluídas puérperas a partir dos mesmos critérios da primeira etapa da pesquisa:

- idade igual ou acima de 18 anos;

- nuliparidade;

- feto único, vivo, a termo e em apresentação cefálica;

- estar entre duas e 56 horas de pós-parto;

- referir dor perineal, maior ou igual a 3 na escala numérica, no momento da inclusão no estudo;

- não ter recebido analgésico nas últimas seis horas;

- não ter recebido anestesia intradural ou epidural;

- sem intercorrências clínicas ou obstétricas como hemorróidas, hematoma, eclâmpsia, coagulopatias, hemorragias pós-parto, entre outras;

- sem dificuldades de comunicação ou compreensão;

- ter RN em boas condições clínicas.

\subsubsection{Critérios de Exclusão}

Foram excluídas do estudo as mulheres que:

- apresentaram síndrome de Raynaud;

- recusaram a bolsa de gelo. 


\subsubsection{Amostra e Randomização}

\section{- Primeira Etapa}

- A aleatorização da primeira etapa do estudo foi feita por meio de uma tabela randomizada gerada pelo computador e identificada por um código numérico, realizada por um epidemiologista que não participou da coleta de dados. Foi criada uma lista com 120 números, pareados em blocos de seis, sendo 40 do grupo experimental, 40 do placebo e 40 do controle. Esta listagem com a seqüência dos grupos experimental, placebo e controle foi recortada e colocada em um envelope opaco, numerado e fechado por um indivíduo alheio ao estudo. No momento da inclusão da mulher no estudo, o envelope era aberto para saber qual o grupo da participante.

Supondo uma prevalência para a dor perineal de $50 \%$, e estabelecendo um nível de significância de $5 \%$ e poder de $80 \%$, o tamanho da amostra foi calculado para uma redução de $60 \%$ da prevalência, o que resulta em um tamanho da amostra de 38 pacientes em cada grupo.

Para obter a estimativa do tamanho da amostra (n) foi usada a fórmula proposta por Rosner (2005):

$$
n_{1}=\frac{\left[z_{1-\frac{\alpha}{2}} \sqrt{\bar{p} \bar{q}\left(1+\frac{1}{k}\right)}+z_{1-\beta} \sqrt{p_{1} q_{1}+\frac{p_{2} q_{2}}{k}}\right]^{2}}{\Delta^{2}}
$$

$p_{1}, p_{2}$ : probabilidades esperadas de sucesso nos dois grupos

$q_{1}=1-p_{1}$

$q_{2}=1-p_{2}$

$\Delta=\left|p_{2}-p_{1}\right|$

$\bar{p}=\frac{p_{1}+k p_{2}}{1+k}$

$\bar{q}=1-\bar{p}$

onde:

$$
\begin{array}{ll}
\mathrm{p}_{1}=0,5 & \mathrm{q}_{1}=0,5 \\
\mathrm{p}_{2}=0,2 & \mathrm{q}_{2}=0,8 \\
\alpha=0,05 & \mathrm{z}(1-\alpha / 2)=1,96 \\
\beta=0,2 & \mathrm{z}(1-\beta)=0,84 \\
\mathrm{k}=1 & \bar{p}=0,35 \\
\bar{q}=0,65 & \mathrm{n}_{1}=38,48 \approx 38
\end{array}
$$




\section{- Segunda Etapa}

Para a segunda etapa do estudo optou-se por manter o mesmo tamanho amostral da primeira etapa, sendo 38 mulheres em cada grupo. A aleatorização das mulheres na segunda etapa foi realizada da mesma forma que na etapa anterior, empregando-se também uma tabela randomizada gerada por computador e identificada com código numérico. Criou-se uma lista com 76 números (Apêndice 1), sendo 38 em cada grupo. Essa listagem com a sequência dos grupos foi recortada e colocada dentro de um envelope opaco, numerado e fechado por uma pessoa alheia ao estudo. $\mathrm{O}$ envelope só foi aberto pela assistente da pesquisa no momento em que a puérpera foi incluída no estudo. Como descrito anteriormente, a aleatorização do Grupo C, ocorreu na primeira etapa do estudo e foi composto pelas puérperas que usaram bolsa de gelo no períneo, durante vinte minutos. Assim, o total da amostra foi de 114 puérperas.

\subsection{Intervenção e Desfechos}

A intervenção consistiu em sessões de crioterapia com aplicação de bolsa de gelo no períneo de puérperas de parto normal durante 10 minutos (Grupo A), 15 minutos (Grupo B) ou 20 minutos (Grupo C, da primeira etapa do estudo)

O desfecho primário considerado foi a redução de $30 \%$ na magnitude da dor perineal, avaliada mediante o uso da escala numérica pela puérpera, antes e imediatamente após a sessão de crioterapia. Para Farrar et al. (2001), uma redução de dois pontos na escala numérica representa uma mudança clínica significativa na avaliação de uma intervenção para alívio da dor e corresponde à diminuição de $30 \%$ na dor.

Como desfecho secundário, foi considerada a redução da temperatura perineal, que deveria atingir entre $10^{\circ} \mathrm{C}$ e $15^{\circ} \mathrm{C}$, após 10 e 15 minutos de aplicação da bolsa de gelo. 


\subsection{Coleta de Dados}

Na primeira etapa, a coleta de dados dos três grupos (experimental, placebo e controle) foi realizada por uma orientanda de doutorado e três enfermeiras treinadas (assistentes da pesquisa), sendo essas assistentes as responsáveis por avaliar a dor perineal e registrar as atividades das puérperas após a intervenção. Esta etapa ocorreu em janeiro e fevereiro de 2008.

A coleta de dados da segunda etapa do estudo contou com o apoio de duas assistentes da etapa anterior e de outra enfermeira que também foi treinada, além da autora do atual estudo. O período dessa etapa foi de 21 de julho a 26 de setembro de 2008 .

Os equipamentos, instrumentos e procedimentos utilizados na segunda etapa do estudo foram os mesmos empregados na primeira etapa.

\subsubsection{Equipamentos e Instrumentos}

- Mensuração da temperatura ambiental

A temperatura do quarto ou enfermaria foi avaliada utilizando-se um termômetro de ambiente tipo capela branco, da marca Incoterm® modelo TA 60.02.

\section{- Mensuração da temperatura axilar}

A temperatura da mulher foi avaliada por um termômetro digital axilar, da marca Techline ${ }^{\circledR}$, modelo TS-101, colocado na axila previamente seca com papel toalha.

\section{- Mensuração da temperatura perineal}

Para verificar a temperatura do períneo foi utilizado um termômetro digital Minipa ${ }^{\circledR}$, modelo MT 405, com duplo canal e um termopar de superfície MTK01 e outro termopar de imersão MTK13 (Figura 1). O termômetro foi calibrado na data da compra, em julho de 2008, para que a mensuração fosse confiável. A faixa de medição do aparelho é entre $-50^{\circ} \mathrm{C}$ e $200^{\circ} \mathrm{C}$, com precisão de $0,75 \%$ da leitura ou \pm $2,2^{\circ} \mathrm{C}$. A extremidade do termopar de superfície foi protegida por filme de plástico de PVC, colocada próxima à raiz da coxa direita, distante cerca de três $\mathrm{cm}$ da fúrcula, 
em uma linha horizontal perpendicular à vagina. Foi fixada com micropore ${ }^{\circledR}$ e permaneceu durante todo período da aplicação entre a bolsa e o períneo.

\section{- Mensuração da temperatura da bolsa}

Para medir a temperatura da bolsa de gelo utilizou-se um termômetro digital Minipa ${ }^{\circledR}$, modelo MT 405, com duplo canal, e um termopar de imersão MTK13 (Figura 1). O termopar permaneceu no interior da bolsa de gelo durante toda da sessão de crioterapia.

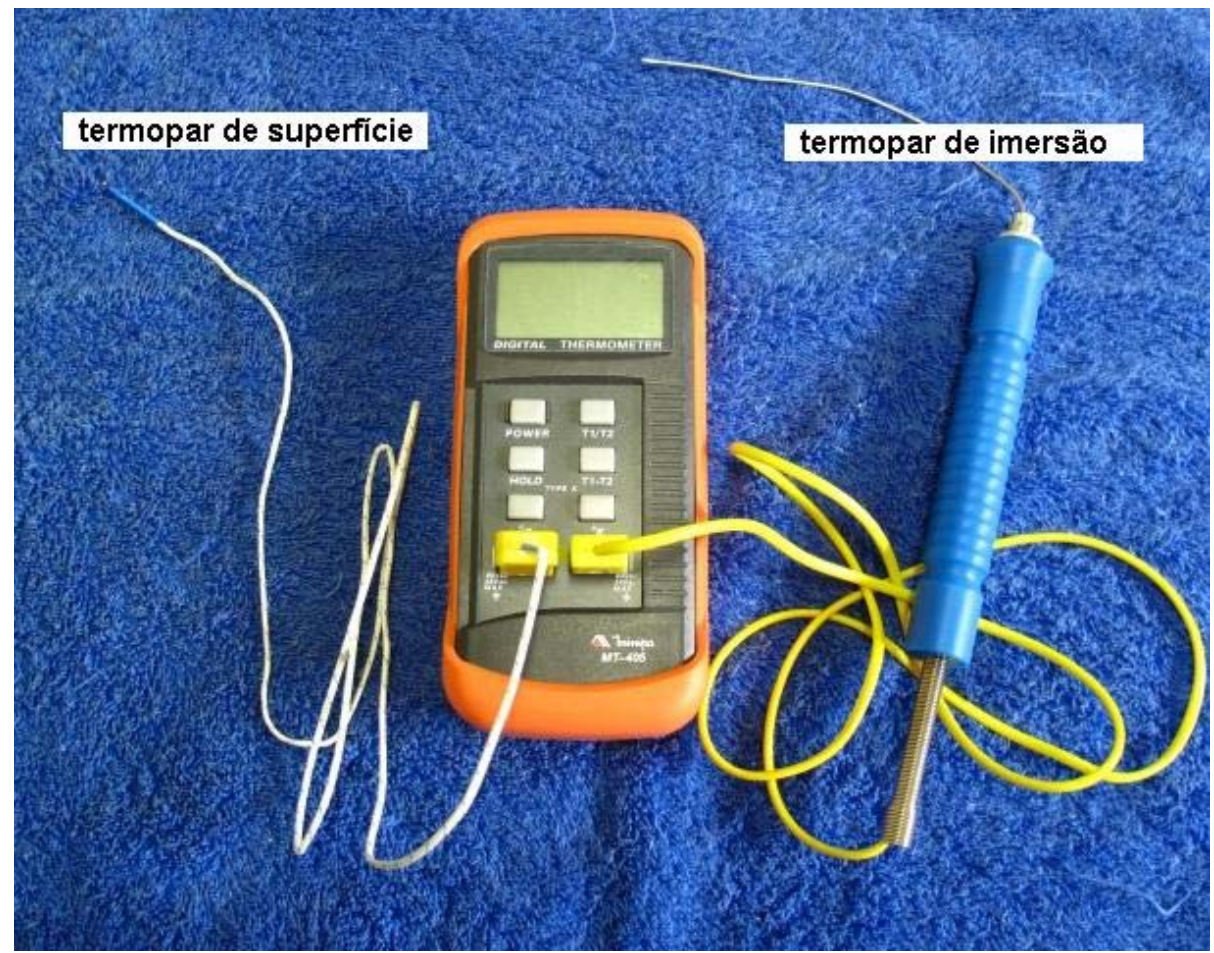

Figura 1 - Termômetro digital com duplo canal.

\section{- Avaliação do comprimento do trauma perineal}

A extensão do trauma perineal corresponde ao tamanho da episiorrafia e foi avaliada por meio da régua Peri-Rule ${ }^{\circledR}{ }^{*}$ (Figura 2), no momento da inclusão da puérpera na pesquisa. Este instrumento é indicado para mensurar a profundidade e o comprimento do trauma no período intraparto, com uso individual e esterilização prévia em autoclave. Neste estudo, em razão do elevado custo de importação e da

*http://www.peri-rule.bham.ac.uk/ 
falta de contato do material com a ferida aberta, a régua foi submetida, antes de cada utilização, à lavagem com água e sabão, assepsia com álcool a 70\% e envolvida em plástico de PVC. Para essa avaliação foi utilizada luva de procedimentos.

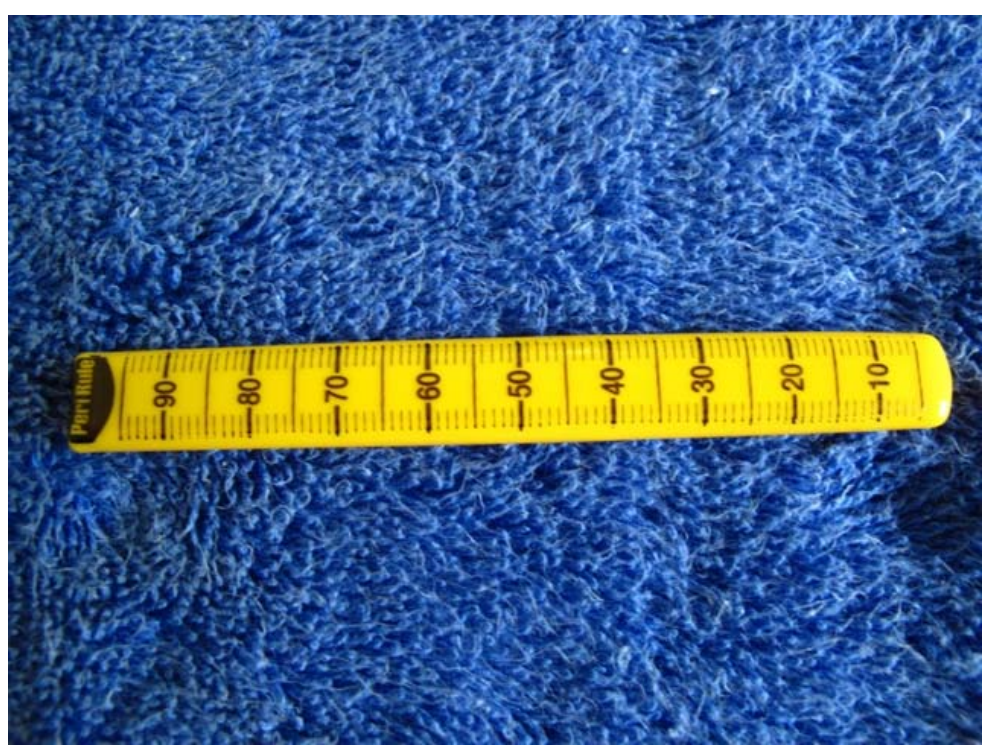

Figura 2 - Peri-rule ${ }^{\circledR}$, régua empregada na avaliação da extensão do trauma perineal.

\section{- Bolsa de gelo}

Com a finalidade de facilitar a moldagem à região perineal, foi confeccionada uma bolsa de gelo com um saco plástico de $7,5 \mathrm{~cm}$ de largura por $22 \mathrm{~cm}$ de comprimento e com 250 mililitros de água, sendo amarrada com um elástico na extremidade (Figura 3). Antes da aplicação na puérpera, a bolsa permaneceu no congelador por mais de três horas, à temperatura de $10^{\circ} \mathrm{C}$ negativos, sendo retirada em forma de gelo. A bolsa foi envolvida em tecido fino de algodão, tipo fralda, medindo 20x20 cm, para evitar o contato direto com o períneo. Cada bolsa e a fralda protetora foram utilizadas uma única vez, sendo descartada após o uso. 


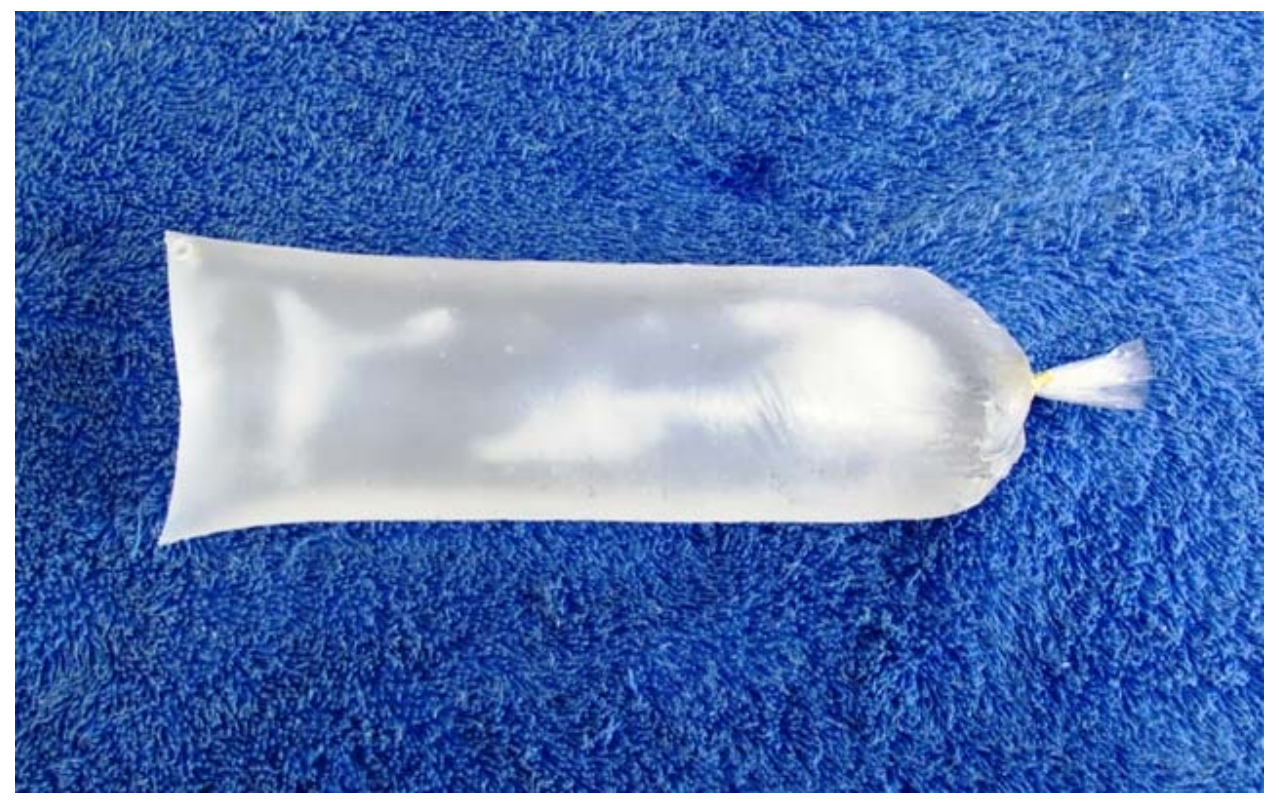

Figura 3 - Bolsa de gelo.

- Controle do tempo de aplicação da bolsa de gelo

Para controlar o tempo de aplicação da bolsa de gelo, foi utilizado um relógio digital com cronômetro Oregon Scientific ${ }^{\circledR}$ modelo HR 102.

\section{- Avaliação da intensidade da dor perineal}

Avaliou-se a intensidade da dor pela escala numérica de 0 (zero) a 10 (dez), sendo 0 nenhuma dor e 10 representando a pior dor possível.

\subsubsection{Procedimentos}

A planilha de visita diária e formulário de coleta de dados elaborados para a primeira etapa do estudo foram utilizados na segunda etapa. No formulário, foram feitas adaptações em relação ao tempo de aplicação da bolsa e avaliação da satisfação da puérpera com a intervenção (Apêndice 2).

Diariamente, entre 10 e 14 horas, uma das enfermeiras assistentes preenchia a planilha de visita (Apêndice 3), que consta do número dos leitos do $\mathrm{AC}$ e da data do preenchimento, seguido por um espaço para o registro do nome da puérpera, tipo de parto, paridade e ocorrência de dor perineal. Esse instrumento foi utilizado para facilitar a identificação das puérperas elegíveis para a pesquisa 
A seguir, os prontuários das mulheres com dor perineal foram consultados para verificar os critérios de inclusão. Para aquelas elegíveis que atenderam os critérios de inclusão, foi feita a abordagem, convidado-as a participar da investigação, explicando o objetivo e a possibilidade de pertencer a um dos dois grupos, que seria indicado por sorteio. A puérpera também recebeu informações sobre o direito de ter esclarecimentos em relação às suas dúvidas quanto ao estudo, assim como da liberdade de desistir de participar a qualquer momento, sem prejuízo da sua assistência na instituição.

A mensuração da temperatura do períneo e da bolsa tiveram início no tempo zero (T0). Durante a aplicação da bolsa, essas temperaturas foram controladas a cada cinco minutos (T5 e T10, para os Grupos A e B; T15 apenas para o Grupo B). Foram realizadas quatro avaliações da magnitude da dor perineal, conforme descrito a seguir.

\section{- $\quad$ Primeira avaliação}

As puérperas elegíveis foram inicialmente questionadas em relação à intensidade da dor perineal, por meio de uma ilustração da escala numérica que lhes foi apresentada, permitindo visualizar e indicar o número que melhor demonstrasse sua dor (Anexo 1). Apenas as puérperas com dor maior ou igual a três foram incluídas na pesquisa e randomizadas uma única vez.

Depois de seu consentimento e da assinatura do Termo de Consentimento Livre e Esclarecido (Apêndice 4), o envelope com o grupo randomizado foi aberto para identificar qual o tempo de aplicação a que a puérpera seria submetida.

A puérpera foi orientada a permanecer no leito em decúbito dorsal horizontal, com a cabeça apoiada no travesseiro, sem levantar, sentar, amamentar ou segurar o filho, durante a aplicação da bolsa. Em seguida, foi feita a mensuração da temperatura ambiental e axilar da puérpera e da extensão do trauma perineal.

Logo após, foi colocado o termopar de superfície no períneo e verificada a temperatura do local. Em seguida, deu-se início a sessão de crioterapia por 10 ou 15 minutos, de acordo com o grupo sorteado. Nesse momento, foi colocado o termopar de imersão dentro da bolsa de gelo, para o controle da temperatura. 
Durante esse período a assistente ficou ao lado da mulher esclarecendo suas dúvidas, fazendo a entrevista e registrando os achados no formulário de coleta de dados.

- $\quad \underline{\text { Segunda avaliação }}$

Imediatamente após a retirada da bolsa de gelo, a assistente avaliou a dor perineal, da mesma maneira que na primeira avaliação. Também questionou a mulher a respeito das sensações sobre a crioterapia.

- $\quad \underline{\text { Terceira avaliação }}$

Após 20 minutos do término da intervenção, foi novamente avaliada a magnitude da dor perineal e registrada a posição assumida pela puérpera.

- Quarta avaliação

Após 40 minutos do término da intervenção, foi feita nova avaliação da magnitude da dor perineal, bem como da posição assumida pela puérpera.

$\mathrm{O}$ analgésico via oral, administrado de rotina às 14 horas, foi oferecido após a quarta avaliação.

\subsection{Variáveis do Estudo}

\subsubsection{Variável Independente}

A variável independente foi considerada o tempo de aplicação da bolsa de gelo na região perineal.

\subsubsection{Variável Dependente}

A magnitude da dor perineal após a intervenção foi considerada como variável dependente e foi avaliada pela escala numérica de 0 (zero) a 10 (dez), graduada em intervalos de uma unidade, com o valor 0 para nenhuma dor e 10 para dor insuportável. 


\subsubsection{Outras Variáveis}

\section{Características sociodemográficas}

- Idade - em anos completos no momento da internação;

- Cor - classificada em branca e não branca, que inclui parda, negra e amarela;

- Estado marital - classificado em com companheiro com co-habitação, com companheiro sem co-habitação e sem companheiro;

- Escolaridade -classificada como analfabeta ou ensino fundamental e médio ou superior;

- Trabalho remunerado - classificado em sim e não.

Características do trabalho de parto e parto

- Trauma perineal - avaliado em sim, quando presente, e não, quando ausente;

- Tipo de trauma - avaliado pelo registro do prontuário e classificado como períneo íntegro, laceração de primeiro grau, laceração de segundo grau, laceração de terceiro grau, episiotomia médio-lateral direita e episiotomia mediana;

- Extensão do trauma perineal - a episiotomia ou laceração espontânea foi avaliada no pós-parto, medida em $\mathrm{cm}$ com a régua Peri-rule ${ }^{\circledR}$, no plano da pele na região do períneo, com início na fúrcula;

- Tempo de pós-parto - calculado a partir da hora da expulsão fetal até o momento de inclusão no estudo, em horas;

- Presença de acompanhante - informada pela mulher e registrada como nenhum, quando ausente no parto, ou sim e quem foi o acompanhante;

- Peso do RN - avaliado pela anotação do prontuário, mensurado em gramas logo após o nascimento.

\section{Temperatura}

- Temperatura do ambiente - verificada em graus Celsius, durante o período da aplicação da bolsa;

- Temperatura axilar - medida em graus Celsius, antes da aplicação da bolsa;

- Temperatura perineal - verificada em graus Celsius e registrada antes da aplicação da bolsa e a cada cinco minutos, durante a aplicação; 
- Temperatura da bolsa de gelo - verificada em graus Celsius e registrada no início da aplicação e a cada cinco minutos, durante a aplicação.

\section{Posição da puérpera e avaliação da crioterapia}

- Posição - classificada como sentada, deitada ou deambulando;

- Opinião sobre o tratamento - as puérperas foram questionadas a respeito da intervenção utilizada;

- Sensações - as puérperas foram questionadas quanto às sensações percebidas durante a intervenção.

\subsection{Tratamento e Análise dos Dados}

Utilizou-se a estatística descritiva para apresentar as variáveis quantitativas na forma de média, desvio-padrão e valores mínimo e máximo.

Avaliou-se a aderência das variáveis quantitativas à distribuição normal por meio do teste de Kolmogorov-Smirnov. Em razão de algumas variáveis não apresentarem distribuição normal, decidiu-se por utilizar testes não paramétricos.

Os grupos foram comparados no início do estudo em relação às características sociodemográficas e clínicas, utilizando-se o teste de Kruskal-Wallis, para as variáveis quantitativas, e o teste de associação pelo Qui-quadrado, para as variáveis qualitativas.

$\mathrm{Na}$ comparação dos grupos antes e após a intervenção, foi utilizada a análise de variância a dois fatores, sendo um fator o grupo (medida independente) e o outro fator o momento (antes e após a intervenção). As comparações múltiplas foram feitas pelo teste de Tukey HSD (honestly significant difference).

Em todas as análises estatísticas adotou-se o nível de significância de 5\%, ou seja, valores de $\mathrm{p} \leq 0,05$ foram considerados estatisticamente significantes. 


\subsection{Aspectos Éticos}

O estudo, incluindo as duas etapas, foi aprovado pelo Comitê de Ética em Pesquisa da Escola de Enfermagem da Universidade de São Paulo (FR128862), em maio de 2007 (Anexo 2). Como descrito anteriormente, as mulheres tiveram participação voluntária e foram incluídas na pesquisa somente depois de assinarem o Termo de Consentimento Livre e Esclarecido. 
5. RESULTADOS 
Durante a coleta de dados da segunda etapa do estudo, entre 21 de julho e 26 de setembro de 2008, ocorreram 1.719 partos, sendo 1.385 (80,6\%) espontâneos, 330 cesarianas $(19,2 \%)$ e $4(0,2 \%)$ fórcipes. No período do estudo, entre os 860 partos de nulíparas, 103 mulheres (12\%) indicaram dor maior ou igual a 3 da escala numérica, entre duas e 56 horas depois do parto espontâneo. Desse total, ocorreu um caso de perda de seguimento e 26 puérperas se recusaram a participar da pesquisa, restando, assim, 76 mulheres, sendo 38 em cada grupo (Figura 4).

Os dados do Grupo C (aplicação de bolsa durante 20 minutos) são referentes à primeira etapa do estudo e foram utilizados para a análise comparativa com os Grupos A e B.

Na segunda etapa da pesquisa, ocorreu um caso de perda de seguimento e nenhuma migração entre os grupos. O fluxo das participantes é apresentado na Figura 4. 


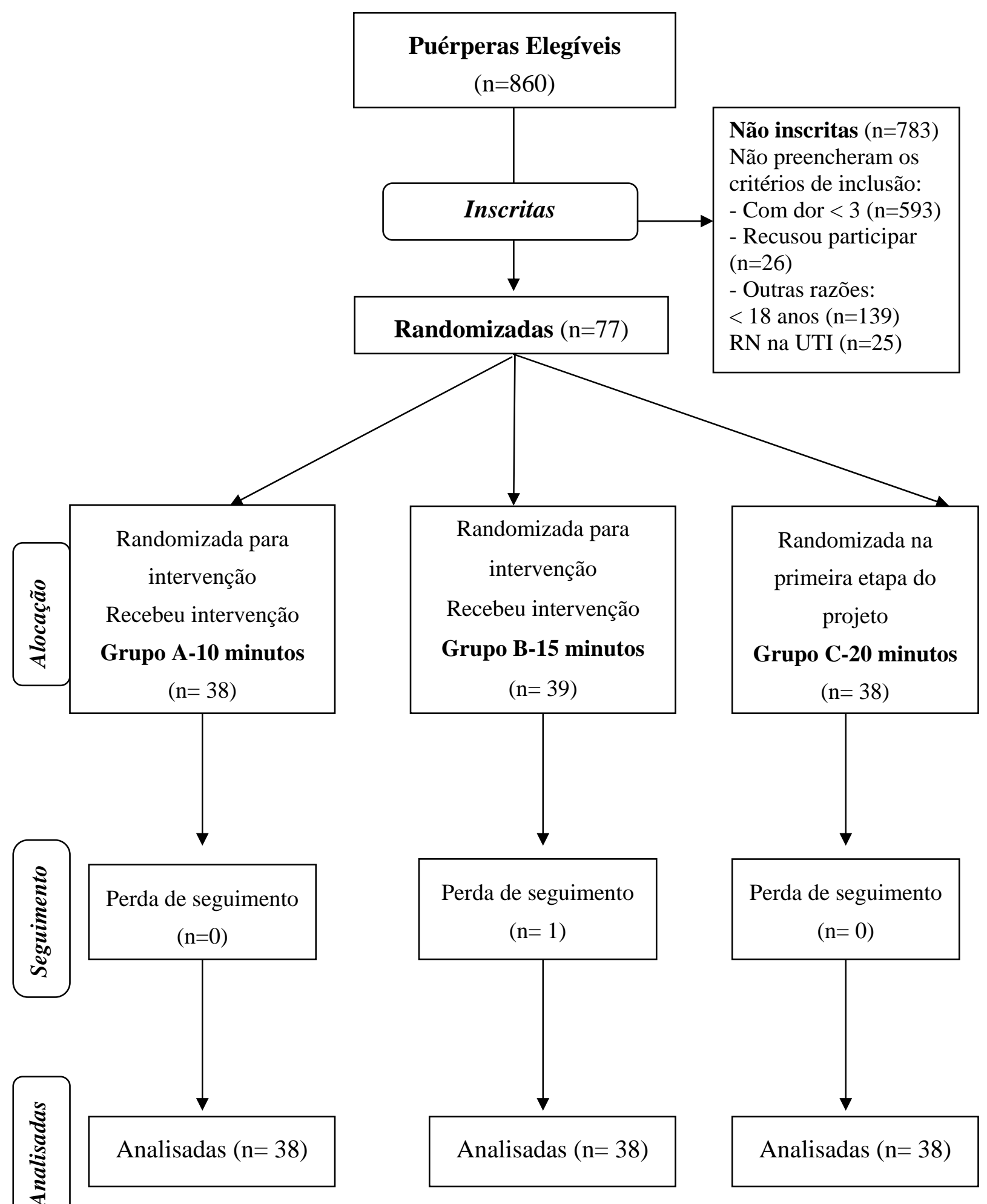

Figura 4 - Diagrama de recrutamento e seguimento das puérperas do estudo, São Paulo - 2008 
A casuística é composta por algumas das variáveis com a finalidade de caracterizar as puérperas e RN e estão apresentados nas Tabelas 1 a 4.

Tabela 1 - Distribuição das puérperas dos Grupos A, B e C segundo as características sociodemográficas, São Paulo - 2008

\begin{tabular}{|c|c|c|c|c|c|c|c|}
\hline \multirow{3}{*}{ Variável } & \multicolumn{6}{|c|}{ Grupo $(n=114)$} & \multirow{3}{*}{ p-valor* } \\
\hline & \multicolumn{2}{|c|}{$\mathbf{A}(\mathrm{n}=38)$} & \multicolumn{2}{|c|}{$\mathbf{B}(\mathrm{n}=38)$} & \multicolumn{2}{|c|}{$C(n=38)$} & \\
\hline & $\mathbf{n}$ & $\%$ & $\mathbf{n}$ & $\%$ & $\mathbf{n}$ & $\%$ & \\
\hline Cor & & & & & & & 0,426 \\
\hline Não branca & 25 & 65,8 & 24 & 63,2 & 29 & 76,3 & \\
\hline Branca & 13 & 34,2 & 14 & 36,8 & 9 & 23,7 & \\
\hline
\end{tabular}

Escolaridade

0,683

$\begin{array}{lcccccc}\text { Analfabeta e Fundamental } & 9 & 23,7 & 8 & 21,1 & 6 & 15,8 \\ \text { Médio e Superior } & 29 & 76,3 & 30 & 78,9 & 32 & 84,2\end{array}$

Estado marital

Co-habitação

$\begin{array}{cccccc}28 & 73,7 & 32 & 84,2 & 29 & 76,3 \\ 6 & 15,8 & 5 & 13,2 & 4 & 10,5 \\ 4 & 10,5 & 1 & 2,6 & 5 & 13,2\end{array}$

Trabalho remunerado

0,781

\begin{tabular}{lcccccc} 
Sim & 20 & 52,6 & 22 & 57,9 & 19 & 50,0 \\
Não & 18 & 47,4 & 16 & 42,1 & 19 & 50,0 \\
\hline Total & $\mathbf{3 8}$ & $\mathbf{1 0 0}$ & $\mathbf{3 8}$ & $\mathbf{1 0 0}$ & $\mathbf{3 8}$ & $\mathbf{1 0 0}$
\end{tabular}

* Teste Qui-quadrado

Pelos dados da Tabela 1, constatou-se semelhança dos grupos quanto à cor da pele $(p=0,426)$, escolaridade $(p=0,683)$, estado marital $(p=0,510)$ e exercer trabalho remuerado $(\mathrm{p}=0,781)$.

Do total da amostra, os achados apontam que grande número era de mulheres pardas (50\%) e pretas (18,4\%), com ensino médio (63,0\%), que tinham companheiro 
(91,3\%), destas a maior parte com co-habitação $(78,1 \%)$ e com trabalho remunerado $(53,5 \%)$.

Tabela 2 - Distribuição das puérperas Grupos A, B e C segundo a presença de acompanhante no parto, ocorrência e tipo de trauma perineal, São Paulo - 2008

\begin{tabular}{lccccccc}
\hline \multirow{2}{*}{ Variável } & \multicolumn{5}{c}{ Grupo $(\mathrm{n}=114)$} & \\
\cline { 2 - 6 } & $\mathbf{A}(\mathrm{n}=38)$ & $\mathbf{B}(\mathrm{n}=38)$ & $\mathbf{C}(\mathrm{n}=38)$ & p-valor* \\
\cline { 2 - 6 } & $\mathbf{n}$ & $\mathbf{\%}$ & $\mathbf{n}$ & $\mathbf{\%}$ & $\mathbf{n}$ & $\mathbf{\%}$ & \\
\hline Acompanhante no parto & & & & & & & 0,153 \\
Marido & 24 & 63,2 & 22 & 57,9 & 16 & 42,1 & \\
Outros & 11 & 28,9 & 13 & 34,0 & 13 & 34,2 & \\
Não & 3 & 7,9 & 3 & 7,9 & 9 & 23,7 &
\end{tabular}

\begin{tabular}{lccccccc} 
Trauma perineal & & & & & & \multicolumn{2}{c}{0,590} \\
Sim & 37 & 97,4 & 36 & 94,7 & 35 & 92,1 & \\
Não & 1 & 0,6 & 2 & 5,3 & 3 & 7,9 &
\end{tabular}

\begin{tabular}{lccccccc} 
Tipo de trauma & & & & & & 0,902 \\
Íntegro e laceração $1^{\circ}$ grau & 15 & 39,5 & 12 & 31,6 & 12 & 31,6 & \\
Laceração $2^{\circ}$ e $3^{\circ}$ graus & 4 & 10,5 & 3 & 7,9 & 4 & 10,5 \\
${ }^{(1)}$ Episiotomia & 19 & 50,0 & 23 & 60,5 & 22 & 57,9 \\
\hline Total & $\mathbf{3 8}$ & $\mathbf{1 0 0}$ & $\mathbf{3 8}$ & $\mathbf{1 0 0}$ & $\mathbf{3 8}$ & $\mathbf{1 0 0}$
\end{tabular}

(1) Inclui episiotomia médio-lateral direita e mediana

* Teste Qui-quadrado

Observou-se que os grupos foram similares em relação a ter acompanhante no parto $(p=0,153)$, apresentar traumatismo perineal $(p=0,590)$ e o tipo de trauma $(\mathrm{p}=0,902)$.

A maioria das mulheres teve um acompanhante durante o parto (76,3\%), predominando o marido $(54,4 \%)$ e a mãe $(17,5 \%)$. O trauma perineal ocorreu em 94,7\% das participantes, desses, 56,1\% foram episiotomia, 28,9\% laceração espontânea de primeiro grau, 7,9\% de segundo grau e 1,8\% de terceiro grau. Não foi observado nenhum caso de laceração de quarto grau. 
As justificativas para realizar a episiotomia podem ser vistas na Tabela 3.

Tabela 3 - Indicação da episiotomia médio-lateral direita e mediana nos Grupos A, B e C, São Paulo - 2008

\begin{tabular}{|c|c|c|c|c|c|c|c|c|}
\hline \multirow{3}{*}{ Indicação } & \multicolumn{6}{|c|}{ Grupo } & \multirow{2}{*}{\multicolumn{2}{|c|}{ Total }} \\
\hline & \multicolumn{2}{|c|}{$\mathbf{A}$} & \multicolumn{2}{|c|}{ B } & \multicolumn{2}{|c|}{ C } & & \\
\hline & $\mathbf{n}$ & $\%$ & $\mathbf{n}$ & $\%$ & $\mathbf{n}$ & $\%$ & $\mathbf{n}$ & $\%$ \\
\hline Rigidez perineal & 13 & 20,3 & 12 & 18,8 & 18 & 28,1 & 43 & 67,2 \\
\hline Macrossomia fetal & 1 & 1,6 & 2 & 3,1 & 1 & 1,6 & 4 & 6,3 \\
\hline Sofrimento fetal & 1 & 1,6 & 2 & 3,1 & 1 & 1,6 & 4 & 6,3 \\
\hline Expulsivo prolongado & 1 & 1,6 & 1 & 1,6 & 0 & - & 2 & 3,1 \\
\hline Sem registro & 3 & 4,6 & 6 & 9,3 & 2 & 3,1 & 11 & 17,1 \\
\hline Total & 19 & 29,7 & 23 & 35,9 & 22 & 34,4 & 64 & 100 \\
\hline
\end{tabular}

Do total das 114 mulheres do estudo, 64 (56,1\%) delas foram submetidas à episiotomia, sendo 52 (81,3\%) com episiotomia médio-lateral direita (Grupos: $A=14$, $\mathrm{B}=22, \mathrm{C}=16)$ e $12(18,7 \%)$, mediana (Grupos: $\mathrm{A}=4, \mathrm{~B}=1, \mathrm{C}=6)$ ). As justificativas mais frequentes para indicar esse procedimento foram: rigidez do períneo (43 $67,2 \%)$ e condições do concepto ( 8 - 12,6\%).

Os dados sobre a idade, tempo decorrido do parto, peso do RN, extensão do trauma perineal, temperatura corporal, do ambiente e do períneo antes da aplicação da crioterapia e dor inicial podem ser observados na Tabela 4, a seguir. 
Tabela 4 - Comparação das médias e desvio-padrão (dp) das variáveis quantitativas dos Grupos A, B e C, antes da intervenção, São Paulo - 2008

\begin{tabular}{|c|c|c|c|c|}
\hline \multirow{3}{*}{ Variável } & \multicolumn{3}{|c|}{ Grupo $(n=114)$} & \multirow{3}{*}{ p-valor* } \\
\hline & \multirow{2}{*}{$\frac{\text { A (n=38) }}{\text { Média (dp) }}$} & \multirow{2}{*}{$\begin{array}{c}\text { B (n=38) } \\
\text { Média (dp) }\end{array}$} & \multirow{2}{*}{$\begin{array}{c}\text { C (n=38) } \\
\text { Média (dp) }\end{array}$} & \\
\hline & & & & \\
\hline Idade (anos) & $22,8(4,9)$ & $23,2(4,8)$ & $21,8(4,0)$ & 0,526 \\
\hline Tempo de pós-parto (h) & $21,8(15,6)$ & $24,0(15,1)$ & $20,1(13,7)$ & 0,526 \\
\hline & 3268,4 & 3256,6 & 3146,4 & 0,293 \\
\hline 2eso do kin (g) & $(417,6)$ & $(313,6)$ & $(399,9)$ & \\
\hline Extensão do trauma (cm) & $3,0(1,5)$ & $3,1(1,5)$ & $3,1(1,4)$ & 0,929 \\
\hline Temperatura axilar $\left({ }^{\circ} \mathrm{C}\right)$ & $36,6(0,4)$ & $36,5(0,5)$ & $36,6(0,5)$ & 0,918 \\
\hline Temperatura ambiental $\left({ }^{\circ} \mathrm{C}\right)$ & $19,8(2,8)$ & $20,0(3,3)$ & $27,1(2,5)$ & 0,000 \\
\hline Temperatura perineal $\left({ }^{\circ} \mathrm{C}\right)$ & $31,1(2,1)$ & $31,6(1,7)$ & $32,7(1,3)$ & 0,003 \\
\hline Dor perineal ( $1^{\text {a }}$ avaliação $)$ & $5,2(1,7)$ & $5,4(1,9)$ & $4,6(1,6)$ & 0,049 \\
\hline
\end{tabular}

* Teste de Kruskal-Wallis

Não foi verificada diferença estatística nas seguintes variáveis quantitativas dos grupos: idade $(\mathrm{p}=0,526)$, tempo de pós-parto $(\mathrm{p}=0,526)$, peso do concepto $(p=0,293)$, extensão do trauma perineal $(p=0,929)$ e temperatura axilar $(p=0,918)$. No entanto, a temperatura do ambiente apresentou diferença significante, sendo o maior valor no grupo $\mathrm{C}\left(27,1^{\circ} \mathrm{C}\right)$. Outra variável com diferença significativa foi a temperatura inicial do períneo, isto é, anterior à aplicação da bolsa de gelo, com o maior valor observado no grupo $C(p=0,003)$. Também foi verificada diferença estatística entre as médias de dor inicial, sendo o menor valor no grupo $\mathrm{C}$, embora no limite da significância estatística ( $\mathrm{p}=0,049)$. 
Merece comentar a grande variação encontrada nos três grupos quanto à temperatura ambiental: Grupo A e B (de $16^{\circ} \mathrm{C}$ a $28^{\circ} \mathrm{C}$ ) e Grupo $\mathrm{C}\left(\operatorname{de} 21^{\circ} \mathrm{C}\right.$ a $32^{\circ} \mathrm{C}$ ); assim como na pontuação da dor anterior à aplicação da bolsa de gelo (primeira avaliação), com valores entre 3 e 10 da escala numérica. Apesar das diferenças encontradas nas três variáveis (temperatura inicial do períneo, dor na primeira avaliação e temperatura do ambiente) dos gGupos A, B e C, pode-se considerar que eles foram equivalentes (Tabelas 1, 2 e 4). As justificativas dessas diferenças serão abordadas no capítulo da discussão.

A idade média das mulheres do estudo foi 22,6 \pm 4,6 anos, sendo o valor mínimo de 18 e o máximo de 38 anos. O tempo médio parto em que as puérperas dos três grupos referiram dor perineal foi de $22 \pm 14$,8 horas, com tempo mínimo de dois e máximo de 56 horas após o parto. Em relação ao RN, a média do peso foi $3.323 \pm$ 380 gramas, com valor mínimo de $2.075 \mathrm{~g}$ e máximo de $4.020 \mathrm{~g}$. A extensão do trauma no soalho pélvico, avaliada na superfície da pele do períneo, oscilou entre 0,5 e $6 \mathrm{~cm}$, sendo os maiores valores encontrados na episiotomia.

Os dados a respeito da temperatura da bolsa e do períneo, antes e após a crioterapia, de acordo com o grupo, estão dispostos na Tabela 5, a seguir. 
Tabela 5 - Médias da temperatura $\left({ }^{\circ} \mathrm{C}\right)$ do períneo e da bolsa de gelo antes (T0) e no intervalo de 5, 10, 15 e 20 minutos após o início da crioterapia (T5, T10, T15 e T20), nos Grupos A, B e C, São Paulo - 2008

\begin{tabular}{llccc}
\hline \multirow{2}{*}{ Intervalo de tempo (minutos) } & $\mathbf{n}$ & Períneo & Bolsa \\
\cline { 4 - 5 } & & Média (dp) & Média (dp) \\
\hline T0 & & & \\
& Grupo A & 38 & $31,1(2,1)$ & $1,9(1,0)$ \\
& Grupo B & 38 & $31,6(1,7)$ & $2,1(1,1)$ \\
& Grupo C & 38 & $32,7(1,3)$ & $3,8(2,8)$
\end{tabular}

T5

$\begin{array}{llll}\text { Grupo A } & 38 & 17,6(6,4) & 1,1(0,9) \\ \text { Grupo B } & 38 & 15,9(6,0) & 1,2(0,9) \\ \text { Grupo C } & 38 & 18,7(4,6) & 2,6(1,7)\end{array}$

T10

$\begin{array}{llll}\text { Grupo A } & 38 & 13,3(4,9) & 0,6(0,7) \\ \text { Grupo B } & 38 & 13,7(5,2) & 0,6(0,8) \\ \text { Grupo C } & 38 & 15,3(4,8) & 2,3(1,8)\end{array}$

T15

$\begin{array}{llcc}\text { Grupo A } & 38 & - & - \\ \text { Grupo B } & 38 & 11,3(4,5) & 0,6(0,9) \\ \text { Grupo C } & 38 & 13,7(5,0) & 1,9(1,3)\end{array}$

${ }^{(1)} \mathrm{T} 20$

$\begin{array}{llll}\text { Grupo C } & 38 & 12,6(4,8) & 1,9(1,5)\end{array}$

(1) Avaliada apenas na primeira etapa do estudo.

Os resultados do estudo indicam que a temperatura do períneo antes da aplicação da bolsa de gelo variou de $31,1 \pm 2,1^{\circ} \mathrm{C}$ no grupo de 10 minutos a 32,7 \pm $1,3^{\circ} \mathrm{C}$ no grupo de 20 minutos. Após 10 minutos de uso da crioterapia, a temperatura perineal nos três grupos estava entre $13,3^{\circ} \mathrm{C}$ e $15,3^{\circ} \mathrm{C}$. Na avaliação intra-grupo, as 
diferenças observadas na temperatura perineal inicial e após o uso da bolsa foram de $17,8^{\circ} \mathrm{C}$ no Grupo A, $20,3^{\circ} \mathrm{C}$ no Grupo B e $20,1^{\circ} \mathrm{C}$ no Grupo C. Verificou-se que a média da temperatura da bolsa de gelo nos três grupos apresentou diminuição do momento inicial até por volta de 10 minutos, mantendo-se praticamente estável a partir de então.

A Tabela 6 a seguir apresenta a comparação das médias de dor antes e imediatamente após a aplicação da crioterapia.

Tabela 6 - Comparação das médias de dor antes e imediatamente após a aplicação da bolsa de gelo segundo nos Grupos A, B e C, São Paulo - 2008

\begin{tabular}{lccc}
\hline \multirow{2}{*}{ Grupo } & \multicolumn{2}{c}{ Dor perineal } & \multirow{2}{*}{ p-valor* } \\
\cline { 2 - 3 } & $\mathbf{1}^{\text {a }}$ avaliação & $2^{\text {a }}$ avaliação & \\
\cline { 2 - 3 } & Média (dp) & Média (dp) & $<\mathbf{0 , 0 0 1}$ \\
B & $5,2(1,7)$ & $1,6(2,0)$ & $<\mathbf{0 , 0 0 1}$ \\
C & $5,4(1,9)$ & $0,9(1,4)$ & $<\mathbf{0 , 0 0 1}$ \\
\hline
\end{tabular}

* Teste de Tukey

Ao se efetuar a análise de variância a dois fatores pelo teste de Tukey, constatou-se que as médias de dor intra-grupo na primeira e na segunda avaliação apresentaram diferença estatisticamente significativa nos três grupos $(\mathrm{p}<0,001)$.

Na comparação da dor intergrupos imediatamente após a aplicação da bolsa de gelo (segunda avaliação), constatou-se que as médias dos Grupos A e B foram similares (1,6 versus 0,$9 ; \mathrm{p}=0,652)$, entre os Grupos $\mathrm{B}$ e $\mathrm{C}$ também não houve diferença estatística ( 0,9 versus 1,$6 ; \mathrm{p}=0,652)$. o mesmo ocorreu entre os Grupos A e C (1,6 versus 1,$6 ; p=1,000)$.

A comparação das médias de dor imediatamente após a aplicação da bolsa de gelo e após 20 minutos pode ser observada nos dados da Tabela 7. 
Tabela 7 - Comparação das médias da dor perineal imediatamente após e 20 minutos depois da aplicação da bolsa de gelo nos Grupos A,B e C, São Paulo - 2008

\begin{tabular}{lccc}
\hline \multirow{2}{*}{ Grupo } & \multicolumn{2}{c}{ Dor perineal } & \\
\cline { 2 - 3 } & $\mathbf{2}^{\mathbf{a}}$ avaliação & $\mathbf{3}^{\mathbf{a}}$ avaliação & \\
\cline { 2 - 3 } & Média (dp) & Média (dp) & \\
\hline $\mathrm{A}$ & $1,6(2,0)$ & $1,5(1,7)$ & 0,984 \\
$\mathrm{~B}$ & $0,9(1,4)$ & $1,1(1,6)$ & 0,935 \\
$\mathrm{C}$ & $1,6(1,9)$ & $1,5(2,0)$ & 0,997 \\
\hline
\end{tabular}

* Teste de Tukey

Ao se comparar as médias de dor intra-grupo na segunda e na terceira avaliação, verificou-se que não houve diferença estatística nos três grupos, sendo os valores semelhantes.

A comparação entre os grupos, depois de 20 minutos da intervenção (terceira avaliação), demonstrou que as médias não apresentaram diferenças significativas entre os Grupos A e B (1,5 versus 1,1; $\mathrm{p}=0,961)$, entre os Grupos B e C (1,1 versus $1,5 ; \mathrm{p}=0,944)$ e entre A e C (1,5 versus 1,$5 ; \mathrm{p}=1,000)$.

A Tabela 8 a seguir apresenta a comparação das médias de dor nos períodos de 20 e 40 minutos após o término da aplicação da bolsa de gelo.

Tabela 8 - Comparação das médias de dor 20 e 40 minutos após o término da aplicação da bolsa de gelo nos Grupos A, B e C, São Paulo - 2008

\begin{tabular}{lccc}
\hline \multirow{2}{*}{ Grupo } & \multicolumn{2}{c}{ Dor perineal } & \multirow{2}{*}{ p-valor* } \\
\cline { 2 - 3 } & $\mathbf{3}^{\mathbf{a}}$ avaliação & $\mathbf{4}^{\mathrm{a}}$ avaliação & \\
\cline { 2 - 3 } Média (dp) & Média (dp) & 1,000 \\
$\mathrm{~A}$ & $1,5(1,7)$ & $1,5(1,8)$ & 1,000 \\
$\mathrm{C}$ & $1,1(1,6)$ & $1,5(2,0)$ & 1,000 \\
\hline
\end{tabular}

* Teste de Tukey

Os resultados da análise intra-grupo indicam que não foi encontrada diferença estatística nas médias de dor entre a terceira e a quarta avaliações, mantendo-se aproximadamente a mesma intensidade. 
Na comparação dos três grupos na quarta avaliação de dor perineal, constatou-se semelhança nas médias dos Grupos A e B (1,5 versus 1,5; p=0,571), Grupos B e C (1,5 versus 1,5; p=0,577) e Grupos A e C (1,5 versus 1,5; $\mathrm{p}=1,000)$.

O Gráfico 1, a seguir, apresenta a comparação das médias de dor na primeira, segunda, terceira e quarta avaliações.

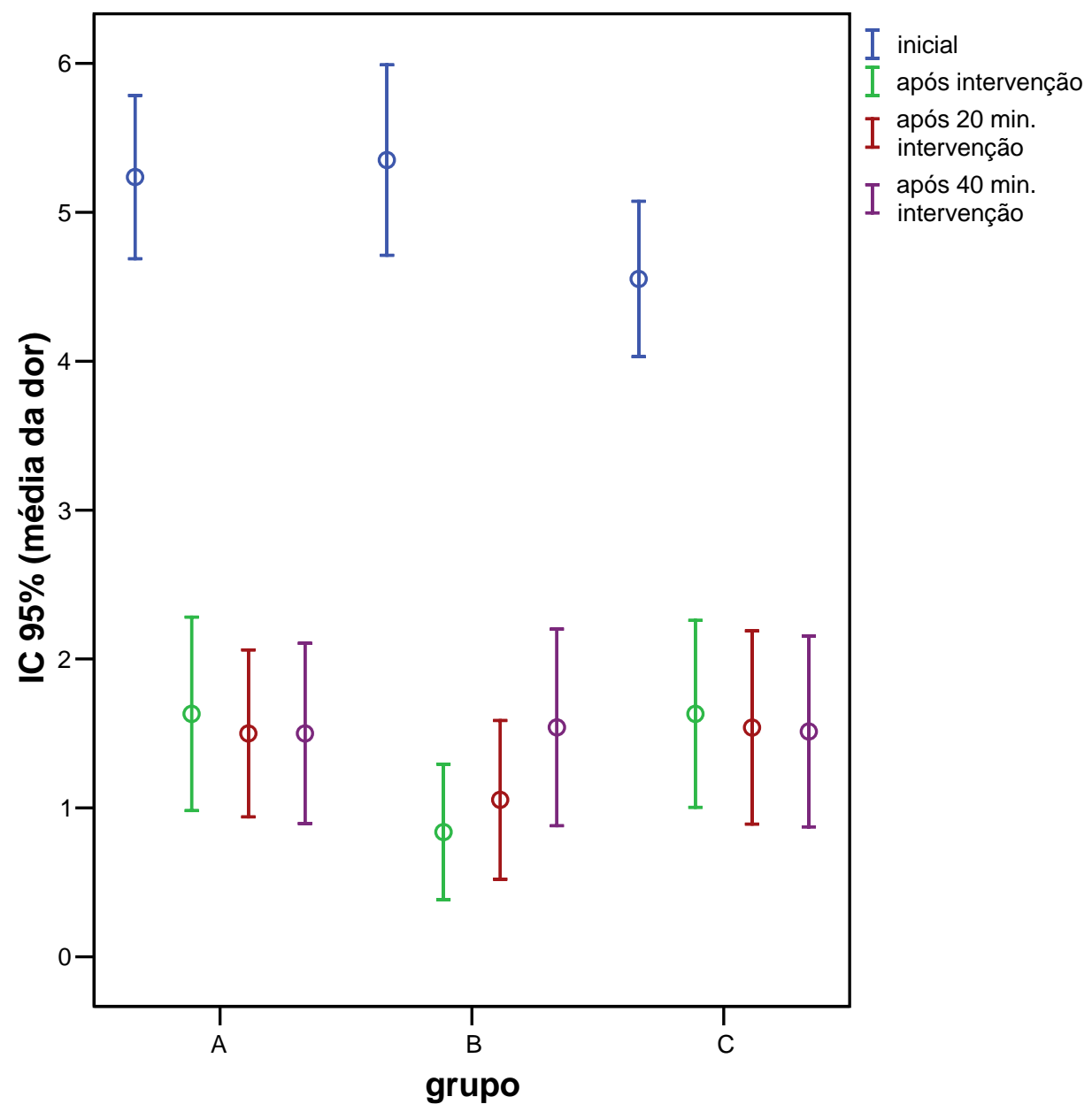

Gráfico 1 - Comparação da dor em quatro tempos (antes da aplicação da bolsa, imediatamente após, 20 e 40 minutos depois) nos Grupos A, B e C, São Paulo - 2008

Ao avaliar o Gráfico 1, constatou-se sobreposição dos intervalos de confiança entre os três grupos nos quatro momentos analisados, indicando que os grupos com aplicação da bolsa de gelo por 10, 15 e 20 minutos foram similares para o alívio da dor na região do períneo. 
$\mathrm{Na}$ segunda etapa do estudo, as mulheres dos Grupos A e B foram questionadas quanto à intervenção recebida. Sua opinião delas é apresentada na Tabela 9.

Tabela 9 - Opinião das puérperas dos Grupos A, B e C sobre a intervenção, São Paulo - 2008

\begin{tabular}{lccccccc}
\hline \multirow{2}{*}{ Opinião } & \multicolumn{9}{c}{ Grupo* $^{*}$} & \multicolumn{2}{c}{ Total } \\
\cline { 2 - 6 } & & $\mathbf{A}$ & $\mathbf{\%}$ & $\mathbf{n}$ & $\mathbf{\%}$ & $\mathbf{n}$ & $\mathbf{\%}$ \\
\hline Muito bom & 17 & 44,7 & 19 & 50,0 & 36 & 47,4 \\
Bom & 21 & 55,3 & 19 & 50,0 & 40 & 52,6 \\
\hline Total & 38 & 100 & 38 & 100 & 76 & 100
\end{tabular}

* Avaliada apenas na segunda etapa.

Os achados apontaram que a totalidade das puérperas submetidas à crioterapia teve opinião favorável ao procedimento realizado.

As proporções de melhora da dor perineal após a crioterapia estão listadas na Tabela 10.

Tabela 10 - Porcentual de redução da dor perineal imediatamente após a intervenção nos Grupos A, B e C, São Paulo - 2008

\begin{tabular}{|c|c|c|c|c|c|c|c|c|}
\hline \multirow{3}{*}{$\begin{array}{l}\text { Redução da } \\
\text { intensidade de } \\
\text { dor }\end{array}$} & \multicolumn{6}{|c|}{ Grupo } & \multirow{2}{*}{\multicolumn{2}{|c|}{ Total }} \\
\hline & \multicolumn{2}{|c|}{ A } & \multicolumn{2}{|c|}{ B } & \multicolumn{2}{|c|}{ C } & & \\
\hline & $\mathbf{n}$ & $\%$ & $\mathbf{n}$ & $\%$ & $\mathbf{n}$ & $\%$ & $\mathbf{n}$ & $\%$ \\
\hline Acima de 50\% & 29 & 76,3 & 32 & 84,2 & 22 & 57,9 & 83 & 72,8 \\
\hline Entre $30 \%$ e $50 \%$ & 6 & 15,8 & 6 & 15,8 & 13 & 34,2 & 25 & 21,9 \\
\hline Menos que $30 \%$ & 3 & 7,9 & - & - & 3 & 7,9 & 6 & 5,3 \\
\hline Total & 38 & 100 & 38 & 100 & 38 & 100 & 114 & 100 \\
\hline
\end{tabular}

Neste estudo, o critério clínico adotado como melhora de dor foi uma redução de 30\%. Assim, a maioria das puérperas referiu alívio da dor (94,7\%) e destas, 83 
(72,8\%) indicaram redução da dor perineal acima de 50\%, 25 (21,9\%), entre 30\% e $50 \%$ e apenas 6 (5,3\%), abaixo de 30\%, considerando a escala numérica.

De acordo com o teste Qui-quadrado, não houve diferença significativa entre os três grupos, demonstrando que o tempo de 10, 15 e 20 minutos de aplicação da bolsa de gelo foram equivalentes para o alívio da dor perineal.

As proporções de melhora da dor perineal após a intervenção podem ser vistas no Gráfico 2.

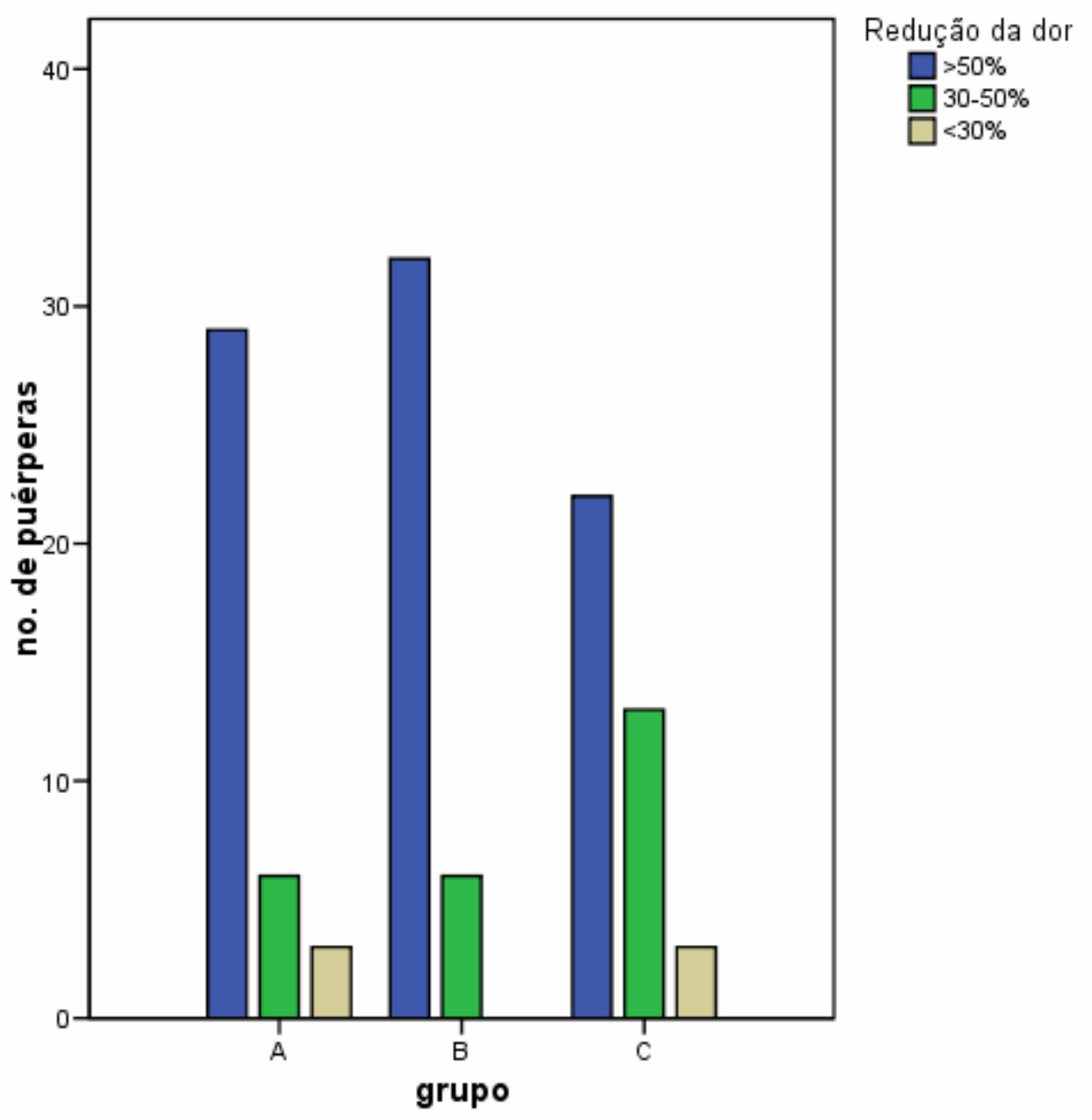

Gráfico 2 - Porcentagem de redução da dor perineal nos Grupos A, B e C, São Paulo $-2008$ 
Na Tabela 11, a seguir, são apresentadas as sensações referidas pelas puérperas durante a crioterapia.

Tabela 11 - Sensações referidas pelas puérperas durante a intervenção, segundo os grupos, São Paulo - 2008

\begin{tabular}{|c|c|c|c|c|c|c|c|c|}
\hline \multirow{3}{*}{ Sensação } & \multicolumn{6}{|c|}{ Grupo } & \multirow{2}{*}{\multicolumn{2}{|c|}{ Total }} \\
\hline & \multicolumn{2}{|c|}{ A } & \multicolumn{2}{|c|}{ B } & \multicolumn{2}{|c|}{ C } & & \\
\hline & $\mathbf{n}$ & $\%$ & $\mathbf{n}$ & $\%$ & $\mathbf{n}$ & $\%$ & $\mathbf{n}$ & $\%$ \\
\hline Frio/gelado & 10 & 26,3 & 14 & 36,8 & 18 & 47,5 & 42 & 36,8 \\
\hline Alívio & 10 & 26,3 & 10 & 26,3 & 7 & 18,4 & 27 & 23,7 \\
\hline Dormência & 3 & 7,9 & 2 & 5,3 & 10 & 26,3 & 15 & 13,2 \\
\hline Queimação no início & 7 & 18,4 & 4 & 10,5 & - & - & 11 & 9,6 \\
\hline Ardor no início & 6 & 15,8 & 3 & 7,9 & 1 & 2,6 & 10 & 8,8 \\
\hline Anestesiado & 2 & 5,3 & 4 & 10,5 & 1 & 2,6 & 7 & 6,1 \\
\hline Nada & - & - & 1 & 2,6 & 1 & 2,6 & 2 & 1,8 \\
\hline Total & 38 & 100 & 38 & 100 & 38 & 100 & 114 & 100 \\
\hline
\end{tabular}

As 76 participantes da segunda etapa do estudo (Grupos A e B) citaram uma ou duas sensações ( $n=92)$, no entanto, foi considerada apenas uma resposta por mulher, privilegiando as sensações de desconforto. As sensações mais referidas pelas puérperas foram frio/gelado, alívio, dormência, queimação, ardor e anestesiado.

As posições assumidas pelas mulheres nos primeiros 20 minutos após o término da aplicação da bolsa de gelo estão apresentadas na Tabela 12.

Tabela 12 - Posições assumidas pelas puérperas dos Grupos A, B e C durante os primeiros 20 minutos após o término da crioterapia, São Paulo - 2008

\begin{tabular}{|c|c|c|c|c|c|c|c|c|}
\hline \multirow{3}{*}{ Posição } & \multicolumn{6}{|c|}{ Grupo } & \multirow{2}{*}{\multicolumn{2}{|c|}{ Total }} \\
\hline & \multicolumn{2}{|c|}{ A } & \multicolumn{2}{|c|}{ B } & \multicolumn{2}{|c|}{ C } & & \\
\hline & $\mathbf{n}$ & $\%$ & $\mathbf{n}$ & $\%$ & $\mathbf{n}$ & $\%$ & $\mathbf{n}$ & $\%$ \\
\hline Em pé/andando & 15 & 39,5 & 17 & 44,7 & 15 & 39,5 & 47 & 41,2 \\
\hline Deitada & 11 & 28,9 & 12 & 31,6 & 17 & 44,7 & 40 & 35,1 \\
\hline Sentada & 12 & 31,6 & 9 & 23,7 & 6 & 15,8 & 27 & 23,7 \\
\hline Total & 38 & 100 & 38 & 100 & 38 & 100 & 114 & 100 \\
\hline
\end{tabular}


Ao se comparar os grupos quanto às posições assumidas nos primeiros 20 minutos após a utilização da bolsa de gelo, verificou-se que não houve diferença estatística $(p=0,445)$, sendo que a maior parte das mulheres estava deambulando. Observou-se que as puérperas permaneceram na posição sentada para amamentar o filho e também para a refeição.

Na Tabela 13, a seguir, estão listadas as posições das puérperas depois da crioterapia, entre 20 e 40 minutos após a retirada da bolsa de gelo.

Tabela 13 - Posições assumidas pelas puérperas dos Grupos A, B e C no período entre 20 e 40 minutos após o término da crioterapia, São Paulo - 2008

\begin{tabular}{|c|c|c|c|c|c|c|c|c|}
\hline \multirow{3}{*}{ Posição } & \multicolumn{6}{|c|}{ Grupo } & \multirow{2}{*}{\multicolumn{2}{|c|}{ Total }} \\
\hline & \multicolumn{2}{|c|}{ A } & \multicolumn{2}{|c|}{ B } & \multicolumn{2}{|c|}{ C } & & \\
\hline & $\mathbf{n}$ & $\%$ & $\mathbf{n}$ & $\%$ & $\mathbf{n}$ & $\%$ & $\mathbf{n}$ & $\%$ \\
\hline Em pé/andando & 15 & 39,5 & 12 & 31,6 & 17 & 44,7 & 44 & 38,6 \\
\hline Deitada & 12 & 31,6 & 16 & 42,1 & 15 & 39,5 & 43 & 37,7 \\
\hline Sentada & 11 & 28,9 & 10 & 26,3 & 6 & 15,8 & 27 & 23,7 \\
\hline Total & 38 & 100 & 38 & 100 & 38 & 100 & 114 & 100 \\
\hline
\end{tabular}

Não foi encontrada diferença estatística $(p=0,554)$ entre as participantes dos três grupos quanto à posição assumida no período de 20 a 40 minutos depois da intervenção. Foram observadas proporções semelhantes de mulheres nas posições sentada e deitada. 
6. DISCUSSÃO 
Até muito recentemente, o enfoque dos estudos se restringia à dor presente no trabalho de parto. A dor no período puerperal era pouco considerada, pois a atenção nessa fase está voltada principalmente para o RN (Alexandre et al., 2006).

Entretanto, nos últimos anos, um número expressivo de trabalhos vêm sendo desenvolvido para analisar as morbidades decorrentes das lesões no períneo após o parto vaginal, bem como avaliar os tratamentos farmacológicos e não farmacológicos de alívio da dor perineal. Os resultados da revisão sistemática realizada por Levitt et al. (2004) confirmam essa afirmação, ao identificarem 671 estudos sobre cuidados no pós-parto, entre 1999 e 2003.

Para Grundy (1997), os cuidados com o trauma perineal devem ter como objetivo promover o alívio da dor e do desconforto, estimular a cicatrização e prevenir a infecção. O autor acrescenta que, ao se propor qualquer medida de tratamento, é importante assegurar que todos os objetivos sejam considerados.

Como ressalta Steen (2005), existe uma variedade de métodos para aliviar a dor na região do períneo e promover a cicatrização, porém, ainda com limitada evidência para indicar a sua efetividade.

Participaram da segunda etapa do presente estudo 76 mulheres distribuídas nos dois grupos de tratamento sob investigação: Grupo A (bolsa de gelo aplicada por 10 minutos) e Grupo B (bolsa de gelo aplicada por 15 minutos), que foram comparados com o tratamento aplicado ao do Grupo C (bolsa de gelo aplicada por 20 minutos) da primeira etapa do projeto, todos compostos de 38 puérperas.

Os resultados apontam que os três grupos analisados foram homogêneos em relação às características sociodemográficas [idade $(\mathrm{p}=0,526)$, cor da pele $(\mathrm{p}=0,426)$, escolaridade $(\mathrm{p}=0,683)$, estado marital $(\mathrm{p}=0,510)$ e ter trabalho remunerado $(\mathrm{p}=0,781)]$. Os dados relativos ao parto, como ter acompanhante durante o parto $(\mathrm{p}=0,153)$, apresentar traumatismo perineal $(\mathrm{p}=0,590)$ e tipo de trauma na região perineal $(\mathrm{p}=0,902)$, também mostraram similaridade.

Merece comentar a elevada proporção de traumatismo perineal $(94,7 \%)$ encontrada entre as participantes dos três grupos estudados, sendo a maioria dos traumas causados pela episiotomia (56,1\%), seguidos por laceração de primeiro grau (28,9\%), segundo grau $(7,9 \%)$ e terceiro grau $(1,8 \%)$, sem nenhum caso de quarto grau. 
A revisão sistemática sobre a prevenção do trauma perineal no parto conduzida por Eason et al. (2000) concluiu que o aumento da integridade do períneo está relacionado com a não-utilização das práticas de episiotomia e fórcipe e que a posição da parturiente durante o período expulsivo tem pouco efeito sobre os traumas da região. Outro trabalho também cita como fator associado aos danos do soalho pélvico a episiotomia, menor paridade, emprego de fórcipe e extração a vácuo, período expulsivo prolongado, tipo de puxo realizado pela mulher, entre outros (Christianson et al., 2003).

Convém mencionar que no CPN, local do estudo, a assistência prestada às parturientes caracteriza-se por intervenção mínima, que vai ao encontro da valorização da fisiologia do parto e nascimento, caracterizada pelo uso restrito de infusão endovenosa, ocitocina e episiotomia. Pesquisa realizada nessa mesma instituição encontrou taxa de episiotomia de 58,4\% entre as mulheres sem partos vaginais anteriores e de 18,6\% entre aquelas com partos vaginais anteriores, indicando que o parto vaginal anterior protegeu o períneo desse procedimento (Silva et al., 2008).

Quanto às variáveis quantitativas - tempo de pós-parto $(\mathrm{p}=0,526)$, peso do concepto $(\mathrm{p}=0,293)$, extensão do trauma perineal $(\mathrm{p}=0,929)$ e temperatura axilar $(\mathrm{p}=0,918)$ - também não foram observadas diferenças estatísticas, demonstrando que os grupos são equivalentes.

Esses achados indicam que, sendo semelhantes as características dos grupos no início da comparação, pode-se avaliar o impacto da intervenção que está sendo analisada, com o mínimo de efeitos de outros fatores que poderiam influenciar os resultados do estudo (Jadad, 1998).

As variáveis que apresentaram diferença estatística foram: temperatura ambiental, temperatura inicial do períneo e dor perineal na primeira avaliação, ou seja, anterior à intervenção. A temperatura média do ambiente no Grupo C apresentou o maior valor, com $27,1^{\circ} \mathrm{C}$ versus $19,8^{\circ} \mathrm{C}$ e $20^{\circ} \mathrm{C}$ dos Grupos A e B, respectivamente. Esse fato aconteceu em razão de a coleta de dados da primeira etapa do projeto ter sido conduzida na época do verão (em janeiro e fevereiro), enquanto a segunda etapa ocorreu no período do inverno (entre julho e setembro), com a temperatura mínima atingindo $16^{0} \mathrm{C}$. 
No atual estudo, contatou-se que a médias da temperatura inicial do períneo dos Grupos $\mathrm{A}\left(31,1^{0} \mathrm{C}\right)$ e $\mathrm{B}\left(31,6^{0} \mathrm{C}\right)$ foram estatisticamente inferiores à do Grupo $\mathrm{C}$ $\left(32,7^{0} \mathrm{C}\right)$. Acredita-se que essa diferença ocorreu em razão da exposição à temperatura fria do ambiente. Segundo Knight (2000), alguns estudos confirmam que a temperatura reduzida do ambiente resultou em diminuição na temperatura superficial das extremidades. Esse autor acrescenta que, se a pele é resfriada por contato direto com uma superfície fria, ela congela em temperaturas maiores do que se resfriada por exposição ao ar frio, pois os efeitos do contato causam maior perda de calor.

O estudo de Livingstone (1976) apud Knight (2000) verificou que em um grupo de soldados, após duas semanas vivendo na região do Ártico, a temperatura média dos dedos da mão mudou de $31,7^{\circ} \mathrm{C}$ para $29,3^{\circ} \mathrm{C}$. O mesmo trabalho comprovou que esse fato também se aplica ao resfriamento por imersão, pois a temperatura média dos dedos na imersão por 30 minutos em água a $0,1^{0} \mathrm{C}$ teve praticamente a mesma diferença $\left(2,3^{0} \mathrm{C}\right)$, ou seja, o valor anterior de $9,7^{0} \mathrm{C}$ passou para $7,4^{0} \mathrm{C}$, após habitar a região citada.

O trabalho de Danielsson (1996) reavaliou a afirmação de Siple \& Passel, que, em 1945, referiram que baixas temperaturas do ar e alta velocidade dos ventos estão associadas ao aumento do risco de congelamento. O primeiro autor concluiu que, à medida que a temperatura superficial da pele cai de $-4,8^{\circ} \mathrm{C}$ para $-7,8^{0} \mathrm{C}$, aumenta o risco de congelamento de 5\% para 95\%.

Os estudos que empregaram a crioterapia para o alívio da dor perineal não mencionam a temperatura da região antes e após a aplicação de frio; assim, faltam dados para a comparação dos nossos resultados. O único trabalho encontrado foi o de Beleza (2008), que, utilizando um termômetro digital infravermelho, observou temperatura perineal média mais elevada $\left(34,5^{\circ} \mathrm{C}\right)$, contudo não foi referida a temperatura do ambiente e a coleta de dados ocorreu durante 10 meses, incluindo períodos de inverno e verão.

Ao comparar os resultados da temperatura inicial do períneo com a axilar, constatou-se que a região perineal possui menor temperatura, sendo que a diferença oscilou entre $5,5^{\circ} \mathrm{C}$ no Grupo A e $3,9^{\circ} \mathrm{C}$ no Grupo C.

Nossos resultados apontam que aos 10 minutos de aplicação do gelo houve redução na temperatura do períneo de $17,8^{0} \mathrm{C}$ no Grupo A (de $31,1^{0} \mathrm{C}$ para $13,3^{0} \mathrm{C}$ ), 
de $17,9^{\circ} \mathrm{C}$ no Grupo B (de $31,6^{\circ} \mathrm{C}$ para $13,7^{\circ} \mathrm{C}$ ) e de $17,4^{\circ} \mathrm{C}$ no Grupo $\mathrm{C}$ (de $32,7^{0} \mathrm{C}$ para $15,3^{0} \mathrm{C}$ ). Esses dados são compatíveis com as respostas fisiológicas descritas por Palastanga (1994), que afirma ocorrer um resfriamento intenso e imediato dos tecidos superficiais, com queda de $15^{\circ} \mathrm{C}$ dentro de dois a cinco minutos, quando essa terapêutica é utilizada. Por outro lado, esse mesmo autor ressalta que os tecidos mais profundos sofrem uma pequena redução de cerca de $5^{0} \mathrm{C}$, e para que isso aconteça pode demorar até 20 minutos, sendo mais lento se existe uma camada espessa de gordura subcutânea. Assim, muitos dos resultados do resfriamento são consequência dos efeitos obtidos na pele e nos outros tecidos superficiais.

Para Granberg (1991) apud Knight (2000), a quantidade de perda de calor é mais importante do que o tempo de aplicação e a temperatura do gelo, quando se considera a possibilidade de dano tecidual.

Segundo Basford (1992), se a modalidade de resfriamento for o gelo, a temperatura da pele diminui rapidamente, atingindo valores aproximados de $12^{\circ} \mathrm{C}$ a $13^{0} \mathrm{C}$, em 10 minutos.

De acordo com Knight (2000), a velocidade e a magnitude de resfriamento e de reaquecimento após a aplicação variam muito, dependendo da modalidade de frio empregada, do tecido a ser resfriado, do ambiente e da duração da aplicação. O calor é transferido do indivíduo para a bolsa, por meio de um processo de condução, cujo resultado é o resfriamento dos tecidos e o aquecimento da bolsa (Palastanga, 1994).

Existe recomendação para que o gelo não seja aplicado diretamente sobre a pele, devido ao risco de queimadura ou ulceração, principalmente, se retirado diretamente do freezer, pois pode estar abaixo do ponto de congelamento. No entanto, a efetividade do resfriamento pode ser reduzida em função da barreira usada entre a pele e o gelo (MacAuley, 2001).

Não foi encontrado nenhum estudo com relato de ulceração pelo frio em decorrência da aplicação de gelo por um período de tempo curto, de 30 minutos (Knight, 2000). Também, Bleakley, McDonough, MacAuley (2006), utilizando bolsa de gelo $\left(0^{0} \mathrm{C}\right)$ por até 20 minutos, na entorse aguda de tornozelo, não observaram queimadura, paralisia das terminações nervosas ou outro efeito adverso.

Merece comentar que neste estudo não foi encontrado nenhum efeito nocivo advindo da aplicação da bolsa de gelo no períneo. 
LaVelle, Snyder (1985) analisaram o efeito das barreiras de proteção mais utilizadas e observaram que após 30 minutos de aplicação de bolsa de gelo entre $0^{0} \mathrm{C}$ e $0,5^{0} \mathrm{C}$ no tornozelo, a temperatura média foi de $30,5^{0} \mathrm{C}$ usando bandagem almofadada, $20,5^{\circ} \mathrm{C}$ somente com a bandagem, $17,8^{0} \mathrm{C}$ com uma tolha seca, $10,8^{0} \mathrm{C}$ sem nenhuma barreira e 9,9 $9^{\circ} \mathrm{C}$ com uma tolha úmida. Também Urban, Knight (1979) apud Knight (2000) confirmam esses achados; ao aplicar gelo por cinco minutos na região lateral do tornozelo, constataram que a temperatura tinha reduzido de $32^{\circ} \mathrm{C}$ para $13,9^{\circ} \mathrm{C}$ com o gelo diretamente sobre a pele, para $18,1^{\circ} \mathrm{C}$ com uso de bandagem úmida entre a pele e a bolsa, para $15,5^{\circ} \mathrm{C}$ com a bandagem gelada e para $26,7^{0} \mathrm{C}$ com bandagem seca.

Estudo experimental realizado em laboratório, com temperatura ambiente mantida em $25^{0} \mathrm{C} \pm 1^{0} \mathrm{C}$, analisou a efetividade de quatro modalidades de crioterapia para reduzir a temperatura da pele do quadríceps direito. Observou que a temperatura superficial das 50 mulheres no início variou de $31,9^{0} \mathrm{C}$ a $32,1^{0} \mathrm{C}$, em quatro grupos. Após 20 minutos de resfriamento, a temperatura reduziu para $10,2^{0} \mathrm{C}$ com aplicação de bolsa de gelo, $13,9^{0} \mathrm{C}$ com bolsa de gel, $14,4^{0} \mathrm{C}$ com gelo triturado e $10^{0} \mathrm{C}$ com mistura de água e álcool. Todas as modalidades de resfriamento foram envolvidas em uma toalha com 100\% de algodão que havia sido embebida em água na temperatura ambiente. Notou-se que a média da temperatura da pele com o gelo e a mistura de água e álcool ficou entre $10^{\circ} \mathrm{C}$ e $13,6^{\circ} \mathrm{C}$, após nove minutos de aplicação. A análise de variância apontou que a média da temperatura superficial da pele após a aplicação do gelo e do gel declinou significativamente de zero a 10 minutos ( $p<0,05$ ). (Kanlayanaphotporn, Janwantanakul, 2005).

Merece destacar que no protocolo deste estudo foi utilizada uma camada única de tecido fino de algodão, tipo fralda, para evitar o contato direto da região perineal com a bolsa de gelo. A temperatura final do períneo após a aplicação da bolsa de gelo resultou em $13,3^{0} \mathrm{C}$ para o Grupo A (10 minutos de aplicação), $11,3^{0} \mathrm{C}$ para Grupo B (15 minutos de aplicação) e $12,6^{\circ} \mathrm{C}$ para o Grupo C (20 minutos de aplicação). Frente aos achados deste estudo, demonstrou-se que a bolsa de gelo é eficaz para o resfriamento da região perineal, considerando os níveis recomendados para analgesia de $10^{\circ} \mathrm{C}$ a $15^{\circ} \mathrm{C}$, como ressalta MacAuley (2001).

Também Starkey (2001a) ressalta que para ocorrer analgesia a temperatura da pele deve cair para aproximadamente $14,4^{\circ} \mathrm{C}$. Além disso, os resultados do atual 
estudo são compatíveis com os achados dos três últimos trabalhos citados (variação de $10,8^{0} \mathrm{C}$ a $13,9^{0} \mathrm{C}$, com o gelo aplicado diretamente na pele), sugerindo não ter ocorrido interferência da camada de tecido tipo fralda no processo de resfriamento da região.

A diferença encontrada na temperatura perineal entre os Grupos C e B antes da aplicação da bolsa $\left(1,1^{0} \mathrm{C}\right)$ manteve-se praticamente a mesma ao final da intervenção $\left(1,3^{0} \mathrm{C}\right)$.

Médias mais elevadas foram identificadas no estudo de Beleza (2008), que constatou $20,5^{0} \mathrm{C}$ após 10 minutos de aplicação de bolsa com gelo triturado envolvida em malha tubular, e $23,4^{0} \mathrm{C}$ após o término, ou seja, após 20 minutos. Considerando a temperatura no início do procedimento menos a final, a redução obtida nessa investigação foi de $11,1^{0} \mathrm{C}$, valor inferior ao observado na atual pesquisa $\left(17,8^{0} \mathrm{C}\right.$ a $\left.20,3^{0} \mathrm{C}\right)$.

Nas aplicações terapêuticas da medicina esportiva, geralmente, o tecido é resfriado a uma temperatura superficial entre $1^{0} \mathrm{C}$ e $10^{\circ} \mathrm{C}$. As respostas fisiológicas desencadeadas pelo frio são: redução da temperatura, queda do metabolismo celular, diminuição dos efeitos inflamatórios e circulatórios, redução da dor, redução do espasmo muscular e aumento da rigidez tecidual (Knight, 2000).

O termômetro empregado para medir a temperatura neste estudo foi o modelo digital Minipa ${ }^{\circledR}$ com duplo canal e dois termopares (de superfície e de imersão), que consiste em dois metais distintos unidos por uma das extremidades. Segundo Knight (2000), a precisão da temperatura medida depende da precisão inerente do dispositivo e de como ele é utilizado. Acrescenta, ainda, que é mais fácil e preciso verificar os valores em um teletermômetro com leitura digital.

Como referido no Método, o aparelho foi calibrado na época da aquisição e tomou-se o cuidado de manter o termopar de superfície protegido com policloreto de vinila (PVC) aplicado do lado direito na linha horizontal perpendicular ao intróito vaginal, distante cerca de três centímetros da fúrcula. O termopar foi fixado à superfície do períneo com uma pequena tira de Micropore ${ }^{\circledR}$, deixando livre sua ponta em contato com a região e sendo colocada sobre ele a bolsa de gelo protegida com o tecido tipo fralda, para que pudesse mensurar a temperatura de interface. $\mathrm{O}$ termopar permaneceu no local durante todo o período da aplicação da bolsa de gelo. 
Conforme citado anteriormente, durante o resfriamento, o calor é transferido dos tecidos para a modalidade de crioterapia que está sendo utilizada, por um processo de condução, em que a troca de calor ocorre da região corporal de maior energia para a de menor energia, resultando que o corpo mais quente esfrie e o mais frio aqueça, até atingir um equilíbrio (Palastanga, 1994; Knight, 2000).

Para avaliar as temperaturas das bolsas de gelo nos três grupos foi usado o termopar de imersão, que permaneceu dentro das bolsas durante todo o tempo da aplicação. Constatou-se que as médias foram diminuindo discretamente até por volta de 10 minutos, mantendo-se, a seguir, praticamente constante. No Grupo A, a média da temperatura no início da aplicação e aos 10 minutos era de $1,9^{0} \mathrm{C}$ passando para $0,6^{0} \mathrm{C}$; no Grupo $\mathrm{B}$, de $2,1^{0} \mathrm{C}$ reduziu para $0,6^{0} \mathrm{C}$; e no Grupo $\mathrm{C}$, de $3,8^{0} \mathrm{C}$ para $2,3^{0} \mathrm{C}$. Isso demonstra que a bolsa, apesar da troca de calor, se manteve gelada, mesmo no verão, época da coleta de dados do Grupo C.

São poucos os trabalhos que citam a temperatura dos métodos de resfriamento empregados. O estudo de Ramler, Roberts (1986) utilizou banho de assento frio na temperatura de $15,6^{\circ} \mathrm{C}$ a $18,3^{\circ} \mathrm{C}$, por 20 minutos. Lafoy, Geden (1989) também empregaram o banho de assento, contudo a temperatura da água foi mantida em $0^{0} \mathrm{C}$ e o tempo de aplicação foi de 15 minutos, entre seis e 24 horas de pós-parto. Por sua vez, Hill (1989) usou uma bolsa de gelo a $33^{0} \mathrm{~F}\left(0,5^{\circ} \mathrm{C}\right)$ por 20 minutos, nas primeiras 24 horas após o parto.

O ensaio clínico de Steen et al. (2000) menciona que a bolsa de gelo e a de gel foram colocadas no freezer por duas a seis horas; no entanto, não indicam qual foi a temperatura utilizada.

Outra variável que apresentou diferença estatística entre os grupos foi a dor perineal anterior à intervenção (primeira avaliação), sendo as maiores médias encontradas nos Grupos A e B (5,2 e 5,4, respectivamente) e a menor no Grupo C $(4,6)$, embora no limite da significância estatística $(p=0,049)$. Apesar da diferença estatística, na prática clínica pode-se considerar que esses valores são equivalentes e correspondem à dor moderada. Segundo Pimenta, Cruz, Santos (1998), existe correpondencia entre os níveis 4 e 5 da escala numérica e a dor avaliada como moderada em escalas com descritores verbais. Valores semelhantes foram observados no estudo de Beleza (2008), que também envolveu a avaliação da dor perineal antes da aplicação da bolsa de gelo e encontrou média de 4,31 \pm 2,09 no 
grupo controle e 5,29 \pm 1,19 no grupo experimental, também utilizando a escala numérica de 0 a 10.

Avaliar a intensidade da dor é fundamental para planejar a terapia antiálgica e para verificar a adequação do esquema proposto (Pimenta, Cruz, Santos, 1998).

A magnitude da dor e a expressão de sofrimento apresentam grande variabilidade entre os indivíduos e nas diferentes espécies de animais. Vários fatores ambientais e individuais podem exacerbar ou diminuir a expressão dolorosa, como aspectos raciais, sociais, culturais, religiosos, filosóficos, experiências pregressas e estado mental (Teixeira, 2001).

A intensidade da dor é, certamente, o componente de grande expressão da experiência dolorosa e a característica mais aferida na prática clínica e na pesquisa. As escalas com descritores verbais são muito conhecidas e a mais empregada em nosso meio está agrupada em cinco categorias (sem dor, dor leve, dor moderada, dor intensa e insuportável) (Pimenta, Cruz, Santos, 1998).

Os trabalhos que envolveram a terapia do frio para o tratamento da dor perineal utilizam diferentes escalas para mensurar a queixa dolorosa. Um dos poucos estudos que informaram a intensidade da dor perineal anterior à intervenção foi o de Lafoy, Geden (1989), que utilizando a escala analógica visual (0, 25, 50, 75 e 100 pontos), constataram que, das 20 mulheres, 13 delas referiram dor 25 (leve), cinco puérperas relataram dor 50 (moderada) e somente duas citaram dor 75 (intensa) e, não foi encontrado nenhum caso de dor acima de 75.

Pesquisa realizada em nosso meio com 40 primíparas submetidas à episiotomia, avaliou os efeitos da estimulação elétrica nervosa transcutânea (TENS) para o alívio da dor perineal, observou médias similares ao deste estudo (grupo controle 5,15 e experimental 3,30), pela escala numérica de 0 a 10 (Pitangui, 2007).

A avaliação da queixa dolorosa neste estudo ocorreu durante o período da internação e a média de tempo encontrada nos grupos e variou de 20,1 a 24 horas, coincidindo com a maioria das avaliações realizadas por outros autores (Ramler, Roberts, 1986; Hill, 1989; Lafoy, Geden, 1989; Steen et al., 2000; Beleza, 2008).

Merece destacar que o Amparo Maternal, local do estudo, atende mulheres, provenientes de todas as regiões da Grande São Paulo, o que dificulta muito qualquer tipo de pesquisa de seguimento. Além disso, a assistência pós-natal é realizada em Unidades Básicas de Saúde. Assim, o foco deste estudo foi avaliar o desfecho da dor 
perineal em mulheres submetidas ao parto normal, durante o período de internação hospitalar, que é de aproximadamente dois dias.

Conforme descrito na Introdução, a sensação dolorosa é uma resposta à injuria tecidual, pois as terminações nervosas especializadas denominadas nociceptores são estimuladas e transmitem sinais ao cérebro, onde a sensação de dor é percebida (Nadler, Weingand, Kruse, 2004). Após o trauma da região do períneo, desencadeia-se a resposta inflamatória, que é a reação local do organismo no nível tecidual a um fator irritante, com a finalidade de promover a regeneração do tecido (Knight, 2000).

Uma das respostas imediatas do organismo ao trauma é a liberação de norepinefrina no local lesado, que leva a vasoconstrição para impedir a perda de sangue na área traumatizada. Enquanto os vasos estão contraídos, o processo de coagulação inicia o reparo do dano primário. A vasoconstrição inicial é transitória e dura alguns minutos após a lesão. Em seguida, os vasos se dilatam, aumentando o volume de sangue não local (Starkey, 2001b).

O processo de inflamação caracteriza-se por: vasodilatação e aumento do fluxo sanguíneo local; aumento da permeabilidade capilar, com saída de grande quantidade de líquido para o interstício, coagulação do líquido nos espaços intersticiais; migração de granulócitos e monócitos. Os produtos teciduais causadores dessas reações são a histamina, a bradicinina, a serotonina, as prostaglandinas, entre outros produtos (Guyton, 2006). Como conseqüência da inflamação, surgem sinais de dor, edema, rubor, calor e perda da função (Knight, 2000).

A finalidade do tratamento com modalidades de resfriamento, após algumas horas e dias do trauma agudo, é controlar a inflamação e conter o objeto da injúria original, por meio da diminuição da lesão hipóxica secundária, controlando o edema e o espasmo (Ryan, 2001)

Com o emprego da crioterapia, que resulta inicialmente em vasoconstrição e redução da resposta inflamatória, alguns pesquisadores manifestam preocupação sobre a possibilidade de retardar o processo de cicatrização (Sleep, 1990 apud Steen et al., 2000; Grundy, 1997).

Não foi possível avaliar se o resfriamento interferiu no processo de cicatrização, pois o período de internação hospitalar da puérpera no local do estudo é 
muito curto e a maternidade não dispõe de um serviço de retorno, como ressaltado anteriormente.

Após conduzir revisão da literatura em oito bases de dados, Hubbard, Denegar (2004) concluíram que existem evidências disponíveis de que a crioterapia é eficaz na diminuição da dor, contudo, os efeitos a longo prazo e sobre a reparação dos tecidos não são conhecidos.

Também Steen, Briggs, King (2006) realizaram uma revisão sobre uso do frio no trauma perineal, entre 1960 e 2005, com o objetivo de identificar tipos de resfriamento utilizados, analisar a eficácia destas terapêuticas em relação a reduzir o nível de dor perineal e interferir na resposta inflamatória e no processo de cicatrização e à satisfação materna. Entre as implicações para a prática, os autores concluem que ainda não há evidências suficientes sobre qual método de resfriamento é mais eficaz; entretanto, defendem que tais tratamentos diminuem a dor e a resposta inflamatória e que deve ser considerada a preferência da mulher.

Como citado no Método, nesta segunda etapa do projeto, comparou-se o tempo de aplicação da bolsa de gelo por 10 e 15 minutos com o tempo usual de 20 minutos, para o alívio da dor no períneo após o parto normal. A comparação da dor intra-grupo entre a primeira e a segunda avaliação (antes e após a intervenção) demonstrou que houve diferença significativa para os três grupos, isto é, a bolsa de gelo reduziu a dor perineal de todas as puérperas.

A análise de variância indicou que não houve diferença estatística entre as médias de dor dos três grupos logo após a aplicação da bolsa de gelo, havendo equivalência entre eles quanto à promoção do alívio da dor perineal, sendo encontradas as médias de 1,6 para o Grupo A, 0,9 para o B e 1,6 para o C.

Igualmente, as comparações intra-grupo, entre a segunda e a terceira avaliação (imediatamente após terminada a intervenção e 20 minutos depois, respectivamente) e entre a terceira e a quarta avaliação (20 e 40 minutos após terminada a intervenção, respectivamente), não apontaram diferenças significativas em nenhum dos grupos, o que confirma a manutenção do efeito analgésico por 40 minutos depois de realizada a intervenção. As médias de dor perineal variaram de 1,1 a 1,5 na terceira avaliação e apresentaram o mesmo valor de 1,5 para os três grupos na quarta avaliação. 
A redução da dor ocorre em consequência da diminuição da excitabilidade das terminações nervosas e da transmissão dos receptores, elevação do limiar de dor e liberação de endorfinas, causada pelo frio (Knight, 2000).

Chama atenção que os Grupos A e C na terceira avaliação, com 20 minutos após o término da crioterapia, continuaram a apresentar uma discreta redução das médias de dor, embora sem significância estatística. Estes achados confirmam em parte a afirmação de Droegemueller (1980) sobre a permanência por 30 minutos do efeito parcial anestésico da crioterapia. Basford (1992) também advoga que embora o tratamento com frio seja restrito a aplicações superficiais, a crioterapia pode produzir alterações fisiológicas de longa duração.

Os resultados da investigação realizada por Beleza (2008) indicaram que houve diferença estatística entre as médias de dor do grupo controle e experimental (4,42 versus 2,38, respectivamente), avaliada 10 minutos após a crioterapia. No entanto, após 70 minutos do término da terapia não foi encontrada diferença significativa nas médias de dor, o que mostra que o efeito analgésico havia passado. Convém comentar, que os valores das médias de dor, logo após a terapia, verificados naquele trabalho foram mais elevados do que os encontrados no presente estudo $(2,38$ contra 1,6$)$.

Estudo referido anteriormente, empregando banho de assento frio por 20 minutos, na temperatura entre $15,6^{\circ} \mathrm{C}$ e $18,3^{\circ} \mathrm{C}$ e utilizando a escala numérica de 0 a 5, verificou que houve redução significativa dos níveis de dor perineal imediatamente após o banho, sendo que $77,5 \%$ das mulheres informaram que a diferença entre a dor logo após e a inicial variou de 0,76 a 3,75, com média de 1,23 e desvio padrão de 0,77 . No entanto, não foi observada diferença estatística após 30 minutos e uma hora depois (Ramler, Roberts, 1986). A justificativa poderia ser que a temperatura utilizada não foi eficaz na redução da temperatura do local para proporcionar analgesia mais prolongada. Além disso, a escala empregada, com pequeno número de opções, pode ter comprometido a sensibilidade da mensuração da dor.

O outro trabalho que comparou o banho de assento frio $\left(0^{0} \mathrm{C}\right)$ com o quente $\left(43^{0} \mathrm{C}\right)$, por 15 minutos, não demonstrou diferença estatística na sequência dos banhos para aquelas puérperas que iniciaram pelo banho frio (Lafoy, Geden, 1989). 
Ensaio clínico aleatorizado, realizado no norte da Inglaterra, comparou duas modalidades de resfriamento (bolsa de gelo e de gel) com um grupo sem tratamento, em 316 puérperas de parto espontâneo e instrumental. Para a avaliação da dor foi empregada a escala verbal de quatro pontos. Observou-se que houve diferença significativa entre os grupos no relato de dor com cinco e dez dias, sendo a estimativa de dor menor no grupo do gel. A taxa de satisfação das participantes foi estatisticamente maior no grupo do gel (93\%) comparado com os outros dois grupos (bolsa de gelo $=76 \%$ e sem tratamento $=84 \%$ ) (Steen, Marchant, 2007) .

Como referido nos resultados, apenas as 76 puérperas da segunda etapa do estudo foram questionadas sobre a satisfação como tratamento utilizado. A totalidade das mulheres teve opinião favorável à terapia de resfriamento, 52,6\% delas referiram bom e 47,4\%, muito bom. Por outro lado, a pesquisa de Steen et al. (2000) constatou que apenas $27 \%$ das puérperas avaliaram o procedimento como bom e muito.

Outra questão a ser abordada é a recusa das mulheres em aceitar essa modalidade de tratamento. Na primeira etapa deste estudo três mulheres negaram-se a participar do trabalho e, na segunda etapa, 26 não quiseram participar, muitas delas alegaram que a temperatura ambiental estava muito fria. Lafoy, Geden (1989) verificaram que das 27 mulheres que preencheram os critérios de inclusão, sete recusaram participar da investigação. Também um elevado número de 119 recusas é citado por Ramler, Roberts (1986).

Convém comentar que a elevada resistência encontrada nesses dois trabalhos pode ser decorrente da técnica de resfriamento empregada, que foi o banho de assento, ou seja, as mulheres deviam sentar-se em uma banheira apropriada, resfriando não apenas a região do períneo, mas também a vulva, nádegas e arredores. A utilização de dispositivos de resfriamento localizados parece ser um método mais aceito pelas mulheres (Steen, Briggs, King, 2006).

Como ressalta Farrar et al. (2000), os resultados obtidos com estudos de analgésicos, em geral, são difíceis para interpretar, pois a importância clínica dos resultados não é óbvia. Dessa forma, uma análise porcentual da melhora da dor deveria ser realizada para estabelecer o alívio adequado.

Conforme referido no Método, foi considerada melhora uma diminuição de dois pontos na escala numérica, que representa uma mudança clinicamente 
significativa na avaliação de uma intervenção e corresponde a uma redução de $30 \%$ (Farrar et al., 2001).

A maioria das participantes deste estudo referiu melhora da dor perineal após a aplicação da bolsa de gelo, sendo constatado que 72,8\% delas indicaram melhora acima de 50\%, 21,9\%, entre 30 e 50\% e as restantes indicaram resolução abaixo de 30\%, que, segundo os critérios adotados, não foi considerada melhora. Nenhuma puérpera referiu piora da dor perineal. Destaca-se que na fase de planejamento desta pesquisa optou-se por usar a escala numérica de 0 a 10 para avaliar a dor perineal, pois ela permite detectar uma pequena melhora e, considerando a dificuldade para interpretar a melhora clínica, foi adotado o nível de corte igual ou superior a três.

Ao se aplicar o teste Qui-quadrado, constatou-se que não houve diferença significativa entre os três grupos, indicando que a duração de 10, 15 e 20 minutos na aplicação da bolsa de gelo são similares para o alívio da dor perineal. Convém comentar que o Grupo C apresentou menores proporções de melhora da dor, embora sem significância estatística. A justificativa poderia ser que esse grupo de mulheres apresentou também, no início do estudo, as menores médias de dor perineal.

A eficácia de um tratamento específico deve ser analisada considerando três fatores para a melhora clínica da condição do doente. O primeiro inclui os efeitos específicos do tratamento atribuíveis à intervenção; o segundo corresponde à história natural e regressão para a média, isto é, a dor pode melhorar ou mesmo resolver completamente independente da terapia utilizada e o terceiro é o efeito inespecífico do tratamento, que inclui a atenção do profissional, o interesse, a preocupação com a cicatrização, a expectativa do paciente e do médico sobre o efeito do tratamento, também conhecido como efeito placebo (Turner, 2001).

A primeira etapa deste estudo que comparou a efetividade da bolsa de gelo aplicada por 20 minutos (grupo experimental), com a bolsa de água em temperatura ambiente (grupo placebo) e com o grupo sem tratamento (controle) para o alívio da dor perineal e verificou que houve redução significativa entre a média de dor inicial e após a intervenção nos três grupos $(\mathrm{p}<0,001)$. As puérperas referiram melhora da dor perineal em todos os grupos, inclusive naquele sem tratamento (Leventhal, 2008).

Como referem Fletcher, Fletcher (2006), as pessoas demonstram uma tendência para alterar o comportamento quando recebem atenção especial e sabem 
que são alvo de interesse, independente da natureza da intervenção que recebem. Esse fenômeno é conhecido como efeito Hawthorne.

Em relação às sensações informadas pelas participantes durante a aplicação do gelo, verificou-se que certo número delas citou ter experimentado queimação $(9,6 \%)$ e ardor (8,8\%), no início da terapia. A maior parte das puérperas indicou a sensação de gelado (36,8\%), seguida por alívio (23,7\%) e dormência (13,2\%).

Ao passo que um atleta pode estar muito motivado para tolerar a terapia, os pacientes, normalmente, consideram desconfortáveis temperaturas abaixo de $13^{\circ} \mathrm{C}$ a $15^{0} \mathrm{C}$ e referem sensações sucessivas de frio, queimação, coceira e dormência (Basford, 1992).

Essa constatação é reforçada por Droegemueller (1980) ao referir que a sensação inicial da pele, quando a temperatura diminui, é de queimação. A crioterapia promove a perda da sensação tátil, que justifica a redução da dor ao repouso e movimento (Beleza, 2008).

Knight (2000) comenta que o indivíduo deve ter um preparo psicológico para enfrentar a primeira sessão de crioterapia, pois a sensação imediata ao tratamento é a dor induzida pelo frio, explicada pela vasoconstrição. Segundo ressaltam Galvan et al. (2006), essa terapia é desconfortável para os novos usuários, mas com a repetição do procedimento o desconforto diminui.

Adotar medidas de alívio para a queixa dolorosa é fundamental, pois essa morbidade pode interferir e limitar as atividades da nova mãe. Nesse sentido, chama atenção o título do artigo de Steen (2005) “I can’t sit down” que inicia afirmando que é freqüente ouvir as puérperas declararem "eu não consigo sentar”.

Neste trabalho constatou-se que, 20 minutos após a aplicação da bolsa de gelo, não houve diferença estatística nos três grupos em relação à posição assumida pelas mulheres, com 41,2\% delas permanecendo a maior parte do tempo deambulando e 23,7\%, sentadas para amamentar o filho ou almoçar. Entre 20 e 40 minutos após a intervenção, também não foi observada diferença significativa entre os grupos, com proporção semelhante de puérperas na posição sentada e deitada (38,6\% e $37,7 \%$, respectivamente).

O estudo de Steen, Marchant (2007) verificou que o mais alto nível de dor perineal foi relatado pelas mulheres quando estavam sentadas (variação de 94\% a 
98\%), no primeiro dia de pós-parto, permanecendo ainda elevada mesmo após 10 dias (42\% a 54\%).

Pesquisa citada anteriormente observou que a dor na região do períneo foi a que mais interferiu nas necessidades básicas de sono, locomoção e eliminação da mulher, além de prejudicar a amamentação e os cuidados com o RN, nos períodos avaliados (20-24h, 56-60h e 10 dias) (Alexandre et al., 2006).

Os trabalhos apontam que elevada porcentagem de mulheres continuam a referir dor perineal, mesmo após transcorridos cinco dias do parto e da utilização de analgesia oral (Steen et al., 2000), indicando que o tratamento oral é insuficiente.

Considerando as necessidades individuais, é provável que para obter o controle adequado da dor perineal haja necessidade de uso concomitante de tratamentos sistêmicos e localizados (Steen, 2005, East et al., 2008). Nesse sentido, o emprego de terapia de resfriamento demonstrou ser eficaz, de fácil utilização, de baixo custo e uma prática não intervencionista.

Uma limitação deste estudo foi o não cegamento das auxiliares da pesquisa e das puérperas, em razão do tipo de tratamento proposto. No entanto, as participantes não foram informadas sobre o grupo randomizado a que pertenciam, ou seja, sobre qual o tempo de aplicação da bolsa de gelo. Outra limitação foi a não inclusão do consumo de analgésicos pela puérpera durante o período da internação.

Avaliar adequadamente a dor, promover seu controle e alívio, incluindo o aspecto humanitário, devem fazer parte da assistência prestada ao indivíduo, tendo como finalidade contribuir para a manutenção de funções fisiológicas básicas, evitando os efeitos adversos que podem decorrer da permanência desse sintoma (Calil, Pimenta, 2005).

Entre as implicações para a prática, pode-se afirmar que o tratamento com gelo é seguro e que o tempo de 10 ou 15 minutos é tão eficaz quanto o de 20 minutos para o alívio da dor perineal, devendo, no entanto, ser consideradas as variações individuais de cada mulher. Ainda são necessários mais estudos para avaliar a duração do efeito analgésico para determinar a periodicidade das aplicações.

Pode-se, a princípio, pensar em protocolos semelhantes aos existentes para tratamento de lesões agudas músculo-esqueléticas, que indicam a crioterapia por 20 minutos a cada meia hora ou por 30 minutos a cada duas horas, entre as primeiras seis e 24 horas após o parto. 
7. CONCLUSÃO

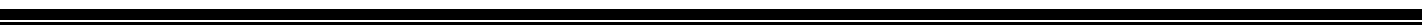


Nesta segunda etapa do projeto, avaliou-se o tempo de uma única aplicação de bolsa de gelo para o alívio da dor perineal, durante as primeiras 56 horas após o parto normal. Participaram dessa etapa do estudo 76 mulheres distribuídas em dois grupos de tratamento sob investigação: Grupo A, em que foi aplicada bolsa de gelo por 10 minutos, e Grupo B, que utilizou bolsa de gelo por 15 minutos, os quais foram comparados com o tratamento controle do Grupo C, da primeira etapa do trabalho e que usou bolsa de gelo durante 20 minutos. Todos os grupos contaram com 38 puérperas.

Os resultados obtidos confirmam a hipótese de que não há diferença na eficácia analgésica obtida pela bolsa de gelo aplicada por 10, 15 ou 20 minutos em mulheres com dor perineal moderada a intensa, após o parto normal.

A comparação das médias de dor entre os Grupos A, B e C, imediatamente após a aplicação da bolsa de gelo (segunda avaliação), não apresentou diferença estatística, ou seja, indicou que as médias são semelhantes.

Na comparação intra-grupo, houve diferença significativa entre a primeira e a segunda avaliações (antes e após a intervenção) da dor perineal nos três grupos.

Não houve diferença estatística na comparação das médias de dor perineal intra-grupo e também entre os três grupos, considerando a segunda e a terceira avaliação e a terceira e a quarta avaliação, indicando que o efeito analgésico permaneceu estável por até 40 minutos após a intervenção nos Grupos A, B e C.

Houve redução da temperatura perineal após a aplicação da bolsa de gelo, e temperatura atingida no períneo ficou entre $11,3^{\circ} \mathrm{C}$ e $13,3^{\circ} \mathrm{C}$, considerando os três grupos.

No atual estudo não foi observado nenhum efeito adverso atribuído à aplicação da bolsa de gelo no períneo.

A maioria das puérperas referiu alívio da dor perineal, sendo que em 72,8\% delas a melhora foi acima de $50 \%$ e em $21,9 \%$, entre $30 \%$ e $50 \%$.

Os resultados apontaram que a totalidade das puérperas submetidas à crioterapia foi favorável ao procedimento realizado, apesar do elevado número de recusas.

Até o momento atual, não existe evidência científica disponível sobre qual a melhor maneira de reduzir a ocorrência de lacerações espontâneas do trato genital no parto vaginal (Albers et al., 2005). Assim, devem-se oferecer terapias, sobretudo não farmacológicas, para o controle desse desconforto, sem interferir no processo de lactação. 


\section{REFERÊNCIAS}


Albers L, Garcia J, Renfrew M, McCandlish R, Elbourne D. Distribution of genital tract trauma in childbirth and related postnatal pain. Birth. 1999;26(1):11-7.

Albers L, Sedler KD, Bedrick EJ, Teaf D, Peralta P. Midwifery care measures in the second stage of labor and reduction of genital tract trauma at birth: a randomized trial Midwifery Womens Health. 2005;50(5):365-72.

Alexandre CW. Prevalência, características e impacto da dor no cotidiano da puérpera. [dissertação]. São Paulo: Escola de Enfermagem, Universidade de São Paulo; 2002.

Alexandre CW, Kimura AF, Tsunechiro MA, Oliveira SMJV. A interferência da dor nas atividades e necessidades da puérpera. Rev Nurs. 2006;93(9):664-8.

Almeida SFS, Riesco MLG. Ensaio clínico controlado aleatório sobre duas técnicas de sutura do trauma perineal no parto normal. Rev Lat Am Enferm. 2008;16(2):2729.

Andrews V, Thakar R, Sultan AH, Jones PW. Evaluation of postpartum perineal pain and dyspareunia: a prospective study. Eur J Obstet Gynecol Reprod Biol. 2008;137(2):152-6.

Barden J, Edwards J, Moore A, McQuay H. Dosis única oral de paracetamol (acetaminofeno) para el dolor postoperatorio (Cochrane Review). In: La Biblioteca Cochrane Plus, Issue 3, 2008a. Oxford: Update Software.

Barden J, Edwards J, Moore A, McQuay H. Single dose oral diclofenac for postoperative pain (Cochrane Review). In: The Cochrane Library, Issue 3, 2008b. Oxford, Update Software.

Basford JR. Agentes físicos e biofeedback. In: Delisa JA. Medicina de reabilitação. São Paulo: Manole; 1992. v.1, cap.13, p.297-317.

Beleza ACS. A dor perineal no pós-parto normal com episiotomia: mensuração, caracterização e efeitos da crioterapia [tese]. Ribeirão Preto: Escola de Enfermagem de Ribeirão Preto, Universidade de São Paulo; 2008.

Brasil. Ministério da Saúde. Departamento de Informática do SUS (DATASUS). Nascidos vivos - Brasil [texto na Internet]. Brasília; [s.d.]. [citado 2009 fev 2]. Disponível em: http://tabnet.datasus.gov.br/cgi/tabcgi.exe?sinasc/cnv/nvuf.def

Berquó E, Garcia S, Lago T, coordenadoras. PNDS 2006: Pesquisa Nacional de Demografia e Saúde da Criança e da Mulher [texto na Internet]. Brasília: Secretaria de Ciência, Tecnologia e Insumos Estratégicos, Ministério da Saúde; 2009. [citado 2009 fev. 2]. Disponível em: http://bvsms.saude.gov.br/bvs/pnds/img/relatorio_final_pnds2006.pdf

Brown S, Lumley J. Maternal health after childbirth: Results of an Australian population based survey. Br J Obstet Gynaecol. 1998;105(2):156-61. 
Calil AM, Pimenta CAM. Intensidade da dor e adequação de analgesia. Rev Lat Am Enferm. 2005;13(5):692-9.

Carroli G, Mignini L. Episiotomy for vaginal birth. Cochrane Database of Systematic Reviews 2009, Issue 1. Art. No.: CD000081. DOI:

10.1002/14651858.CD000081.pub2.

Cavalcante VO. Fisiopatologia da dor. In: Figueiró JAB, Angelotti G, Pimenta CAM. Dor e saúde mental. Rio de Janeiro: Atheneu; 2005. p.23-32.

Christianson LM, Bovbjerg VE, McDavitt EC, Hullfish KL. Risk factors for perineal injury during delivery. Am J Obstet Gynecol. 2003;189(1):255-60.

Corrêa CF, Pimenta CA de M. Princípios do tratamento da dor. In: Figueiró JAB, Angelotti G, Pimenta CA de M. Dor e saúde mental. São Paulo: Atheneu; 2005. p.41-50.

Cunningham FG, MacDonald PC, Gant NF, Leveno KJ, Gilstrap LG, Hankins GDV, et al. Williams obstetrícia. Rio de Janeiro: Guanabara Koogan; 2000. O puerpério; p.465-76.

Danielsson U. Windchill and the risk of tissue freezing. J Appl Physiol. 1996;81(6):2666-73.

Declercq E, Cunningham DK, Johnson C, Sakala C. Mother's reports of postpartum pain associated with vaginal and cesarean deliveries: results of a national survey. Birth. 2008;35(1):16-24.

Droegemueller W. Cold sitz baths for relief of postpartum perineal pain. Cin Obstet Gynecol. 1980;23(4):1039-43.

Eason E, Labrecque M, Wells G, Feldman P. Preventing perineal trauma during childbirth: a systematic review. Obstet Gynecol. 2000;95(3):464-71.

East Christine E, Begg Lisa, Henshall Naomi E, Marchant Paul, Wallace Karen. Local cooling for relieving pain from perineal trauma sustained during childbirth (Cochrane Review). In: The Cochrane Library, Issue 2, 2008. Oxford: Update Software.

Edwards JE, Meseguer F, Faura CC, Moore RA, McQuay HJ. Dipirona en dosis única para el dolor agudo postoperatorio (Revisión Cochrane traducida). In: La Biblioteca Cochrane Plus, número 2, 2008. Oxford: Update Software.

Ellis JW. Cuidados pós-parto. In: Ellis JW, Beckmann CRB, editoras. Manual de obstetrícia. Rio de Janeiro: Printice-Hall do Brasil; 1986. p.198-204.

Enkin M, Keirse MJNC, Neilson J, Crowther C, Duley L, Hodnett E, et al. Guia para atenção efetiva na gravidez e no parto. $3^{\text {rd }}$ ed. Rio de Janeiro: Guanabara Koogan; 2005. Dor e desconforto perineal; p.243-7. 
Farrar JT, Portenoy RK, Berlin JA, Kinman JL, Strom BL. Defining the clinically important difference in pain outcome measures. Pain. 2000;88(3):287-94.

Farrar JT, Young JP Jr, LaMoreaux L, Werth JL, Poole RM. Clinical importance of changes in chronic pain intensity measured on an 11-point numerical pain rating scale. Pain. 2001;94(2):149-58.

Fletcher RH, Fletcher SW. Epidemilogia clínica: elementos essenciais. $4^{\mathrm{a}}$ ed. Porto Alegre: Artmed; 2006. Tratamento; p.154-78.

Galvan HG, Tritsch AJ, Tandy R, Rubley MD. Pain perception during repeated icebath immersion of the ankle at varied temperatures. J Sport Rehabil. 2006;15(2):10515.

Glazener CMA. Sexual function after childbirth: women's experiences, persistent morbidity and lack of professional recognition. Brit J Obstet Gynaecol. 1997;104(3):330-5.

Glazener C. Women’s health after delivery. In: Henderson C, Bick D. Perineal care: an international issue. London: Quay Books; 2005. p.11-7.

Grundy L. The role of the midwife in perineal wound care foiiowing childbirth. Br J Nurs. 1997;6(10):584-8.

Guyton AC. Tratado de fisiologia médica. 11 a ed. Rio de Janeiro: Elsevier. 2006. p.434

Jadad AR. Randomised controlled trials. London: BMJ Books; 1998.

Hill PD. Effects of heat and cold on the perineum after episiotomy/laceration. J Obstet Gynecol Neonatal Nurs. 1989;18(2):124-9.

Hedayati H, Parsons J, Crowther CA. Anestésicos de aplicación tópica para el tratamiento del dolor perineal después del parto (Revisión Cochrane traducida). In: La Biblioteca Cochrane Plus, número 2, 2008. Oxford: Update Software.

Hubbard TJ, Denegar CR. Does cryotherapy improve outcomes with soft tissue injury? J Ath Train. 2004;39(3):278-9.

Kanlayanaphotporn R, Janwantanakul P. Comparison of skin surface temperature during the application of various cryotherapy modalities. Arch Phys Med Rehabil. 2005;86(7):1411-5.

Kearney R, Miller JM, Ashton-Miller JA, DeLancey JO. Obstrectic factors associated with levator ani muscle injury after vaginal birth. Obstet Gynecol. 2006;107(1):144-9.

Kettle C, Johanson RB. Material de sutura sintético absorbible versus catgut para reparaciones del periné (Revisión Cochrane traducida). In: La Biblioteca Cochrane Plus, número 3, 2007. Oxford: Update Software. 
Kettle C, Hills RK, Ismail KMK. Continuous versus interrupted sutures for repair of episiotomy or second degree tears. Cochrane Database of Systematic Reviews 2007, Issue 4. Art. No.: CD000947. DOI: 10.1002/14651858.CD000947.pub2.

Klein MC, Gauthier RJ, Robbins JM, Kaczorowski J, Jorgensen SH, Franco ED et al. Relationship of episiotomy to perineal trauma and morbidity, sexual dysfunction, and pelvic floor relaxation. Am J Obstet Gynecol. 1994;171(3):591-8.

Knight KL. Crioterapia no tratamento das lesões esportivas. São Paulo: Manole; 2000 .

Lafoy J, Geden EA. Postepisiotomy pain: warm versus cold sitz bath. J Obstet Gynecol Neonatal Nurs. 1989;18(5):399-403.

LaVelle BE, Snyder M. Differential conduction of cold through barriers. J Adv Nurs. 1985;10(1):55-61.

Leventhal LC. Analgesia pela bolsa de gelo sobre no períneo após o parto normal: ensaio clínico randomizado [tese] São Paulo: Escola de Enfermagem, Universidade de São Paulo; 2008.

Levitt C, Shaw E, Wong S, Kaczorowski J, Springate R, Sellors J, et al. Systematic review of the literature on postpartum care: methodology and literature search results. Birth. 2004;31(3):196-202.

Lydon-Rochelle MT, Holt VL, Martin DP. Delivery method and self-reported postpartum general health status among primiparous women. Paediatr Perinat Epidemiol. 2001;15(3):232-40.

Macarthur AJ, Macarthur C. Incidence, severity, and determinants of perineal pain after vaginal delivery: a prospective cohort study. Am J Obstet Gynecol. 2004;191(4):1199-204.

MacAuley DC, Ice therapy: how good is the evidence? Int J Sports Med. 2001;22(5):379-84.

Melson KA, Jaffe MS, Kenner C, Amlung S. Enfermagem materno-infantil: planos de cuidados. Rio de Janeiro: Reichmann\&Affonso; 2002. Puerpério; p.128-36.

Nadler SF, Weingand K, Kruse RJ. The physiologic basis and clinical applications of cryotherapy and thermotherapy for the pain practitioner. Pain Physician.

2004;7(3):395-9.

Neeson JD, May KA. Comprehensive maternity nursing: nursing process and the childbearing family. Philadelphia, J.B. Lippincott, 1986. Nursing care of the family in the postpartum period; p.887-933.

Nunes S, Vargens OMC. A crioterapia como estratégia para alívio da dor no trabalho de parto: um estudo exploratório. Rev Enferm UERJ. 2007;15(3):337-42. 
Olds SB, London ML, Ladewig PA. Maternal-newborn nursing: a family-centered approach. $2^{\text {nd }}$ ed. Menlo Park: Addison-Wesley; 1984. The pospartal family: assessment, needs, and care; p.900-50.

Organização Mundial de Saúde (OMS). Assistência ao parto normal: um guia prático. Brasília: OPAS/USAID: 1996. [OMS/SRF/MSM/96.24].

Palastanga NP. Heat and colt. In: Wells PE, Frampton V, Browsher D, editors. Pain management by physiotherapy. $2^{\text {nd }}$ ed. Oxford: Butterworth-Heinemann; c1994. p.177-86.

Pimenta CAM, Cruz DALM, Santos JLF. Instrumentos para avaliação da dor: o que há de novo em nosso meio. Arq Bras Neurocir. 1998;17(1):15-24.

Pinkerton JH, Beard RW. Ice packs after episiotomy. Br Med J. 1961;1(5238):15367.

Pitangui ACR. Avaliação do efeito da estimulação elétrica nervosa transcutânea (TENS) no alívio da dor pós-episiotomia em primíparas submetidas ao parto normal [dissertação]. Ribeirão Preto: Escola de Enfermagem de Ribeirão Preto, Universidade de são Paulo; 2007.

Ramler D, Roberts J. A comparison of cold and warm sitz baths for relief of postpartum perineal pain. J Obstet Gynecol Nenonatal Nurs. 1986;15(6):471-4.

Riesco MLG, Oliveira SMV. Avaliação do edema perineal no pós-parto: concordância entre observadores. Rev Gaúcha Enferm. 2007; 28(4):465-72.

Rhode MA, Barger MK. Perineal care. Then and now. J Nurs Midwifery. 1990;35(4):220-30.

Rosner B. Fundamentals of biostatistics. $6^{\text {th }}$ ed. Belmont: Thomson-Brooks Cole; c2006. p.416.

Ryan J. Desenvolvimento e implementação do protocolo de tratamento. In: Starkey C. Recursos terapêuticos em fisioterapia. $2^{\text {a }}$. ed. São Paulo: Manole; 2001. p.70-113.

Samuelsson E, Ladfors L, Lindblon BG, Hagberg H. A prospective observational study on tears during vaginal delivery: occurrences and risk factors. Acta Obstet Gynecol Scand. 2002;81(1):44-9.

Sanders J, Peters TJ, Campbell R. Techniques to reduce perineal pain during spontaneous vaginal delivery and perineal suturing: a UK survey of midwifery practice. Midwifery. 2005;21(2):154-60.

Signorello LB, Harlow BL, Chekos AK, Repke JT. Postpartum sexual functioning and its relationship to perineal trauma: a retrospective cohort study of primiparous women. Am J Obstet Gynecol. 2001;184(5):881-90. 
Silva SF, Costa ASC, Riesco MGL, Basile ALO. Ocorrência de episiotomia e rotura perineal no Centro de Parto Normal do Hospital Geral de Itapecerica da Serra-SP. In: Anais da $1^{\text {a }}$ Conferência Internacional sobre a humanização do Parto e Nascimento; 2000 nov. 2-4; Fortaleza: JICA; 2000. p.32.

Silva FMB, Koiffman MD, Osava RH, Oliveira SMJV, Riesco MLG. Centro de parto normal como estrategia de incentivo del parto normal: estudo descriptivo. Enferm Global. 2008;7(1):1-11.

Sleep J, Grant A. Relief of perineal pain following childbirth: a survey of midwifery practice. Midwifery. 1988;4(3):118-22.

Starkey C. Recursos terapêuticos em fisioterapia. $2^{a}$ ed. São Paulo: Manole; 2001a. Agentes térmicos; p.114-75.

Starkey C. Recursos terapêuticos em fisioterapia. $2^{a}$ ed. São Paulo: Manole; 2001b. O processo de resposta à lesão; p.1-36.

Steen M, Cooper K. A new device for the treatment of perineal wounds. J Wound Care. 1999;8(2):87-90.

Steen M, Cooper K, Marchant P, Griffiths-Jones M, Walker J. A randomised controlled trial to compare the effectiveness of icepacks and Epifoam with cooling maternity gel pads at alleviating postnatal perineal trauma. Midwifery. 2000;16(1):48-55.

Steen M. “I can’t sit down”: easing genital tract trauma. Br J Midwifery. 2005;13(5):311-4.

Steen M, Briggs M, King D. Alleviating postnatal perineal trauma: to cool or not to cool? Br J Midwifery. 2006;14(5):304-8.

Steen M, Marchant P. Ice packs and cooling gel pads versus no localised treatment for relief of perineal pain: a randomised controlled trial. Evid Based Midwifery. 2007;5(1):16-22.

Stetson B. Avaliação e cuidado no quarto trimestre. In: Lowdermilk DL, Perry SE, Bobak IM. O cuidado em enfermagem materna. 5a ed. Porto Alegre: Artmed; 2002. p.424-56.

Teixeira MJ. Anatomia e fisiologia das vias nociceptivas e supressoras da dor. In: Teixeira MJ. Dor: Epidemiologia, fisiopatologia, avaliação, síndromes dolorosas e tratamento. São Paulo: Editorial Moreira Jr; 2001. p.14-40.

Thompson JF, Roberts CL, Currie M, Ellwood DA. Prevalence and persistence of health problems after childbirth: Associations with parity and method of birth. Birth. 2002;29(2): 83-93.

Turner JA. Nonspecific treatment effects. In: Loeser JD, Butler SH, Chapman CR, Turk DC. Bonica's management of pain. Philadelphia: Lippincott Williams\&Wilkins; 2001. p.1649-56. 
Waters B, Raisler J. Ice massage for the reduction of labor pain. J Midwifery Womens Health. 2003;48(5):317-21.

Williams A, Herron-Marx S, Hicks C. The prevalence of enduring postnatal perineal morbidity and its relationship to perineal trauma. Midwifery. 2007;23(4):392-403.

Ziegel EE, Cranley MS. Enfermagem obstétrica. Rio de Janeiro: Interamericana; 1985. Assistência da enfermagem à família no pós-parto: respostas fisiológicas; p.428-37. 
APÊNDICES

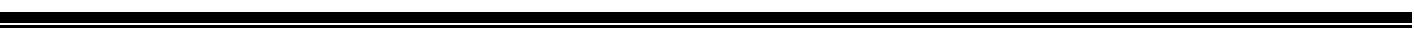




\section{APÊNDICE 1}

\section{Tabela de randomização}

1.grupo 15

2.grupo 10

3.grupo 10

4.grupo 15

5.grupo 10

6.grupo 10

7.grupo 10

8.grupo 10

9.grupo 10

10. grupo 15

11 . grupo 10

12. grupo 10

13. grupo 15

14. grupo 15

15 . grupo 15

16. grupo 15

17. grupo 10

18. grupo 10

19. grupo 15

20. grupo 15

21. grupo 10

22. grupo 15

23. grupo 10

24. grupo 15

25. grupo 15

26. grupo 15

27. grupo 10

28. grupo 10

29. grupo 15

30 . grupo 10

31. grupo 15

32. grupo 15

33. grupo 15

34 . grupo 10

35 . grupo 15

36 . grupo 10

37. grupo 15

38. grupo 10
39. grupo 10

40. grupo 15

41. grupo 10

42. grupo 15

43. grupo 15

44. grupo 10

45. grupo 10

46. grupo 15

47. grupo 15

48. grupo 15

49. grupo 15

50. grupo 15

51. grupo 10

52. grupo 15

53. grupo 10

54. grupo 15

55. grupo 15

56. grupo 15

57. grupo 10

58. grupo 10

59. grupo 15

60 . grupo 10

61 . grupo 10

62. grupo 10

63. grupo 15

64. grupo 15

65. grupo 10

66. grupo 15

67. grupo 10

68. grupo 15

69. grupo 15

70 . grupo 10

71 . grupo 10

72. grupo 10

73. grupo 10

74. grupo 10

75 . grupo 10

76. grupo 15 


\section{APÊNDICE 2}

\section{Formulário}

Grupo $\mathrm{N}^{\circ}$

Data

Hora

Você está com dor na região do períneo? （ ） sim （ ) não

Como você classificaria sua dor $(\mathrm{T}=0)$ ?

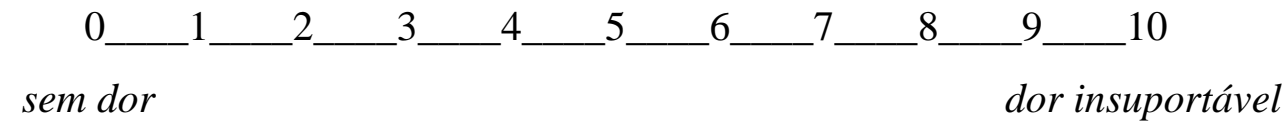

\section{A) DADOS DO PRONTUÁRIO}

1.Identificação:

Iniciais

Idade

$\mathrm{RH}$

Leito

2. Dados Obstétricos:

a) Parto atual: Data:

Hora:

b) Horas de pós-parto

c) Trauma perineal ( ) sim ( ) não

d) Tipo:

( ) EMLD ( ) episiotomia mediana Indicação

( ) laceração $1^{0}$ grau

( ) laceração $2^{0}$ grau

( ) laceração $3^{0}$ grau

( ) laceração $4^{0}$ grau

e) Peso do recém-nascido gramas

3. Medicação:

a) Usou algum analgésico: ( ) sim （ ） não

Caso sim, qual? (freqüência, horário, dose, solicitado ou prescrito de rotina)

\section{B) ENTREVISTA}

a) Cor: ( ) branca ( ) negra ( ) parda ( ) amarela/oriental ( ) outra Qual?

b) Escolaridade:

( ) analfabeta

Ensino fundamental ( ) completo ( ) incompleto

Ensino médio ( )completo ( )incompleto

Ensino superior ( )completo ( ) incompleto

c) Trabalho remunerado: ( ) sim ( ) não 
d) Estado marital:

( ) com companheiro com co-habitação ( ) com companheiro sem co-habitação

( ) sem companheiro

e) Você teve um acompanhante no parto atual? ( ) sim （ ) não Caso sim, quem?

\section{C) EXAME PERINEAL}

f) Comprimento do trauma perineal centímetros

\section{D) CONTROLE DAS TEMPERATURAS}

$\mathrm{T}^{\circ} \mathrm{C}$ axilar $\mathrm{T}^{\circ} \mathrm{C}$ do ambiente

E) APLICAÇÃO DA BOLSA início término

\begin{tabular}{|l|l|l|}
\hline Tempo & $\mathrm{T}^{\circ} \mathrm{C}$ do períneo & $\mathrm{T}^{\circ} \mathrm{C}$ da bolsa \\
\hline T0 & & \\
\hline T5 & & \\
\hline T10 & & \\
\hline T15 & & \\
\hline
\end{tabular}

a) DURANTE A APLICAÇÃO - Descrever o comportamento da mulher

b) O que você sentiu durante a aplicação da bolsa?

c) Qual a sua opinião sobre a aplicação da bolsa de gelo?

$\square$ muito bom (1) $\quad \square$ bom (2) $\quad \square$ ruim (3) $\square$ péssimo (4) $\square$ sem opinião (9)

d) AVALIAÇÃO DA DOR

\begin{tabular}{|l|l|l|}
\hline Tempo & Escala numérica $0-10$ & $\begin{array}{l}\text { Sua dor: melhorou, piorou ou } \\
\text { permanece igual }\end{array}$ \\
\hline $\begin{array}{l}\text { imediatamente } \\
\text { após a aplicação }\end{array}$ & & \\
\hline 20 min depois & & \\
\hline 40 min depois & & \\
\hline
\end{tabular}

\section{G) APÓS A APLICAÇÃO}

Descrever as posições assumidas pela puérpera

(Primeiros 20 minutos, após a aplicação da bolsa)

(40 minutos após a aplicação da bolsa) 


\section{APÊNDICE 3}

Planilha de visita diária - Alojamento Conjunto

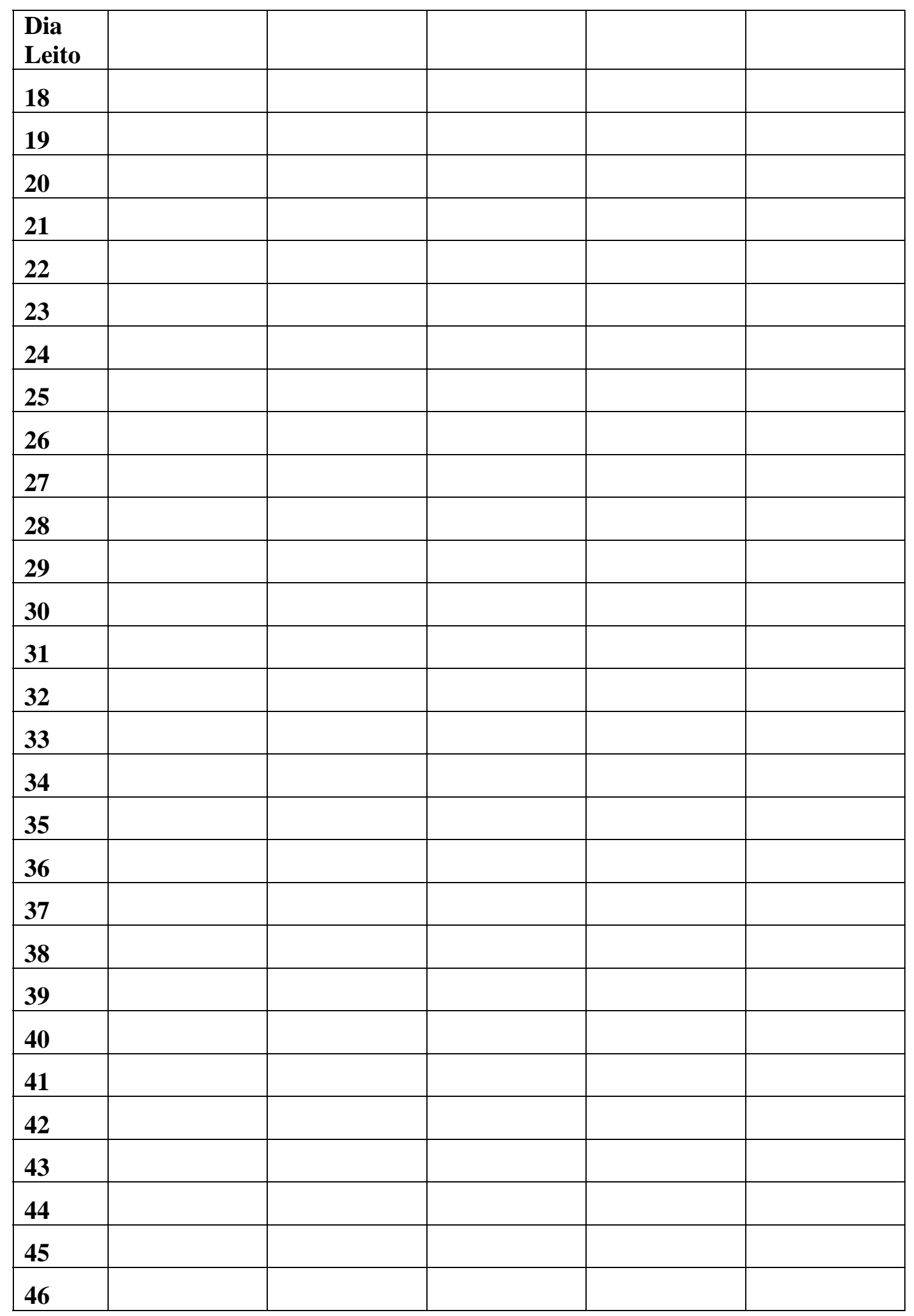




\begin{tabular}{|l|l|l|l|l|l|}
\hline 47 & & & & & \\
\hline 48 & & & & & \\
\hline 49 & & & & & \\
\hline 50 & & & & & \\
\hline 51 & & & & & \\
\hline Ex.1 & & & & & \\
\hline Ex.2 & & & & & \\
\hline Ex.3 & & & & & \\
\hline 52 & & & & & \\
\hline 53 & & & & & \\
\hline 54 & & & & & \\
\hline 55 & & & & & \\
\hline 56 & & & & & \\
\hline 57 & & & & & \\
\hline 58 & & & & & \\
\hline 59 & & & & & \\
\hline 60 & & & & & \\
\hline 61 & & & & & \\
\hline 62 & & & & & \\
\hline 63 & & & & & \\
\hline 64 & & & & & \\
\hline 65 & & & & & \\
\hline 66 & & & & & \\
\hline 67 & & & & & \\
\hline 68 & & & & & \\
\hline 69 & & & & & \\
\hline 70 & & & & & \\
\hline 71 & & & & & \\
\hline 72 & & & & & \\
\hline 73 & & & & & \\
\hline 74 & & & & & \\
\hline 75 & & & & & \\
\hline
\end{tabular}




\begin{tabular}{|l|l|l|l|l|l|}
\hline 76 & & & & & \\
\hline 77 & & & & & \\
\hline 78 & & & & & \\
\hline 79 & & & & & \\
\hline 80 & & & & & \\
\hline 81 & & & & & \\
\hline 82 & & & & & \\
\hline 83 & & & & & \\
\hline 84 & & & & & \\
\hline 85 & & & & & \\
\hline 86 & & & & & \\
\hline 87 & & & & & \\
\hline 88 & & & & & \\
\hline 89 & & & & & \\
\hline 90 & & & & & \\
\hline 91 & & & & & \\
\hline 92 & & & & & \\
\hline 93 & & & & & \\
\hline 94 & & & & & \\
\hline 95 & & & & & \\
\hline 96 & & & & & \\
\hline 97 & & & & & \\
\hline 98 & & & & & \\
\hline 99 & & & & & \\
\hline 100 & & & & & \\
\hline
\end{tabular}




\section{APÊNDICE 4}

\section{Termo de Consentimento Livre e Esclarecido}

\section{Prezada Senhora}

Eu, Sonia Maria Junqueira V. de Oliveira, professora da Escola de Enfermagem da Universidade de São Paulo, estou pesquisando sobre "A eficácia da bolsa de gelo para alívio da dor perineal após o parto normal”. Esta pesquisa é para saber se o uso de gelo no períneo com 10 minutos e 15 minutos alivia a dor após o parto normal.

Este estudo é formado por dois grupos de mulheres: um grupo que utilizará uma bolsa de gelo no períneo por 10 minutos e outro grupo que usará a mesma bolsa por 15 minutos. Esses grupos serão determinados por sorteio.

Em caso de dúvidas, meu telefone para contato é 3061-7603 ou 3061-7602. O o telefone do Comitê de Ética em Pesquisa da EEUSP é 3061-7548.

$\mathrm{Eu}$, $\mathrm{RG}$ número abaixo-assinada, recebi e entendi as informações acima e concordo em participar voluntariamente da pesquisa. Declaro que conheço os meus direitos, que estão explicados a seguir:

- Tenho o direito de receber orientações sobre as dúvidas que eu tiver em relação à pesquisa.

-Tenho a liberdade de deixar de participar da pesquisa em qualquer momento, e isso não irá prejudicar a assistência prestada neste hospital.

- Sei que os resultados deste estudo serão apresentados em eventos científicos e encaminhados para publicação em periódicos da área e, em nenhum momento, meu nome aparecerá como colaboradora ou participante da pesquisa.

Este documento tem duas vias, sendo que uma ficará em seu poder e outra comigo, garantindo as condições referidas.

São Paulo, de de 
ANEXOS

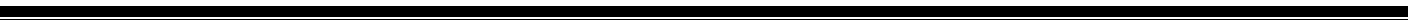




\section{ANEXO 1}

\section{Escala numérica}

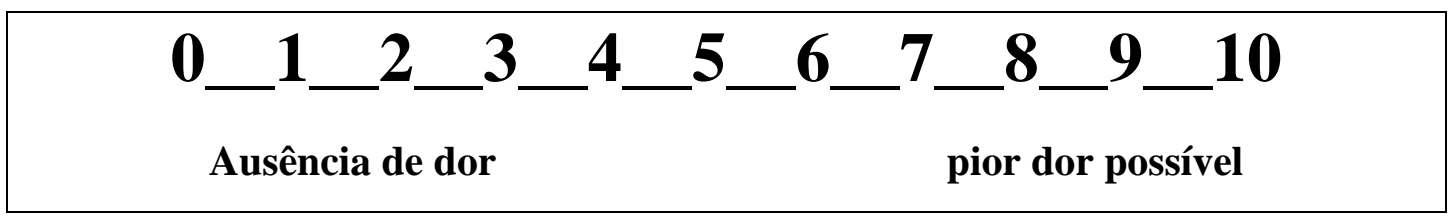




\section{ANEXO 2}

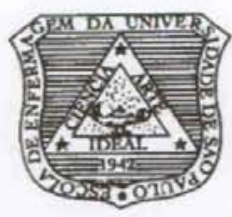

UNIVERSIDADE DE SÃO PAULO ESCOLA DE ENFERMAGEM

Av. Dr. Enéas de Carvalho Aguiar, 419 - CEP 05403-000

I: Fone.: 3061-7548 - Fax.: 3061-7548

C.P. 41633 - CEP $05422-970$ - e-mail.: edipesq@usp.br

\section{DECLARACC̃̃O}

Ref.: Processo $n^{\circ}$ 632/2007/CEP-EEUSP

Declaro para os devidos fins que o Comitê de Ética em Pesquisa da Escola de Enfermagem da Universidade de São Paulo aprovou, em 25/04/2007, o projeto de pesquisa "O efeito da bolsa de gelo para o alívio da dor perineal após o parto normal", a ser desenvolvido pela pesquisadora Lucila Coca Leventhala, sob a orientação da Professora Doutora Sônia Maria Junqueira Vasconcellos de Oliveira.

Analisado sob o aspecto ético-legal, atende às exigências da Resolução $n^{\circ}$ 196/96 do Conselho Nacional de Saúde.

Atenciosamente,

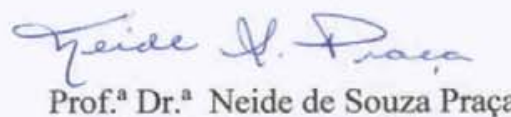

Vice-Coordenadora do Comitê de Ética em Pesquisa da Escola de Enfermagem da Universidade de São Paulo 